\title{
Measurement of Water in Gases by Electrical Conduc- tion in a Film of Hygroscopic Material and the Use of Pressure Changes in Calibration
}

\author{
By Elmer R. Weaver and Ralph Riley ${ }^{1}$
}

\begin{abstract}
The electrical, conductivity of a thin film of such a material as phosphoric acid changes over a wide range with changes in the concentration of water in the atmosphere with which it is in contact. By adjusting the pressures of a sample of gas of known and one of unknown composition, they can be made to have the same concentration of water, shown by the production of equal resistances of the detecting film. Apparatus and procedures for making such adjustments and calculating analyses are given in detail, and numerous applications are described. The method has the merits of simplicity, speed, and great sensitivity. Only small samples are needed, and few substances interfere.
\end{abstract}

\section{Introduction}

\section{General Method}

The measurement of water vapor in gases by observing the resistance of thin films of electrolyte has been employed occasionally at the National Bureau of Standards for a variety of purposes during a period of nearly 30 years. The essentials of the method are extremely simple. A thin film of liquid, which may be such a material as phosphoric or sulfuric acid or a solution containing one or more acids, bases, or salts with a binding material such as gelatin or a high-polymer plastic, is spread over the surface of a solid insulator between metallic electrodes. The electrolyte tends to reach equilibrium with the water vapor in the atmosphere that surrounds it and to form a solution, the electrical resistance of which is a measure of the water vapor in the atmosphere. We need, in addition, some sort of instrument for measuring or comparing electrical resistances and a means of calibrating the film by comparison with a gas of known moisture content. Polarization makes necessary the use of alternating current for the measurement.

\footnotetext{
1 The senior author has been unable to learn the whereabouts of Mr. Riley, who served as a civilian at Pearl Harbor during the latter part of the war. The senior author is therefore entirely responsible for the text of the present paper, but most of the observations on which it is based were made by $\mathrm{Mr}$. Riley, who also contributed much of the constructive thought that went into the development of the method.
}

The method was devised initially [1] ${ }^{2}$ to detect very small concentrations of water vapor in gases entering a catalytic reaction in which water is a poison. The material first tried for the conducting film was a salt, calcium chloride; but it was soon found that the salt became a nonconducting solid at a humidity far higher than that to be detected, and numerous other electrolytes were tried. Among them phosphoric and sulfuric acids were found most useful, because they served to detect the smallest concentrations of water vapor. However, films of these materials changed resistance so rapidly that it seemed hardly worthwhile to calibrate them by comparison with known atmospheres, laboriously prepared.

The method therefore fell into disuse except for qualitative work until F. W. Dunmore [2, 3] employed it successfully for much higher humidities in connection with meteorological observations. He used a salt, lithium chloride, as the electrolyte in a plastic film of very high resistivity, but one which held its calibration well. The need during the war for a method of determining rapidly very small quantities of water vapor in aviator's oxygen led to the development of a means of calibrating a sensitive film at the time of its use so quickly and simply that little need remained for a permanent calibration. This at

\footnotetext{
${ }^{2}$ Figures in brackets indicate the literature references at the end of this paper.
} 
once greatly extended the possible applications of the method, several of which will be suggested later in this paper.

\section{Principle Involved in Calibration by the Ad- justment of Pressure}

As a rough approximation, deviations from which will be discussed later, the resistance of a given film is independent of the gases other than water vapor with which it is in contact and depends only on the amount of water contained in unit volume. If a sample of gas, such as oxygen or air, of known water content per unit volume is passed over the film it will assume a certain resistance. If a second sample of gas of unknown water content is then passed over the film, the resistance will usually be different, but it may be restored to its original value by compressing or expanding the second sample until it contains the same quantity of water per unit volume (more exactly until the water vapor has the same fugacity) as the first sample. When this condition is reached, we note the pressure and readily compute what the water content would be in a unit volume at any other pressure (usually, but not always, 1 atmosphere). If the unknown gas is initially at atmospheric pressure, it may be more convenient to change the pressure of the standard gas until the same resistance is produced by both.

As a simple illustration of the first procedure, let us say that the first sample of gas used as a standard is known to contain $2 \mathrm{mg}$ of water per liter, and that the second sample causes the detecting film to have the same resistance as the first (and that it therefore also contains $2 \mathrm{mg}$ of water per liter) when at a pressure of 100 atmospheres. If the second sample of gas is now expanded to 1 atmosphere, it has about 100 times the volume but the same total quantity of water as before expansion, and the water content is, therefore, $0.02 \mathrm{mg}$ per liter. The second procedure may be illustrated by the following example. A cylinder of oxygen known to contain 8 micrograms $(0.008 \mathrm{mg})$ of water per liter when expanded to atmospheric pressure was used as the standard gas. The resistance produced by exposing the film to a sample of freon at atmospheric pressure was matched by adjusting the oxygen to $18 \mathrm{psig}$ (pounds per square inch gage) or a total pressure of 2.2 atmospheres. Then the freon at atmospheric pressure contained 2.2 times as much water as did the oxygen at atmospheric pressure, or 18 micrograms per liter.

Frequently it is convenient, in order to make the best use of available gages, to set one gas to an arbitrary pressure of no interest in itself and to match it by adjusting the pressure of the other. For brevity, the process of adjusting the pressure of one or both gases to produce the same electrical resistance of the detector will be called comparing the gases. In general four pressures are involved in a comparison:

$P_{s}$, the pressure at which the standard gas contains a known concentration of water vapor, $S$.

$P_{c}$, the comparison pressure at which the standard gas is matched with the electrical resistance produced by the unknown gas at pressure $P_{x}$.

$P_{x}$, defined by the preceding statement.

$P_{w}$, the pressure at which we wish to know the concentration of water in the unknown gas.

The water content, $C$, of the standard gas at the comparison pressure is

$$
C=S \frac{P_{c}}{P_{s}}
$$

Since it is known that the unknown gas has this same water content at the matching pressure $P_{x}$, the water content, $W$, at pressure $P_{w}$ of the unknown gas is derived from $C$, just as $C$ was derived from $S$ :

$$
W=C \frac{P_{w}}{P_{x}}=\frac{S P_{c} P_{w}}{Y_{s} P_{x}}
$$

Having determined the value of $W$ we can obviously use the newly analyzed gas as the standard to determine $W_{1}$, the water content of still another unknown gas at $P_{w_{1}}$ after matching it electrically at pressure $P_{x_{1}}$ against the new standard at $P w$, thus:

$$
W_{1}=W_{3} \frac{P_{w_{1}}}{P_{x_{1}}}=S_{2} \frac{P_{c} P_{w} P_{w_{1}}}{P_{s} P_{x} P_{x_{1}}}
$$

There is obviously no limit to the number of steps of this kind that can be taken, but because some error is involved in each comparison, the results soon lose significance.

A gas that contains an approximately known concentration of water, to be used as the first or the only standard, can be obtained easily by saturating compressed air (or other compressed gas that may be available) with water vapor at any convenient pressure. $S$ then represents the concentration of water vapor in equilibrium with 
liquid water at the temperature of the measurement, and $P_{s}$ is the pressure in the saturator. $S$ and $W$ may be expressed in any units, not necessarily in micrograms per liter, pounds per thousand cubic feet, or other units of mass per unit of volume; they may also be expressed as partial pressures, relative humidities, or percent by volume. Since only ratios of pressures are involved in the computation of $W$ and $S$, any unit of pressure may be used, provided it is kept clearly in mind that total pressures are involved, not gage pressures (above atmospheric).

In the application of the method that has been most extensively made-determining the moisture content of compressed gases - it is convenient to use as the standard gas air, oxygen, or nitrogen saturated at about 35-atmospheres pressure and expanded to 1 atmosphere. The water content of the unknown gas is to be determined at 1 atmosphere. Hence, if pressures are expressed in atmospheres, $P_{c}$ and $P_{w}$ of eq 2 are both unity, and the equation becomes

$$
W=\frac{S}{P_{s} P_{x}}
$$

in which $S$ is the concentration of water in a vapor space in equilibrium with liquid water.

In the method of use described, the pressure gages are the measuring instruments. We are usually not at all concerned with the actual value of the electrical resistance of the sensitive film, and the electical instruments are used only to show that two resistances, corresponding to measured pressures, are the same; but in some cases, especially when following changing concentrations of water vapor, it is impracticable to make a separate calibration through the adjustment of pressure for every variation of humidity, and readings of the electrical instruments are recorded and interpreted, usually by interpolation between values determined by pressure readings. The electrical circuit is then truly used as a measuring instrument and not merely as a nullpoint indicator.

In the foregoing description of principles, it was necessary to qualify many of the statements with the words about, approximate, etc. The corrections to be made to produce more accurate results and the sources of error will be discussed after the construction of the instrument and its operation have been described.

\section{Description of Apparatus Employed}

\section{General Arrangement and Procedure}

The general method which has been outlined above may be employed with apparatus of great variety. For certain purposes the equipment may be designed for pressures either above or below atmospheric, and many of the parts may be made of glass, metal, or plastic in numerous arrangements. Since the principal application of the method in the past has been to the testing of compressed oxygen, the apparatus designed specifically for and preferred for that purpose will be that first described, and alternative constructions and accessories will follow.

The essential electrodes, the separating insulation on which the conducting film is spread, and their support will be called collectively the detector. The electrical equipment used for showing equality of resistance of the film under different conditions will be called the indicator. The indicator consists essentially of two parts, the indicating circuit involving an adjustable bridge with its power supply and amplifying device and an indicating instrument, which will be called more briefly the galvanometer, although its name plate is more likely to bear the word microammeter. The other necessary parts of the equipment are a pressure-tight enclosure for the detector called the cell, a saturator, two pressure gages, four valves, a cylinder of compressed nitrogen, air, or other gas, and connecting tubing. A high-pressure regulator and a computer are desirable but not indispensable.

The preferred arrangement of gas connections is shown diagrammatically in figure 1 . When

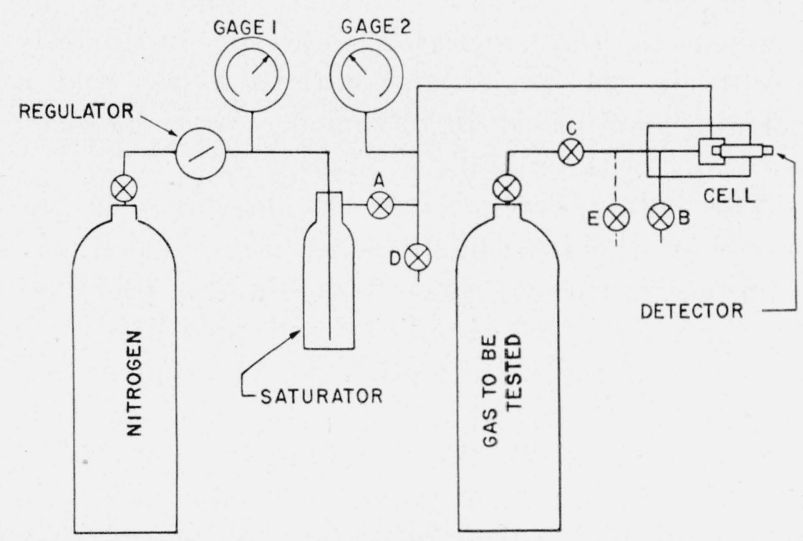

FIGURE 1.-Diagram of mechanical connections for testing compressed gas. 
used for oxygen testing, the regulator on the nitrogen cylinder is set to deliver gas to the saturator at a pressure of about 500 psi, as shown by gage 1. The saturated gas is admitted in a slow stream to the cell through valve $A$ and, after passing over the detector, is discharged through valve $B$, which is generally left wide open. When the detector has reached equilibrium, the indicating circuit is adjusted so that the galvanometer needle is on-scale and the reading is noted. Valves $A$ and $B$ are then closed, and the gas to be tested is admitted to the cell through valve $C$ and discharged through valve $D$. These two valves are manipulated so that with the gas flowing at a moderate rate, the galvanometer balances at the reading previously noted. The reading of gage 2 is then recorded. The reading of gage 1 while gas was passing through the saturator is $P_{s}$, of eq 4 , and the reading of gage 2 is $P_{x}$.

In the arrangement illustrated, slight leakage of gas through valves $A$ or $C$, which it is hard to avoid with complete certainty, does not affect the result, because in each case the leaking gas is discharged without reaching the detector. Nitrogen is indicated as the gas to be saturated, because it is usually as available at an oxygen plant, where most of the testing is done, as is oxygen or compressed air, and it does not corrode the steel bottle used as a saturator. Except for the rusting of the saturator, air or oxygen is as satisfactory as nitrogen. If only one cylinder of gas is to be tested, it may first be attached to the saturator to provide the standard gas and then connected as the gas to be tested. If a high-pressure regulator is not available and gage 1 has a sufficient range, the full pressure of the cylinder may be applied to the saturator, but this ultimately results in the waste of compressed gas and a certain amount of inconvenience or a reduced accuracy in the reading of pressures.

The actual arrangement of apparatus in the model of the instrument most used, which was adopted by the Army Air Forces and is preferred by the authors for simplicity and accessibility, is shown in profile in figure 2 . The valves are lettered as in figure 1. A spare valve, $E$, controlling entrance to the system at the same point as valve $C$, has been found very convenient for the attachment of a gage more sensitive than gage 2 (0 to $3000 \mathrm{psi}$ ) or of a secondary standard,
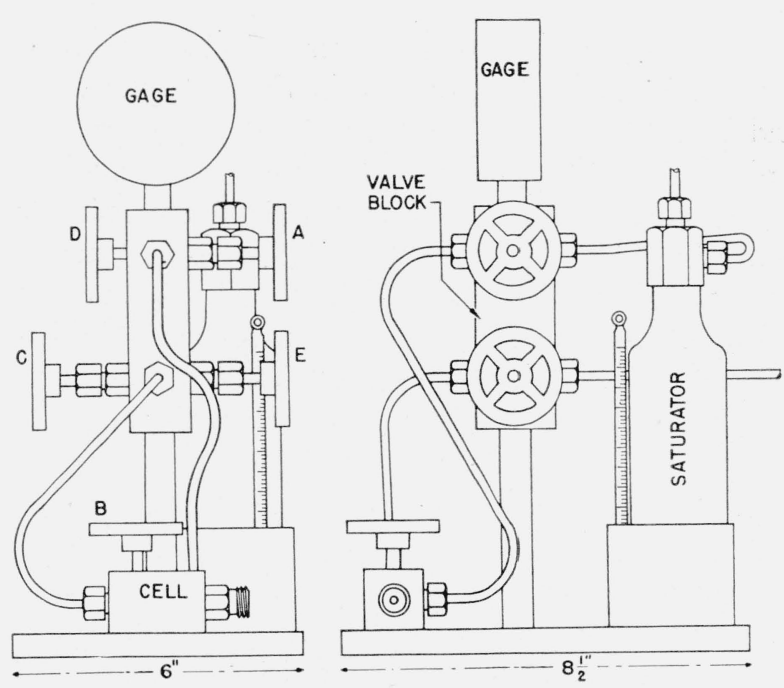

FIGURE 2.-Front and side elevations of portable instrument.

a cylinder of gas drier than can be obtained from the saturator. Valve $E$ is not needed for the routine testing of oxygen under the Army-Navy specification, however.

Four of the valves are mounted in a single valve block for simplicity of support. Dimensions and further details are shown in cross section in figure 3. The block is made of heavy metal to conduct heat as readily as possible to the points of expansion of the gas through the principal valves. The cell is connected to the valve block only through considerable lengths of small metal tubing to minimize the effects of expansion on the temperature of the detector. Valve $B$ is placed directly on the cell to minimize the pressure drop from detector to outlet when the standard gas is to be used as 1 atmosphere without measurement or corrections. It is quick-opening, and its passages are large for the same reason.

Details of construction of the various parts will now be discussed.

\section{Detector}

\section{(a) Detector Currently Used for Oxygen Testing}

In figure 4 is shown the detector preferred by the authors because of its compactness and ease of handling when recoating or transferring from a place of use to a cell for calibration. It is the form that has been used in most of the oxygen testing apparatus and also in most of the experimental work to be described. Unless otherwise specified, it may be considered to be the detector 


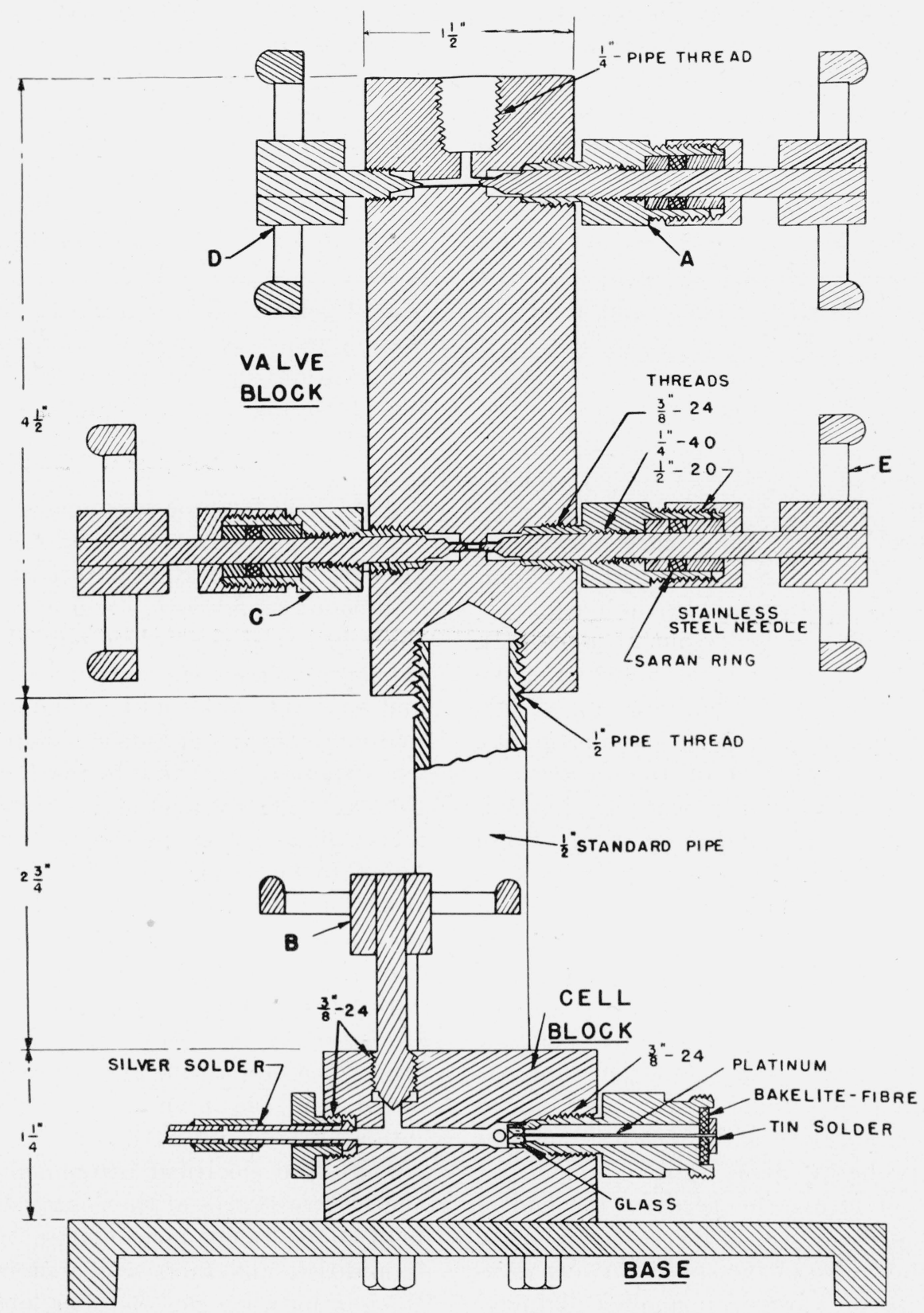

Figure 3.- Section of valve block and cell block of portable instrument.

referred to throughout the remainder of this paper. It is made as follows: The end of a platinum wire of about $0.5-\mathrm{mm}$ diameter is fused to form a bead about $1.5 \mathrm{~mm}$ in diameter. A larger bead of glass, made for sealing to platinum, is fused over the end of the wire and then into a short length of thin-walled platinum tubing about $3 \mathrm{~mm}$ in

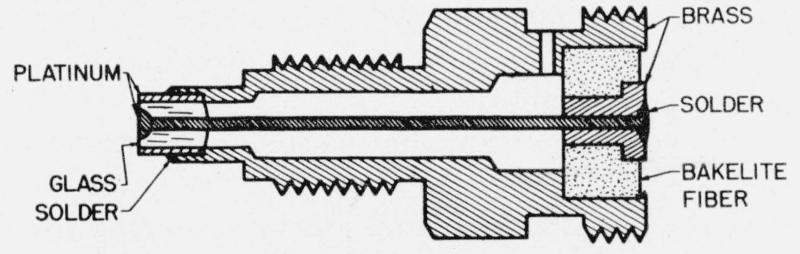

Figure 4.-Detail of detector most frequently used. 
diameter. The glass readily wets the metal and should be allowed to flow slowly into the tube by capillarity at as low a temperature as practicable in order to avoid the formation of bubbles by the decomposition of the glass. The platinum sleeve is then soldered into a brass or stainless steel fitting that can be screwed into the cell. Both soft- and hard-soldering have been employed with about an equal percentage of failures, which are much too numerous. During soft-soldering, the platinum sleeve is heated quickly and tends to break away from the glass, as it would not do if glass and metal were slowly heated together. When the unit has cooled down, the break is not repaired but remains an invisible crack into which the liquid electrolyte is eventually forced by high pressures. When the tip is hard-soldered, cracking is even more likely to take place during the initial heating, but the glass can be heated enough to repair the break by fusion. In the meantime, the central wire may get badly out of place. In spite of these difficulties, several detectors have been made by the authors without the aid of jigs, annealing chambers, or other special arrangements.

After assembling, the end of the detector is ground off with an abrasive powder to approximately the middle of the platinum bead. From time to time the surface is examined under a lens, and all pits left by bubbles are ground out if practicable. An optical polish is not needed and probably not even desirable. The degree of roughness of the finish does not seem to make much difference; it will probably be satisfactory to make the finish such that the surface appears dull but without visible roughness to the unaided eye. A finishing abrasive with grains 20 microns in diameter is probably about right.

The purpose of fusing the bead on the end of the small wire is, of course, to increase the length and diminish the width of the space between electrodes. The use of a wire of smaller diameter than is wanted at the surface saves platinum, but its principal purpose is to minimize the chance of cracking the glass around it during heating and cooling. An attempt to use smaller platinum tubing for the outer electrode resulted in a higher percentage of failures.

It is very important that no soldering flux get to the back of the electrodes and their insulation, and that the glass be free from cracks extending from one electrode to the other. When such cracks occur, not only is the sensitive film shunted by a resistance slowly variable with changes of humidity, which introduces lag but might be tolerated, but there is also a continuous fluctuation of resistance, irregular both in period and magnitude. In the worst case observed, the fluctuations, which occurred from once in 8 or 10 seconds to three or four times a second, were sufficiently violent to caúse off-scale deflections of the galvanometer in each direction. This particular detector appeared perfect when examined in diffused daylight even under a low-power microscope, but strong illumination showed interference colors from a transverse fissure well below the surface.

\section{(b) Detectors of Other Forms}

The first detector was made by twisting two wires close together around a glass tube and painting the elctrolytic film between them. This was soon abandoned because, as it evaporated, the solution of electrolyte tended to be drawn by capillarity under the curving surface of the wire and to leave most of the conducting material in relatively thick deposits partially covered by the wire where it was slow to reach equilibrium with the gas. Platinizing the closed end of a glass tube and etching a gap in the platinum coating was found to be easier than the use of wires and to result in a nearly smooth surface easy to coat with a relatively uniform film of the electrolyte. Electrical connections were made through platinum wires sealed through the glass before platinizing. Detectors of this form are quite satisfactory for use in glass apparatus at low pressure. For use in metal, the platinum coated tube was soldered into a brass bushing [1].

With the electrical instruments used until recently, resistances of the coated detector were too high to be easily measured in the low range of humidities, and there was a premium on making the gap between electrodes as long and narrow as possible. A detector, made for the ArmyNational Geographic Society stratosphere flight of the Explorer II in 1935, but not used because the electrolytic coating did not hold its calibration well enough, was made by platinizing a glass tube about $1 \frac{1}{2}$ in. in diameter and $1 \mathrm{ft}$ long and cutting the coating into two helical strips with a sharpedged grinding wheel. The result was a line of separation between electrodes about $0.1 \mathrm{~mm}$ wide and $3 \mathrm{~m}$ long. In his first radio-sonde hygrom- 
eter, F. W. Dunmore [2] ground helical grooves into a glass tube in the same way but employed wires laid in the grooves as conductors instead of a platinum coating between grooves. Later [3] he employed wires wound on a polystyrene-coated metal tube.

The earlier detectors were not strong enough to withstand the high pressures required in oxygen testing, and several other types have been tried for high-pressure work in addition to the one described in section II, 2, (a). Figure 5 illustrates

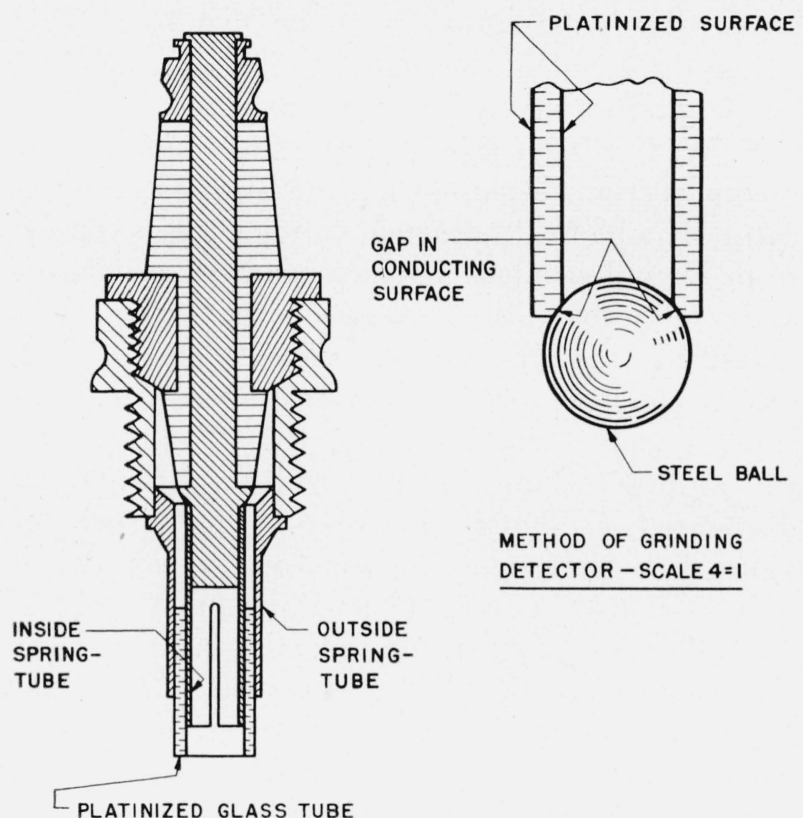

FIGURE 5.-Detail of detector made from a high-test aviation spark plug, type $43 \%$.

the one that is simplest to make. The sparkpoints of an aviation spark plug (which does not depend on the strength of porcelain to prevent bursting under pressure, the fault of the usual automobile spark-plug), are replaced by coaxial tubes of thin metal, the outer ends of which are split into segments that can be bent to make secure spring contacts with the inside and outside of a glass tube inserted between them. The glass tube need not be more than $2 \mathrm{~cm}$ long. Internal and external diameters of 6 and $8 \mathrm{~mm}$ are convenient. The tube is left open at both ends. One end is dipped into a platinizing solution (made by dissolving $1 \mathrm{~g}$ of platinic chloride in 10 $\mathrm{ml}$ of 99.5-percent alcohol and adding $2.5 \mathrm{ml}$ of U. S. P. collodion) and heated above a Bunsen flame, at first gently but finally to the initial softening point of the glass. Usually there is no trouble from lack of adherence of the platinum, and one dipping is enough. Adherence can be improved by very slightly etching the glass with hydrofluoric acid before coating. A rounded piece of metal, conveniently a bearing-ball soldered to a piece of metal tubing, is used with a little fine abrasive to grind the platinum coating from the edge at which the cylindrical inner surface of the tube intersects the plane surface of its end, as shown in the small insert in figure 5. The initially continuous platinum coating is thus divided into two conductors separated by a ground-glass surface 0.2 to $0.5 \mathrm{~mm}$ wide, which is then coated with the conducting film. The end of the tube that is not platinized should be firepolished ever so slightly. If the glass is left sharp, it may shave shreds of metal from the holders and cause puzzling short circuits. If fire-polishing results in an easily noticeable change of diameter of the tube, it may be difficult to slide over the inside spring-tube, and the contact with the inside platinum coating is likely to be poor.

Because they are so easily constructed, several detectors in various forms were made of metal, usually stainless steel, with plastic instead of glass insulation. Lucite (methyl methacrylate) and two or three other plastics were tried. The detectors were quite usable but generally and somewhat vaguely less satisfactory than detectors with glass insulation. They seemed to be sluggish in response, particularly after they had been in use for some time, an effect attributed to some penetration of the electrolyte into the plastic where it was relatively but not entirely unresponsive to changes of humidity. Other effects were attributed to poor adherence of the coating to the plastic. These unsatisfactory results must not be considered conclusive against plastic insulators. The polystyrene used successfully by Dunmore was not tried because no machinable pieces were at hand, nor were Saran, Nylon, or other promising materials tried.

One form of detector, with plastic insulation shown in section in figure 6 will be described since it is extremely easy to make. It is not well suited to high-pressure use but was designed for installation in sheet-metal containers within which the humidity is to be determined from time to time. The detector consists merely of two metal washers with a thin sheet of insulating material between 


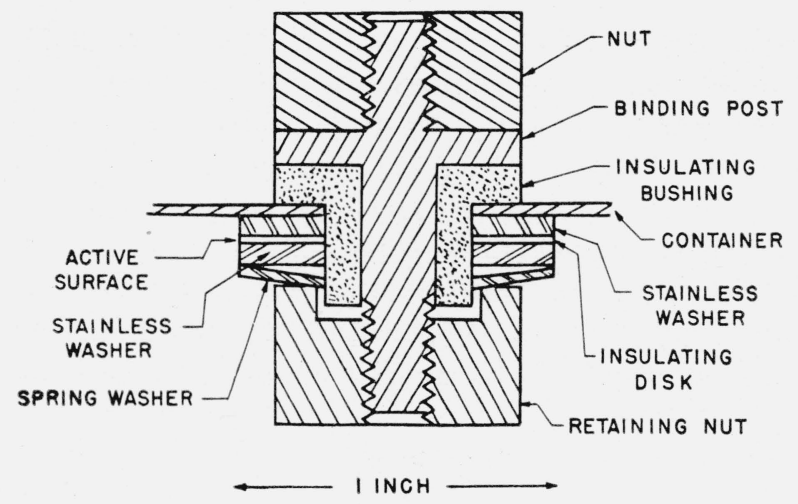

Figure 6.-Detail of simple detector with plastic insulation.

them, held together by a central bolt and spring washer. An insulating bushing surrounds the bolt. The diameter shown, 1 in., is probably the largest there will ever be occasion to use. The same construction can be employed with a diameter of only a few millimeters. The edges of the washers and sheet insulation are painted with the film of electrolyte. Several sheet insulating materials of different compositions and thicknesses were tried with equal success so far as could be judged from the limited study made. Commercial cellophane, $0.03 \mathrm{~mm}$ thick, appeared to be as good as anything. Brass washers were used, and the electrolytic coating was a solution of lithium chloride and cullulose acetate in acetone containing a little alcohol and water. This coating adhered perfectly for a year but, as F. W. Dunmore [3] observed, with copper wire and lithium chloride, the metal corroded. Stainless steel washers with a sheet of Saran (polymerized vinylidene chloride) melted between them, and others with polystyrene insulation, are now being tried.

\section{Electrical Indicator}

In the initial study of the method [1] and the occasional uses made of it from 1919 to 1935, a simple Wheatstone bridge and alternating-current galvanometer were employed with 60-cycle alternating current from the power supply. The electrical system designed in 1935 by Frank Wenner was essentially the same, except that power was supplied from batteries and a motordriven reversing commutator. F. W. Dunmore used Wenner's system in the laboratory, but for meteorological work the detector was made the resistance element of an oscillating circuit, the frequency of which was the measure of the resistance of the detector.

It was a common characteristic of these indicating systems, except the last, that they responded satisfactorily only to comparatively large currents through the detector. This placed a premium on detectors of large size to accommodate an opening between electrodes of sufficient length and on thick coatings of slow response. In Dunmore's hygrometer, the current is direct (though interrupted), and extremely low current densities between electrodes are necessary, if interference by polarization is to be avoided. This necessitates much the same design as though a larger alternating current were required.

F. W. Gross, of the Bureau's Electrical Instruments Section, designed for the authors an indicator in which alternating voltage was supplied from an independent battery-operated oscillator, and the unbalance voltage of the bridge was amplified through vacuum tubes. The original circuit has been modified several times, usually in the direction of simplification, by E. C. Creitz and the authors. Four of the resulting circuits are illustrated in figures 7 to 10 . The circuit of figure 7 is thoroughly satisfactory, except when it is to be used as a measuring and not merely as an indicating instrument (cf. the next to last paragraph of section I, 2). It is the circuit that has been most used and is still preferred for most work by the authors. The variable resistance, $V$, in the arm of the bridge adjacent to the detector is commonly changed only in large steps to within an order of magnitude of the resistance of the detector. The galvanometer reading is then brought on-scale by adjusting the point of contact on resistance $R$, and further electrical measurement is limited to observing the position of the galvanometer needle.

The circuit shown in figure 8 permits a fairly accurate measurement of the electrical resistance of the detector and is employed when for any reason the electrical equipment, rather than a combination of pressure gages, is to be used as the measuring instrument. It was used in the studies of the resistance of films, rate of attainment of equilibrium, etc., to be reported.

Figure 9 shows a simplification of the circuit of figure 7 that appears to be entirely satisfactory for most purposes and is less expensive. The 


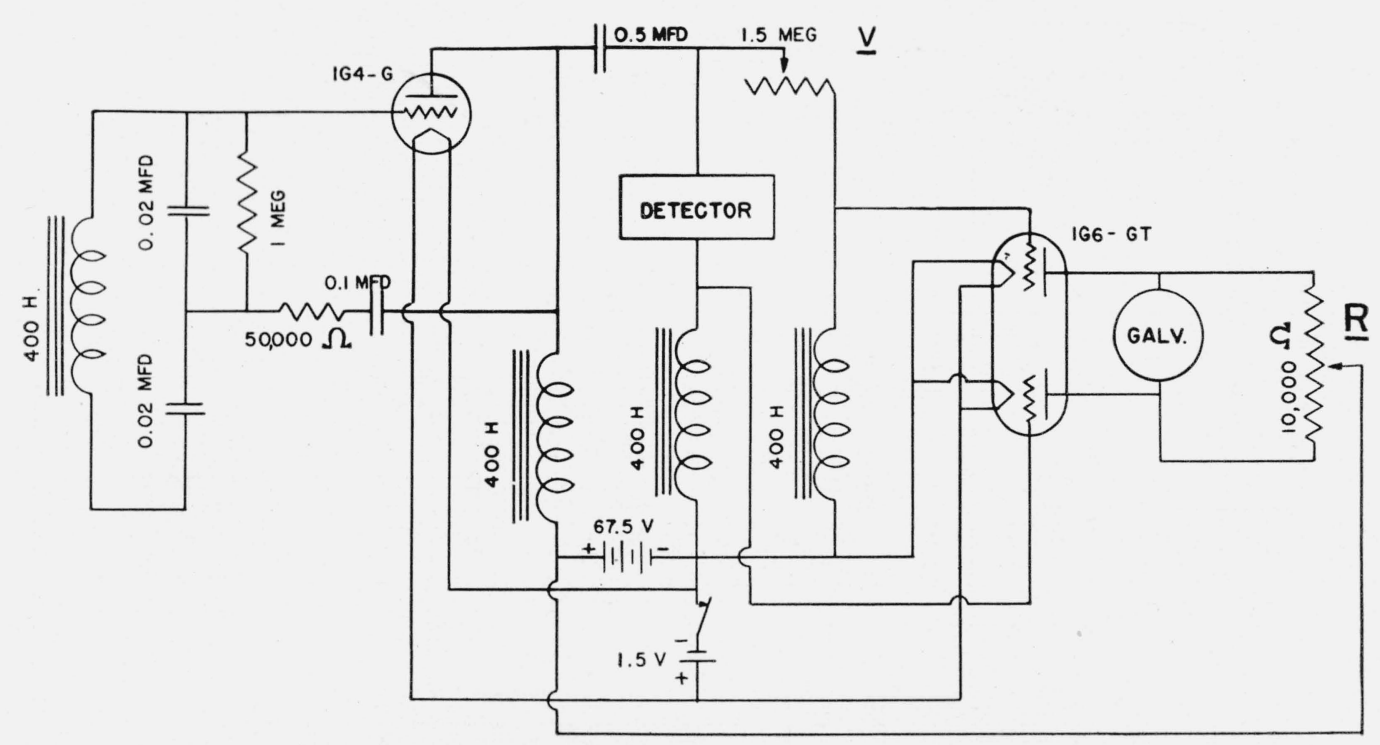

Figuke 7.-Diagram of indicating circuit.

Used when gages are employed as primary measuring instruments.

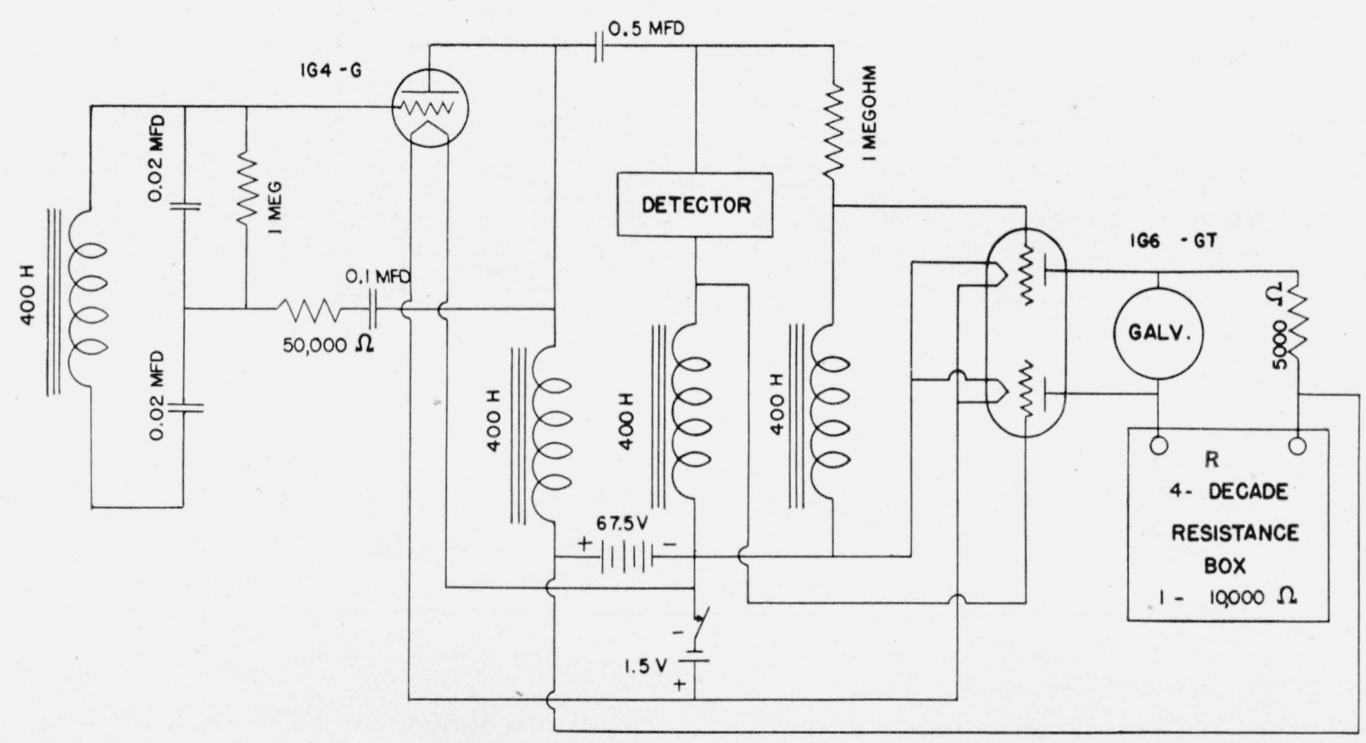

Figure 8.-Diagram of measuring circuit.

Most used when measurements depend on electrical calibration.

modifications consist of the substitution of three 1-megohm fixed resistances for the two chokecoils and the variable resistance $V$ in the bridge containing the detector, and of a fixed and a variable resistance for the single variable resistance $R$ of figure 6 . The modified circuit is comparatively recent, has been only crudely assembled and has not been used very often for that reason.

Figure 10 shows a circuit, designed by E. C.
Creitz, which uses 60-cycle alternating current and thus eliminates batteries. Readings made with it have appeared to be less steady than with the battery-operated circuits, which are preferred in consequence. The low frequency also causes the galvanometer needle to vibrate visibly. The oscillator of figures 7 to 9 has a frequency of about 400 cycles per second.

The galvanometer is a direct-current instrument that receives alternate pulses in opposite direc-

\section{Water in Gases}




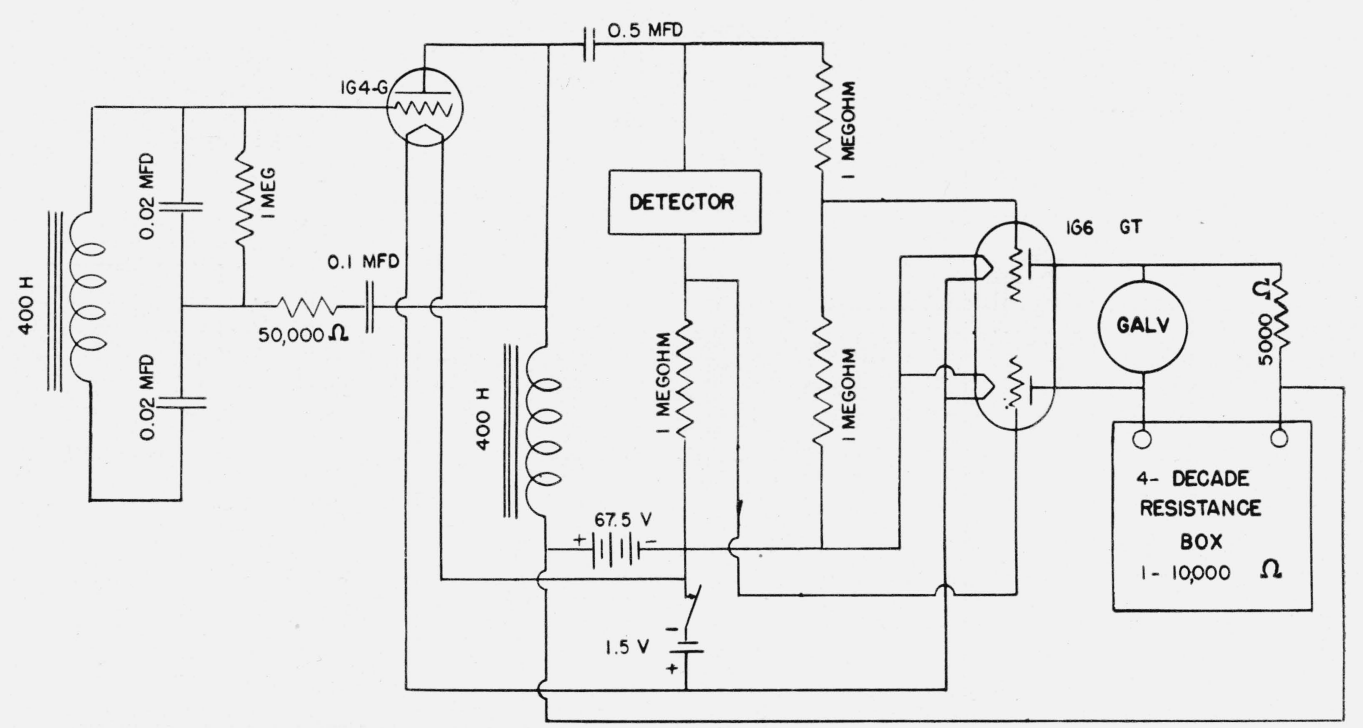

Figure 9.-Diagram of simplified measuring circuit.

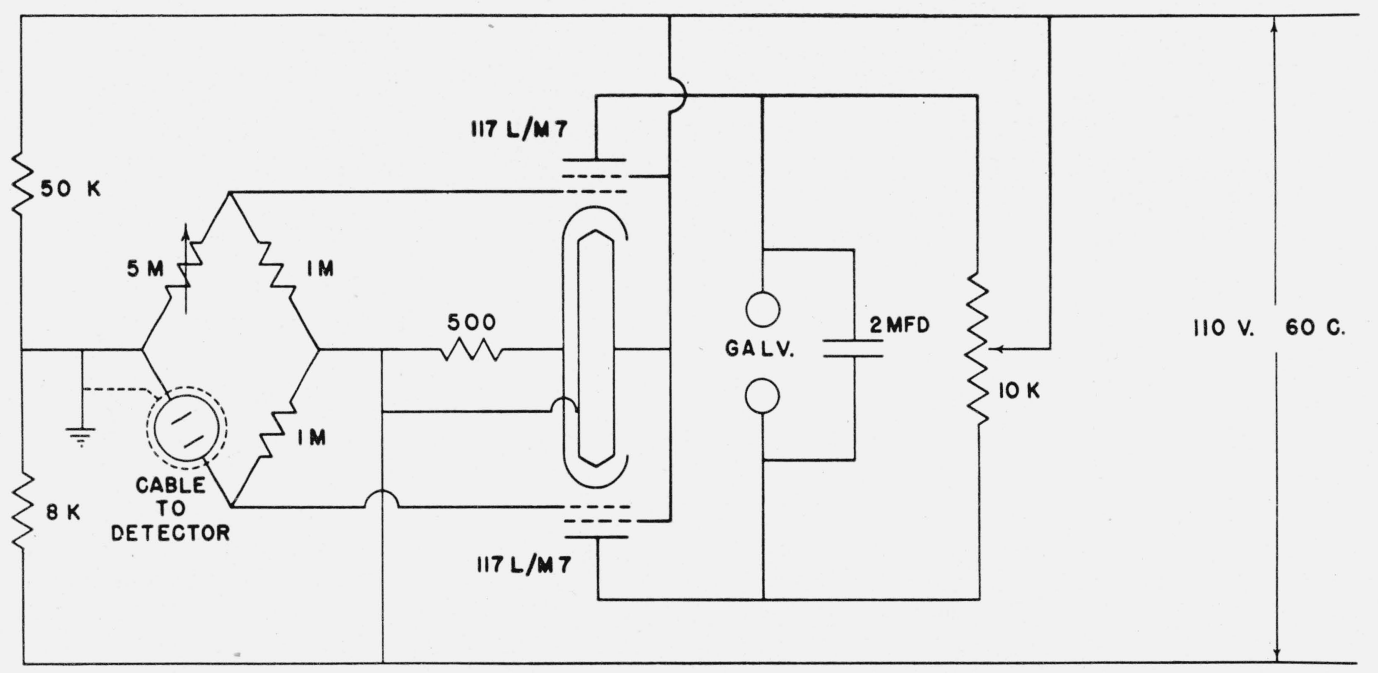

FIGURE 10.-Indicating circuit for water detector for 60 cycles, $110 \mathrm{v}$, alternating current.

tions from the plates of the twin amplifier. Weston galvanometers Model 440 and microammeters model 801 have been used with equal satisfaction. The galvanometers have a resistance of about $123 \mathrm{ohms}$ and a range of 15 microamperes divided into 60 scale divisions. The microammeters have a range of 50 microamperes with 50 scale divisions. The galvanometers with their thin needles backed by mirrors can be read with greater accuracy, but this is rarely required, and the microammeters cost less and are easier to read.

The characteristics of the electrical indicator as a whole (they are about the same for all four cir- cuits) are shown for the circuit of figure 9 by the calibration curves of figure 11 . The galvanometer used was a Weston model 440 and the variable resistance, $R$, was a plug-box of 10,000 ohms in steps of $0.1 \mathrm{ohm}$. The three curves in the figure, with their corresponding scales, show resistances of the detector and corresponding values of the variable resistance, $R$, required to bring the galvanometer to balance. The calibration was made by replacing the detector with successive measured fixed resistances. The entire range of possible resistances from short circuit to open circuit is covered. The higher resistances are plotted on a reciprocal scale. 


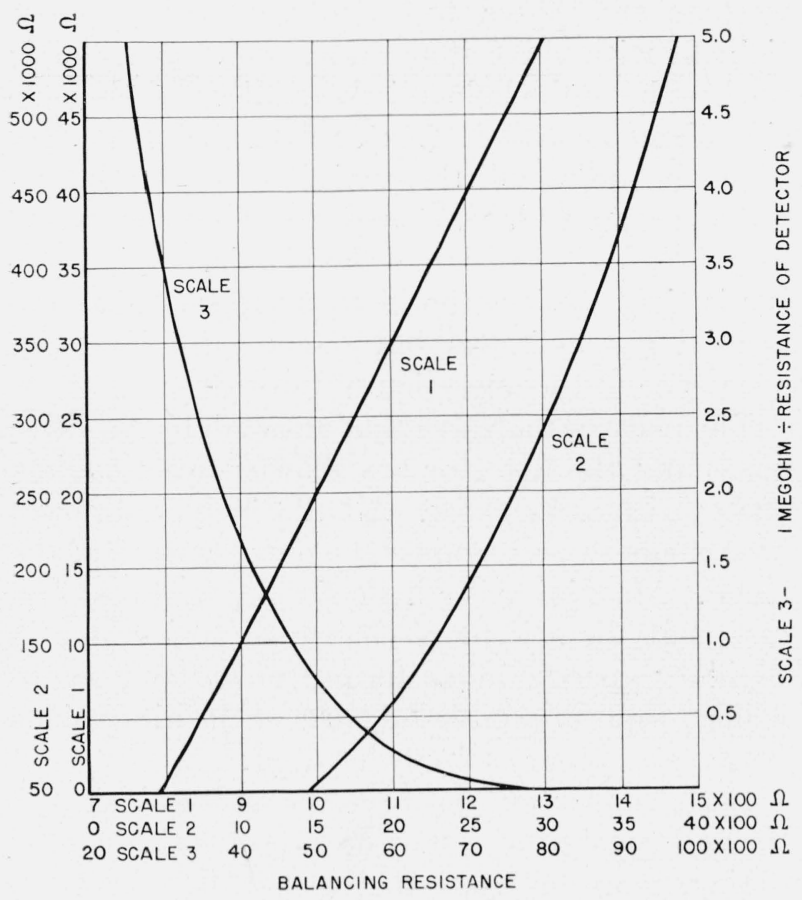

FIGURE 11.-Calibration of measuring circuit in terms of resistance of detector.

The amount of current available from the electronic amplifier is never sufficient to damage the galvanometer, hence at any time any resistance can be connected in the place of the detector with impunity. In view of the very great range of resistances to be encountered and the suddenness with which they sometimes change on going from one atmosphere to another, this is a great advantage.

\section{Saturator}

The saturator pictured in figure 12 has been generally used. Saturators with more elaborate packing have not worked as well. Saturators more simply packed have worked better. The saturator filling illustrated consists of about 4 in. of fragments of pumice stone the size of a finger nail and an inch of glass wool. The entering gas bubbles through about an inch of water. The filling was designed with the idea that the bubbles would break and most of the spray would be entrapped within the pumice, the porous nature of which would keep the surfaces wet but would tend to prevent bridging between solid fragments. The glass wool was intended as a filter for spray from the breaking bubbles. In practice the glass wool usually became water-logged and either left only

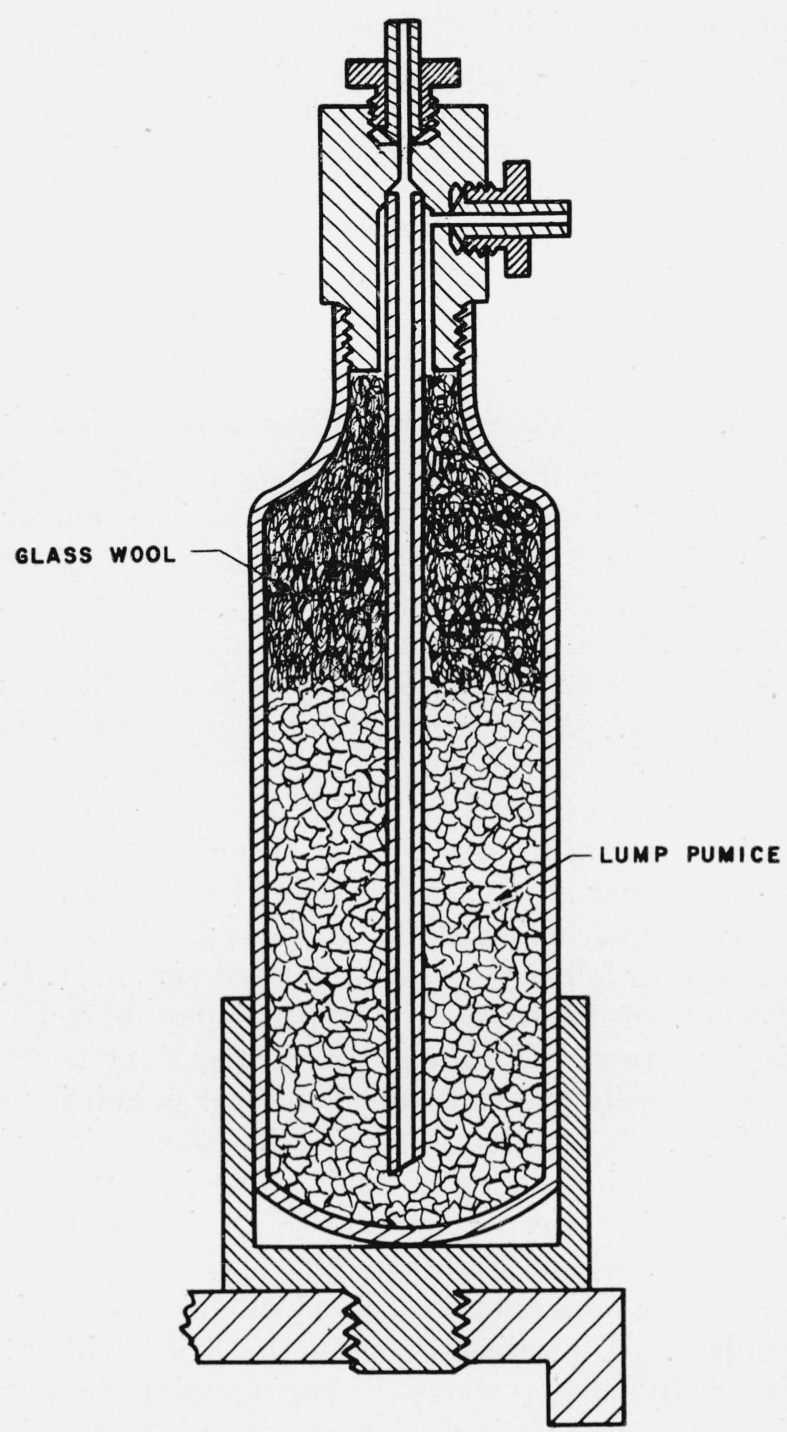

Figure 12.- Section of saturator first used.

narrow passages through which bubbles worked and broke near the outlet of the saturator, or gas entering below the pad squeezed it like a sponge and caused the water to overflow in a mass.

Unfortunately the first packing of this type worked well, and a large number of other saturators were packed in the same way. More recently the saturator has simply been filled with streamwashed gravel screened to pass a sieve of 5 meshes and be retained by one of 10 meshes per inch. If there is $3 \mathrm{in}$. of gravel above the water level, no trouble has been encountered with spray from cylinders filled in this way, even when the rate of flow of gas was much greater than necessary. The saturator leaves much to be desired. The 
gravel has a high heat capacity, and with cooling from evaporation at the bottom and changing temperature in the surroundings, the actual temperature of saturation is uncertain. For highly accurate results the whole should be placed in a thermostat, of course. What it is hoped will prove to be a better saturator has been designed for use in further study but has not yet actually been employed.

\section{Valves, Connections, Gages, Regulators}

Accurately made needle valves of the simple construction shown in figure 3 have been mostly used. Valves of other types that have been tried have been no more satisfactory, at the best. Valves $B$ and $D$, shown in the figure, have been used without packing, but this is now considered a mistake. Although packing is not needed in these valves for tightness, it helps to hold the stem steady when the valve is open and facilitates the adjustment of pressure. It is accordingly recommended that all valves be made like valve $A$.

The construction of the valve and the method of packing follow rather closely the design of $\mathrm{H}$. F. Stimson of this Bureau. The packing of the valve is important. It should permit the stem to be turned easily and smoothly but never permit it to wobble. It should also resist the penetration of water, as the holding of liquid water in any place from which it can evaporate slowly into the cell or its connection is perhaps the most troublesome of all the sources of error to which this method is subject. A packing that can be dried without injury by heating above the boiling point of water is much to be desired. The packing indicated in the drawing is the plastic Saran, a vinylidene chloride polymer selected because it is less permeable to water than any other plastic known to us, can be dried by careful heating, and does not burn readily even in pure oxygen. It can be molded in place to an exact fit by compressing while heated above its softening temperature. This packing is good but makes the valves a little hard to turn. A packing most satisfactory in this respect, but a little harder to make or to dry out if it gets wet, consisted of the following in order along the valve stem. A brass washer about $1 \mathrm{~mm}$ thick, a cellulose acetate washer, $0.5 \mathrm{~mm}$ thick, a sole-leather washer impregnated with paraffin about $2 \mathrm{~mm}$ thick, a cellulose acetate washer and a brass washer like the first ones. The metal washers are turned to make a close but not a tight fit with valve stem and barrel. The plastic washers have the hole a little smaller and the outside diameter a little greater than the parts they are to fit, so that a little flow is involved when they are forced into place. The leather washer should fit a little less snugly than the plastic. This packing is tight against the highest pressures of commercial gas cylinders but offers a minimum of resistance to the operation of the valve.

The body of the valve that screws into the valve block and the detector are shown seated against offsets within the block. Alternatively, both have been made to seat against the outer surface of the block. Machining is a little simpler in the second case, but there is more chance to trap water in capillary spaces, more torque must be used to make a tight fit, and brass parts of the dimensions shown are rather easily twisted off.

Each connection between the valve-block and the cell consists of a foot or two of $1 / 16$-in. copper tubing, more or less coiled to act as a heat exchanger. The apparatus should be easy to take apart completely for drying and to reassemble. The connecting fittings shown have been particularly satisfactory; they are simple, rugged, and easy to make tight. Only metal-to-metal joints should be considered. Threads, tapered or otherwise, cannot be made tight without a vast amount of trouble; fiber washers and other forms of packing are as bad or worse, chiefly because they retain water.

In making up the assembly of valves and connections, every precaution must be taken to eliminate places where water can be stored by such things as hydroscopic salts, rubber, or rust (which is a good adsorbent and acts much like a little silica gel). Soldering flux is particularly bad, and capillary spaces such as screw threads can be troublesome. It is good practice before final assembly of the equipment to wash the parts with a solvent for grease and then to boil them for several hours with several changes of water to remove hydroscopic salts. Finally, the parts are dried in an oven.

Gages of the Bourdon type have been used exclusively for work involving pressures above atmospheric. In some work below atmospheric pressure, mercury manometers were used. If sufficient care is taken with other things, the accuracy of the pressure gages is at least one of the 
limiting factors in the accuracy with which the method can be applied to various problems. Hence the gages used should be as good as it is practicable to obtain unless a lower degree of accuracy in the final result is considered sufficient. In the testing of oxygen, it is frequently desirable to apply the full pressure of the cylinder to the cell. Even when this is not the case, there is always the chance that the full pressure, sometimes as high as 2,640 psi, will be applied accidentally. Consequently, a gage reading to 3,000 psi should be used on the cell. There is generally less trouble from obscure sources of water if the standard gas is not too dry, hence the saturator is seldom kept at a pressure higher than $500 \mathrm{psi}$, and a gage reading to 500 or at most 1,000 psi is all that is required at this point. If only high concentrations of water, say above 1 percent relative humidity, are of interest, gages reading to 200 psi will afford greater accuracy than those of higher range.

Although lack of a high-pressure regulator does not preclude saturating the gas at a high pressure, such as 500 or 1,000 psi, by attaching directly to a cylinder at that pressure, a regulator is a great convenience. Regulators with upper limits of 500 and 1,000 psi have been used. The latter works slightly better at 500 psi than the former and is probably the more desirable for general use.

\section{Systems Operating Below Atmospheric Pressure}

The apparatus previously described has been designed for use only above atmospheric pressure. The employment of pressures less than atmospheric offers some inducements. The practicability of using glass apparatus of moderate strength is one. No supply of compressed gas is needed for saturation. If the usual comparison pressure, $P_{c}$, of eq 2 is reduced to 0.1 atmosphere instead of 1 atmosphere, that of $P_{s}$ and $P_{x}$ or both can be reduced to change their product in the same ratio, and the uncertainty of deviations from the ideal gas laws can be largely eliminated. These advantages are offset for most purposes by the fact that we lack suitable glass valves for controlling pressure, that low-pressure manometres have a lower percentage accuracy than high-pressure gages of equal convenience and cost, and that for gases of the same composition, sensitivity is lost by going to lower pressures. The use of metal needle valves with apparatus otherwise built of glass has been tried and may be desirable for work involving not too low or too extended ranges of humidity, especially the testing of reagents. We employed a mass of crushed ice, through which air was drawn, as the saturator in this apparatus. The greatest difficulty encountered with it was the certain prevention of leakage. Because an apparatus of this kind is immersed in an atmosphere usually containing 10,000 to 20,000 times the concentration of water vapor, easily detectable, a very small leakage is fatal to accuracy, and there is no easy way of detecting its occurrence. The temperature of saturation also gave trouble. Although the saturator was imbedded in as well as filled with crushed ice, droplets of water sometimes appeared so near the outlet that their temperature was in doubt.

If a vacuum system is to be employed, it is suggested that room air be used as the standard gas without attempting to saturate it, and that its moisture content be determined as often as necessary by separate tests. In this way, the uncertainties, both of leakage and temperature, can be eliminated from the main series of experiments, though not, of course, from the calibration.

\section{Conducting Films}

\section{Phosphoric and Sulfuric Acids}

(a) Range and Permanence

The electrolytic film preferred by the authors for most purposes is plain phosphoric aicd. At ordinary laboratory temperatures it changes resistance steadily and adequately between a concentration of water vapor of about 8 micrograms per liter and one of about $20 \mathrm{mg}$ per liter (or relative humidities from about 0.03 percent to about 90 percent). Below 8 micrograms per liter, the resistance is likely to increase suddenly, particularly under high pressure, probably because of the crystallization of a solid phase. Phosphoric acid films have served for measurements as low as 3 micrograms per liter and are usually all right for 5 micrograms. The variation probably represents failure to crystallize under some conditions because of impurities or lack of a seed nucleus. In fact, the behavior of the resistance of a film under these conditions is fairly typical of crystallization in general; a film has worked well at about 3 micrograms per liter and a few minutes 
later has been completely insensitive at 5 micrograms per liter. A film containing sodium chloride as the electrolyte behaves in much the same way, except that the humidity at which crystallization is likely to occur is about 2,000 times higher. $^{3}$

Sulfuric acid has no lower limit of sensitivity that we have discovered, and it can be used successfully to indicate humidities of a fraction of a microgram per liter. The application of the method in this low range appears to be limited only by difficulties other than the sensitivity of the indicating electrolyte. One of these is the rapid disappearance of the sulfuric acid itself, probably by evaporation but possibly by reaction with the materials of the detector.

Phosphoric acid is much superior to sulfuric acid in this respect, but a phosphoric acid film also shows an increasing resistance on long exposure to a constant humidity. The rate is slow enough not to interfere with the usefulness of the film when calibrations are made to determine the significance of each reading. The change that takes place through loss of acid between a test and a prompt calibration is nearly always negligible.

It is a little hard to specify the magnitude of the losses of electrolyte in general terms, particularly because changes of temperature or other conditions cause the resistance of a detector coated with phosphoric acid to drift toward lower almost as frequently as toward higher values. The following observations will indicate something of the magnitude of the effects to be expected. A simple phosphoric acid film of 600,000 ohms in gas containing $0.06 \mathrm{mg}$ of water per liter lost about threefourths of its conductance in 24 hours. A film of sulfuric acid in metyl methacrylate, which had a resistance of about 1 megohm in an atmosphere containing $1 \mathrm{mg}$ of water per liter, lost about 20 percent of its conductance in 3 hours. A roughly corresponding film of phosphoric acid lost about 30 percent of its conductance in 2 weeks. A film of phosphoric acid in gelatin prepared in 1919 and kept in a desk drawer in the laboratory was still usable 3 years later [1]. However, as will be

\footnotetext{
3 One set of observations with a sodium chloride film, for example, showed no conductivity with increasing relative humidities until about 65 percent was reached, when the film suddenly became strongly conducting. On drying out, the film remained sensitive down to a relative humidity of about 40 percent, when it became suddenly nonconducting. Under increasing humidity, conductivity did not reappear until 65 percent was again reached.
}

shown, it is best to renew the film at least daily except when the detector must be undisturbed for longer periods.

In the range of humidities below about 8 micrograms per liter, it is advantageous to use mixtures of phosphoric and sulfuric acids. They do not crystallize as readily as the first nor change as rapidly as the second.

\section{(b) Application of the Film}

In the beginning it was considered necessary to apply the thin films in the form of dilute solutions of the electrolytes, to be left behind by the evaporation of the solvent. It was soon found that films of a salt or sulfuric acid when exposed to even moderately high concentrations of moisture seldom returned to even approximately the same value, and the tentative explanation that the changes resulted from physical displacement of the mobile solutions was confirmed when it was found that the trouble diminished if a binding agent such as gelatin was added to the solution. However, it was discovered by F. A. Smith that phosphoric acid is viscous enough and adheres well enough to glass to be used without a binder except possibly at humidities above 90 percent, and that the sticky concentrated acid can be applied to the smooth surface of a detector and wiped off to leave a film of almost any conductivity desired. The usual reagent phosphoric acid (85 percent) may be used, or a small quantity of phosphorus pentoxide may be exposed to the air until it becomes fluid enough for use. The detector is coated simply by touching a toothpick or the point of a lead pencil to the phosphoric acid and then to the surface of the insulator and wiping off the excess with a bit of cotton. Less than a minute is usually required. One soon learns about how much to rub off. Wiping with a moderate pressure on three successive clean portions of the cotton is one rule of thumb. Another is to wipe until the finely ground glass surface appears dull but not quite dry. If greater accuracy is desired, the adjustable resistances of the indicator can be set to approximately the desired reading in room air and the coating wiped off with one light touch of the cotton after another until the swing of the galvanometer needle shows that the resistance has become higher than corresponds to electrical balance. 
Fortunately, the thickness of the film is not at all critical. One film may have five times the resistance of another, but their difference be hardly noticeable in use. In some ranges of humidity, it is quite possible to use interchangeably films having a ratio of resistances of $50: 1$. In general, a thicker film permits greater sensitivity, and a thinner one reaches equilibrium more rapidly. The rule is, therefore, to use as thin a film as will have the desired sensitivity, but the thinner the film the more rapid is the drift caused by loss of the reagent and the greater is the effect of leakage in the insulation of the detector and the measuring circuit. These may be the deciding factors in some cases.

Sulfuric acid is always applied in a solution containing a binder. Gelatin [1] and Crystalite (methyl methacrylate) have been used. The latter is preferred. The best method of applying the coating has not been studied, but the following will give a good result. Half a gram of the plastic is dissolved in $100 \mathrm{ml}$ of acetone. To a 50-percent solution of sulfuric acid in water, an equal volume of acetone is added. Equal portions of the two solutions are mixed. If the plastic precipitates, enough acetone is added to redissolve it. The solution is painted on the detector with a camelhair brush. It dries almost instantly and is ready for use.

\section{(c) Sensitivity}

The actual resistance of a single phosphoric acid film, film $A$, over almost the whole range of humidities was measured with the circuit of figure 8. The observed data are given in table 1 and represented by curve 1 of figure 13 . The concentration of water in micrograms per liter is plotted on a logarithmic scale with respect to the balancing resistance (resistance $R$ of fig. 8) on a linear scale. The approximate resistance of the film itself is plotted on a logarithmic scale with respect to the same ordinate in curve 2 , the data for which were taken from curve 1 and the calibration of figure 11. Film $A$ was such as would ordinarily be used in the lower part of the range accessible to phospphoric acid. For humidities in the higher range, a thinner film is preferable because it reaches equilibrium with the atmosphere more quickly and does not begin to flow at so low a humidity. A typical application of phosphoric acid for this purpose, film $B$ is represented by curve 3, drawn on the same scale as curve 1. One film has about 20 times the resistance of the other, but both are readily usable over most of the range of humidities. In figure 14, the balancing resistances are plotted with respect to relative humidity. The two films were used at different temperatures of $83.6^{\circ} \mathrm{F}$ and $81^{\circ} \mathrm{F}$, hence the ratios of weights per unit volume and of relative humidities are not the same. The resistance of film $B$ reached a minimum before a relative humidity of 100 percent was reached, and the hook on the upper end of curve 3 of figure 13 represents a real effect. During exposure to the highest humidity observed with film $A$, its resistance passed through a minimum (which was the resistance recorded) and was increasing when the experiment was discontinued. In both cases the effects noted were probably caused by flow of the too mobile solutions formed as saturation was approached.

TABLE 1.-Resistance of a film of phosphoric acid (A) at various concentrations of water vapor

\begin{tabular}{|c|c|c|c|c|c|c|}
\hline \multirow{3}{*}{$\begin{array}{c}\begin{array}{c}\text { Balane- } \\
\text { ing re- } \\
\text { sistance }\end{array} \\
\text { Ohms }\end{array}$} & \multirow{4}{*}{$\begin{array}{c}\begin{array}{c}\text { Resistance } \\
\text { of detector }\end{array} \\
\text { Ohms } \\
2,870 \times 10^{3}\end{array}$} & \multicolumn{5}{|c|}{ Concentration of water } \\
\hline & & \multirow{2}{*}{$\begin{array}{l}\text { Micro- } \\
\text { grams } \\
\text { per } \\
\text { liter a }\end{array}$} & \multirow{2}{*}{$\begin{array}{c}\text { Rela- } \\
\text { tive hu- } \\
\text { midity } \\
\text { at } 83.6^{\circ} \\
\mathrm{F} \\
\text { Percent }\end{array}$} & \multirow{2}{*}{$\begin{array}{l}\text { Partial } \\
\text { pres- } \\
\text { sure }\end{array}$} & \multicolumn{2}{|c|}{$\begin{array}{l}\text { Approximate } \\
\text { dew point }\end{array}$} \\
\hline & & & & & ${ }^{\circ} \mathrm{C}$ & ${ }^{\circ} F$ \\
\hline 5,730 & & 11.3 & 0.039 & 0.011 & -74 & -101 \\
\hline 5,664 & 2,700 & 22.0 & .076 & .021 & -53 & -63 \\
\hline 5,541 & 2,390 & 35.2 & .12 & .034 & -49 & -56 \\
\hline 5,540 & 2,050 & 56.4 & .19 & .055 & -45 & -47 \\
\hline 5,167 & 1,600 & 86.9 & .30 & .084 & -41 & -42 \\
\hline 4,913 & 1,280 & 138 & .48 & .13 & -38 & -36 \\
\hline 4,700 & 1,040 & 171 & .59 & .17 & -35 & -31 \\
\hline 4,320 & 720 & 263 & .91 & .26 & -30 & -22 \\
\hline 3,836 & 528 & 411 & 1.4 & .40 & -26.7 & -16.2 \\
\hline 3,420 & 394 & 563 & 1.9 & .55 & -23.5 & -10.3 \\
\hline 3,195 & 337 & 655 & 2.3 & .64 & -22.0 & -7.6 \\
\hline 3,174 & 332 & 655 & 2.3 & .64 & -22.0 & -7.6 \\
\hline 2,955 & 280 & 790 & 2.7 & .77 & -20.0 & -4.0 \\
\hline 2,830 & 253 & 879 & 3.0 & .85 & -19.0 & -2.2 \\
\hline 2,304 & 154 & 1,520 & 5.2 & 1. 48 & -13.1 & +9.4 \\
\hline 1,980 & 106 & 2,170 & 7.5 & 2. 11 & -9.1 & 15. 6 \\
\hline 1,825 & 88 & 2,600 & 9.0 & 2. 53 & -7.0 & 19.4 \\
\hline 1,420 & 50 & 4,510 & 15.6 & 4. 38 & -0.5 & 31.1 \\
\hline 1,177 & 37 & 7,220 & 24.9 & 7.01 & +6.0 & 42.8 \\
\hline 973 & 17 & 13,200 & 45.5 & 12.8 & 15.0 & 59.0 \\
\hline 886 & 8 & 20,800 & 71.7 & 20.2 & 22.3 & 72.2 \\
\hline 790 & 0 & (b) & -... & -..-- & - & $\ldots$ \\
\hline 7,814 & $\infty$ & (c) & ..... & -....- & -....... & ..... \\
\hline
\end{tabular}

a To obtain parts per million by volume, multiply micrograms per litez by 0.804 . To obtain parts per million of air by weight, multiply by 0.62 . b Short eircuit.

- Open circuit. 


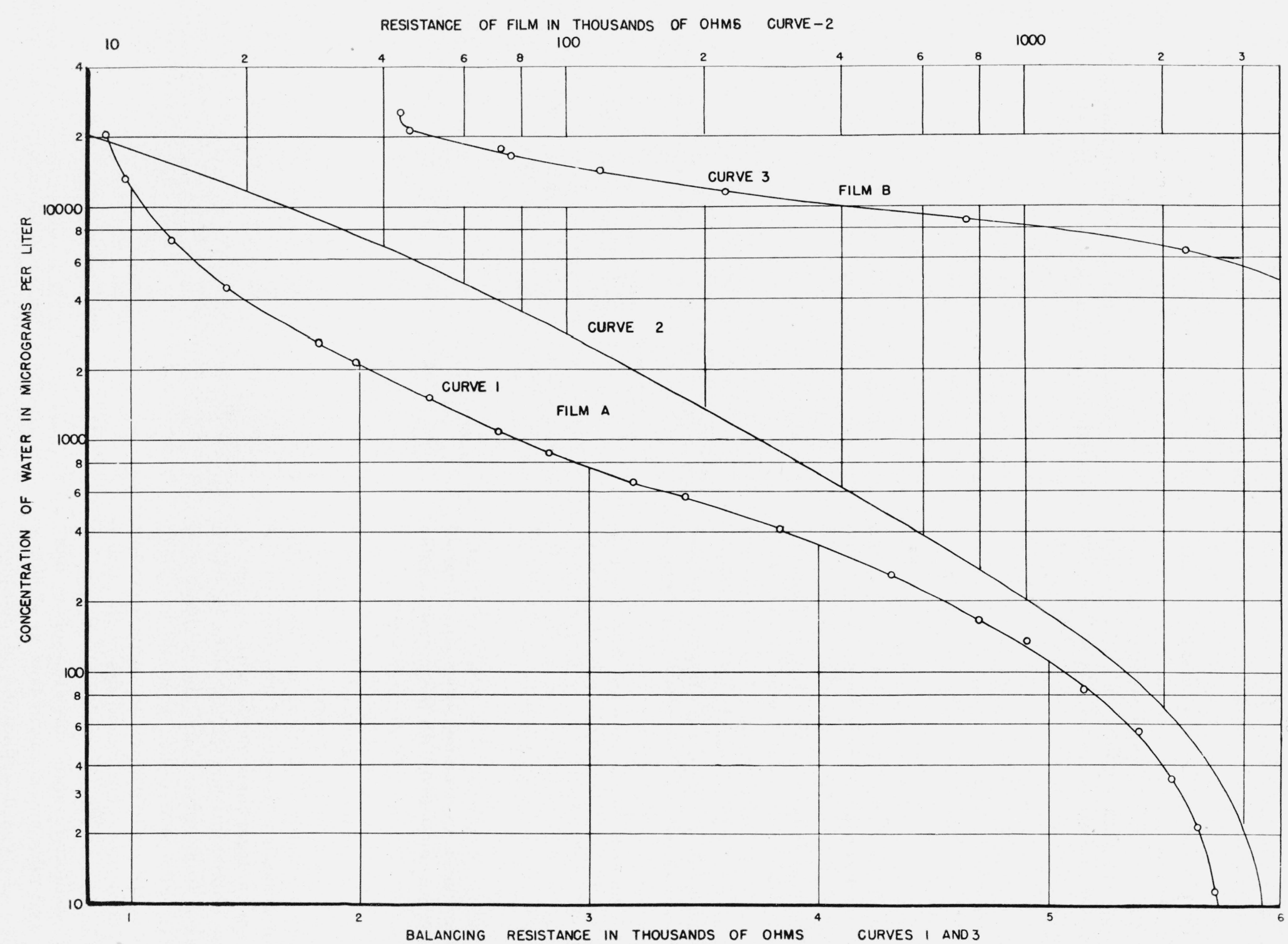

FIGURE 13.-Calibration of two conducting films in terms of concentration of water. 


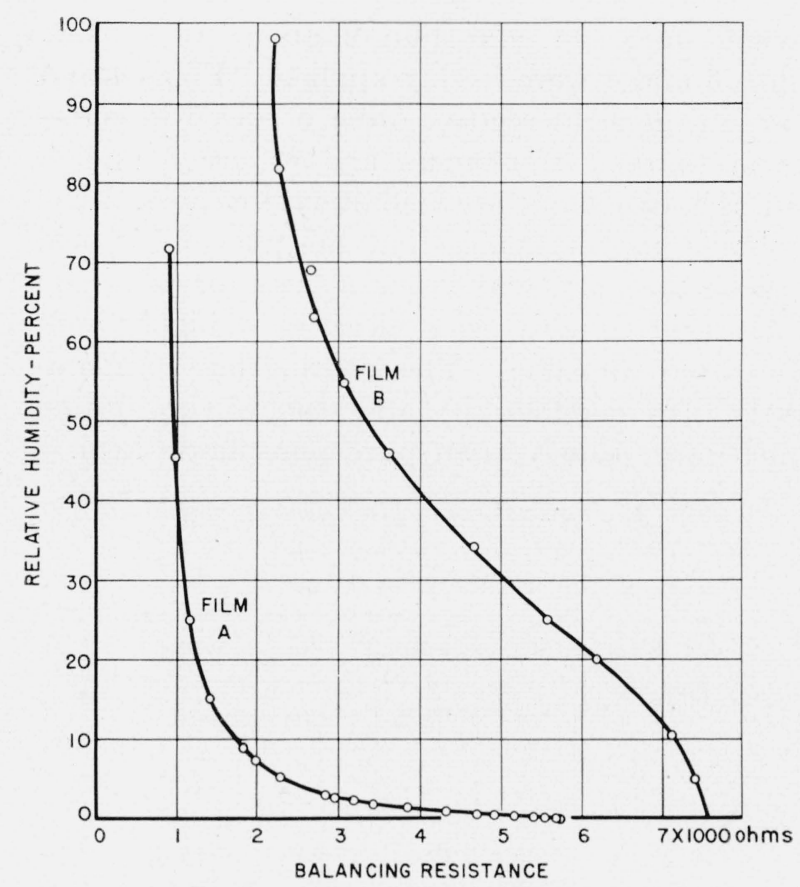

FIGURE 14.-Calibration of two conducting films in terms of relative humidity.

The sensitivity of the electrical indicator of figure 8 with film $A$ is shown by figure 15 . The curves were derived as follows. It was assumed that the balancing resistance could be read to 0.05 percent of its magnitude at any point. This corresponds to about 0.8 scale division of the galvanometer. The sensitivity, by which is meant the change in concentration of water that could be observed with the instrument, was assumed to have the same ratio to the difference between two observed humidities as the 0.05 percent of the mean balancing resistance had to the difference between balancing resistances, and this sensitivity was plotted with respect to the average of the two observed humidities. It is apparent at once that the sensitivity approaches about 0.3 microgram per liter or 0.1 percent of the water present, whichever is greater.

Figure 15 indicates instrumental sensitivity only. It must not be supposed that an absolute accuracy as great as this is usually or ever obtainable. The effects of all other sources of uncertainty remain to be accounted for. Actually, sensitivities, in the lower range of humidities at least, can be considerably increased by using thicker films or by examining gases under pressure, but at present there is usually no object in doing so be- cause the overall accuracy would not be improved.

It is to be remembered, of course, that the differences of water content that can be detected are smaller than the minimum amount that can be detected with phosphoric acid because of the formation of a solid phase already mentioned.

\section{(d) Speed of Approach to Equilibrium}

The speed with which phosphoric acid films approach equilibrium with the atmosphere in which they are placed is shown for four different films by figure 16 . The observations were all made by the use of the circuit of figure 8 in the following manner. The detector, with its film, was exposed at atmospheric pressure to gas containing $1.4 \mathrm{mg}$ per liter until a steady condition was obtained and the resistance, $R$ of figure 8 , required to balance the galvanometer was recorded. The flow of the first gas was stopped; a different (higher) resistance $R$ was set, leaving the galvanometer off balance; then as nearly simultaneously as possible a stopwatch was started and the valve of a cylinder containing $0.0114 \mathrm{mg}$ of water per liter of gas was opened. When the galvanometer needle passed through zero, the stopwatch was read. The observed interval of time is plotted with respect to the difference between the initial and the preset resistance expressed as a percentage of the difference between the initial balancing resistance and that reached after 15 minutes of exposure to the second gas.

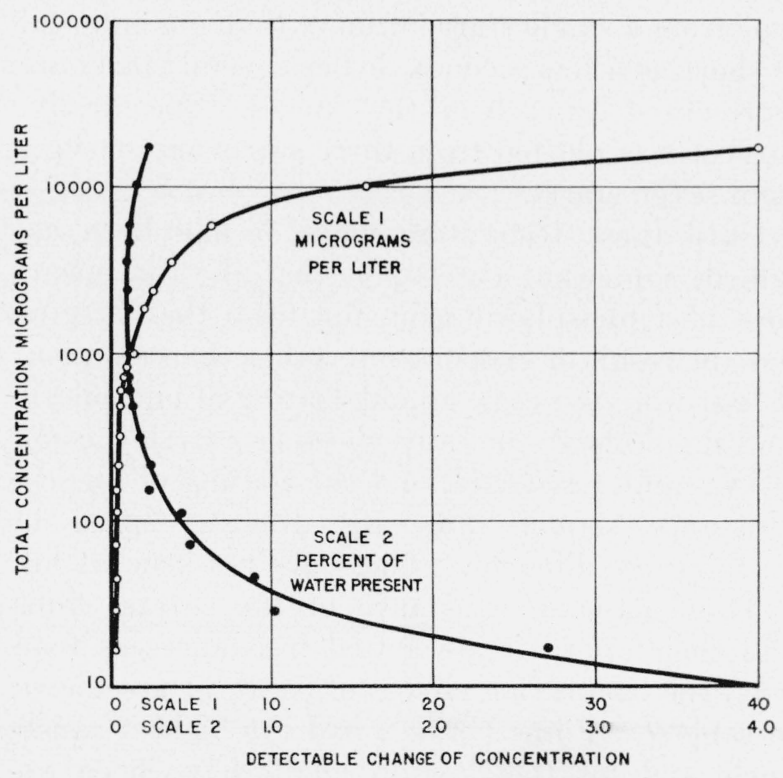

Figure 15.-Sensitivity of a typical phosphoric-acid film. 


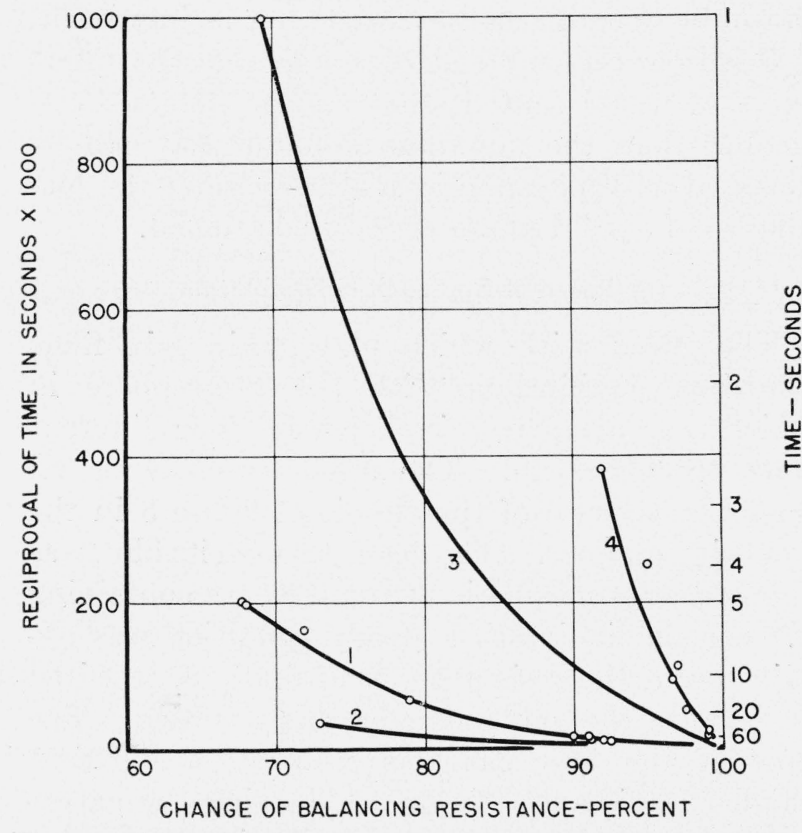

FIGUFE 16.-Speed of approach to equilibrium of typical films.

In figure 16, the smallest change of resistance of each film for which a time was recorded is shown by the circle at the upper end of the curve. Other observed points are shown for only films 1 and 4. No interval of time longer than about 2 minutes is indicated because the reciprocal timescale is too crowded. The many readings of longer intervals were consistent with the shorter intervals shown. It was impossible to read the time from a single start for more than one interval as short as a few seconds, hence several starts are represented by each of the curves. Specifically, curve 1 was plotted from three starts and curve 4 from seven starts.

Until these tests were made it had been assumed, somewhat carelessly, that the disappearance of a phosphoric acid film from the detector was the result of evaporation rather than reaction. If that were the case, an old coating of phosphoric acid should have the same speed as a fresh coating of the same resistance, and the coating of highest resistance should show the greatest speed in reaching equilibrium. These are not true at all.

The balancing resistance of the several films and their approximate actual resistances as read from the calibration curves of figure 11 are shown in table 2. Films 1 and 2 had the highest resistance, and for that reason might have been expected to react most rapidly. But film 1 was several days old and film 2 about $18 \mathrm{hr}$ old. Films 3 and 4 were freshly applied. Films 1 and 2 are in the right relative order of speed to correspond to their resistances and so are 3 and 4 . But the two pairs are definitely reversed. The probable explanation is that the phosphoric acid attacks the glass and forms a layer of salts and silicic acid roughly equivalent to a highly contaminated silica gel. This coating has comparatively little conductivity and reaches equilibrium much more slowly than pure phosphoric acid.

TABLE 2.-Resistances of films used in speed tests

\begin{tabular}{|c|c|c|c|c|c|}
\hline \multirow{4}{*}{ Film } & \multicolumn{4}{|c|}{ Concentration of water, $\mathrm{mg} /$ liter } & \multirow{4}{*}{$\begin{array}{c}\text { Ratio, } \\
\text { D/C }\end{array}$} \\
\hline & 1.4 & 0.011 & 1.4 & 0.01 & \\
\hline & \multicolumn{2}{|c|}{$\begin{array}{l}\text { Balancing resist- } \\
\text { ance }\end{array}$} & \multicolumn{2}{|c|}{ Film resistance } & \\
\hline & A & $\mathrm{B}$ & $\mathrm{C}$ & $\mathrm{D}$ & \\
\hline & Ohms & Ohms & Megohms & Megohms & \\
\hline $1 \ldots$ & 6,840 & 7,720 & 11. 0 & 104 & 9.4 \\
\hline $2 \ldots$ & 5,500 & 7,550 & 2. 26 & 50 & 22.1 \\
\hline $3 \ldots$ & 3,930 & 7,000 & 0.562 & 14. 1 & 25.1 \\
\hline $4 \ldots \ldots$ & 5,100 & 7,474 & 1. 50 & 38.5 & 26.6 \\
\hline
\end{tabular}

The numbers in the last column suggest also that old films do not change resistances in the same ratio as fresh ones, but the question is complicated by the fact that there is some conduction of current in the detector other than through the film, and there is room for considerable error in reading the higher resistances from figure 11.

\section{Films Containing Salts as the Electrolyte}

It would be obviously desirable to prepare films that always have the same resistances at the same humidities and could be given permanent calibration. Inorganic salts, in general, are not expected to evaporate or react with glass or the usual constituents of the atmosphere, hence they were the first electrolytes tried [1], and several attempts have since been made by the authors to use them, with indifferent success even in the limited upper range of humidities in which they form liquid solutions.

Dunmore's study of combinations of electrolytes and supporting materials in the development of his successful electrical hygrometer for meteorological work disclosed the source of at least a part of the difficulties. These are so great that "no limit was found which would maintain a satisfactory calibration when exposed to varying 
humidities for long periods." He distinguished long-period and short-period aging and later [3] developed means for eliminating some of the causes of both, among them the corrosion of glass by water. In the end, however, the hygrometers "must go through an aging period of at least 10 to 14 days before they are ready for use." [3]

Some of the authors' experiences with films of the high conductivity needed for successful application with the detector designed for use in pressure-tight cells may help in the more complete understanding of the problem.

Figure 17 shows the results of observations made

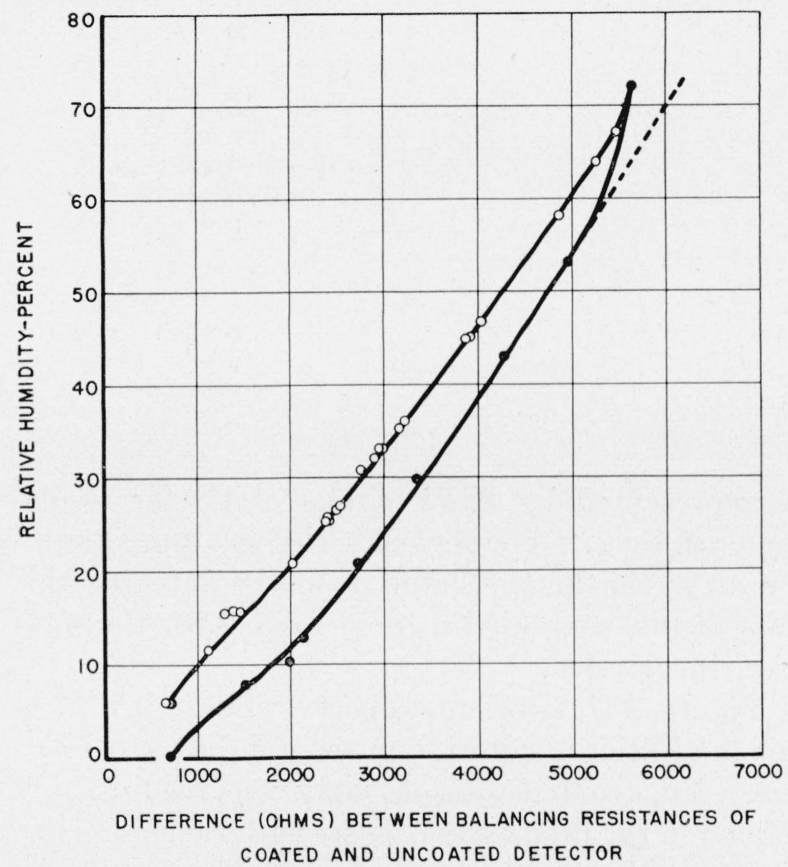

FIgURE 17. Observations with a film containing lithium chloride in glycerol.

with a coating of lithium chloride in glycerol. Equal volumes of glycerol and of a 5-percent solution of lithium chloride in water were mixed and applied to the detector like phosphoric acid. The detector was dried quickly by exposing it to air of about 0.1-percent relative humidity; then its resistance was measured at each of several humidities in increasing order. The results are represented as the difference between the balancing resistance ( $R$ of fig. 8 ) of the coated detector and that of the detector before coating. Hence the plotted values, shown by black circles, increase as the resistance of the detector decreases. At the highest humidity the resistance of the film decreased as water was absorbed, then began to increase. The point plotted represents the minimum resistance of the film at this humidity. The point is out of line with the observations at lower humidities, just as is the highest point of curve 3 of figure 13, representing a film of phosphoric acid, probably for the same reason - because the solution began to flow. Had there been no movement of the coating, it is probable that the change of resistance would have followed approximately the broken line drawn as an extension of the lower curve.

A series of observations at lower humidities followed immediately. They are represented by open circles and by the left-hand curve in the figure, which was drawn to approximate their average. Readings were made up and down this curve, but care was taken not to reach a relative humidity at which flow was expected to begin. The humidity corresponding to each of the observed resistances was then read from the average curve and compared with the observed humidity. The results are given in table 3 in the order in

TABLE 3.-Relative humidities measured with a film of lithium chloride in glycerol made in the sequence given in the first column

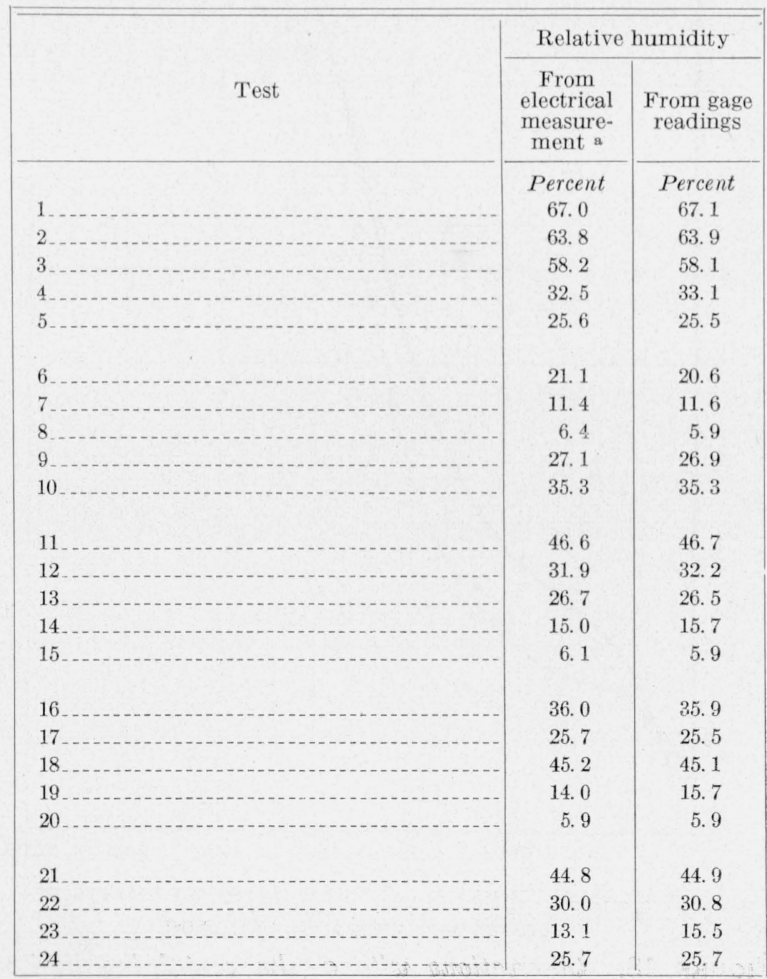

a Values read from average curve. 
which the observations were made. The table shows that there was no important change in the calibration of the film during a short period of use if too high humidities were avoided. Not all the irregularities, perhaps none of them, are to be attributed to changes in the film. They are no greater than the probable errors of calibration of a constant film. Unfortunately, the calibration did change appreciably in a day or two, probably because the glycerol evaporated.

The solution of lithium chloride in glycerol, of which several films were made, was found to be amply sensitive down to a relative humidity of about 1 percent, and almost as fast as phosphoric acid itself. It has little or no advantage in permanence or in the upper range possible without flow. It may be useful in atmospheres that would react with an acid.

Figure 18 represents observations made with a film obtained by applying a solution of lithium chloride and polymerized methyl-methacrylate (Crystalite) in acetone. Again the series of exposures of the film made immediately after coating

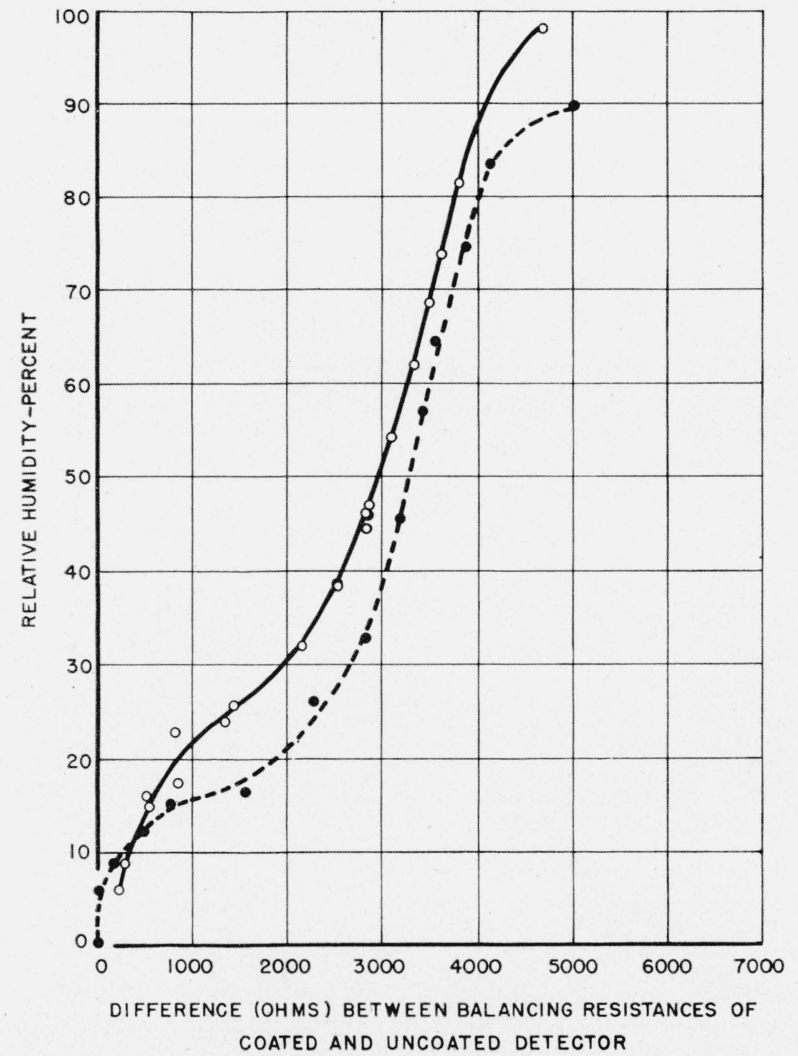

F1GURE 18. Observations with a film containing lithium chloride in methyl methacrylate.
TABLE 4.-Relative humidities measured with a film of lithium chloride in Crystalite

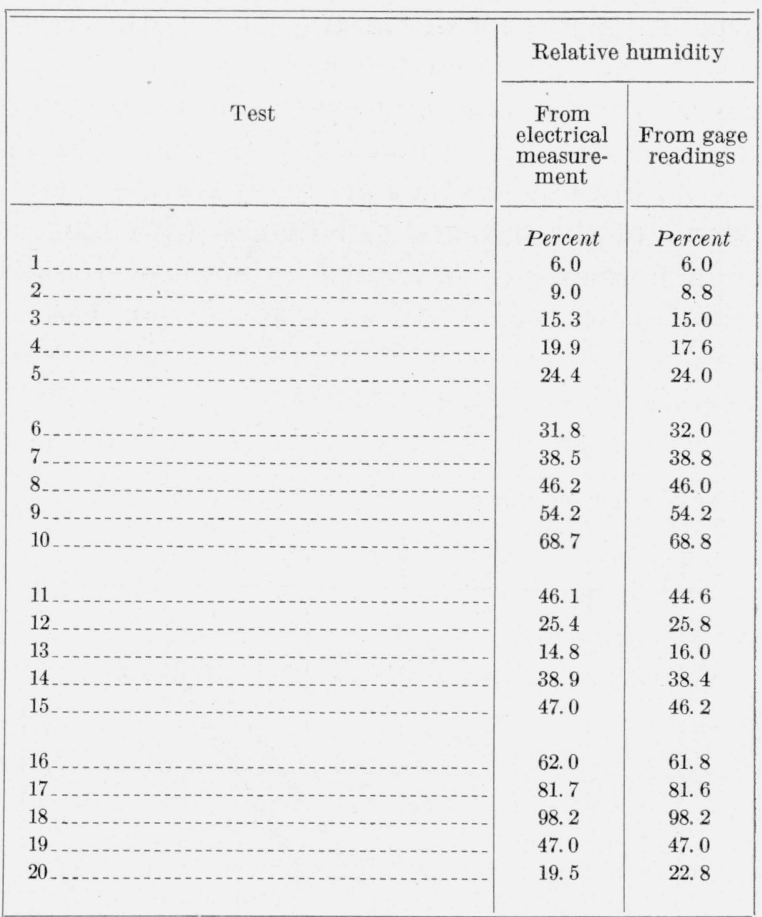

is represented by black circles and later results by open ones. The second series was run about 5 $\mathrm{hr}$ after the first. Table 4 shows data for this film of the same kind as does table 3 for the solution in glycerol.

Figure 19 represents observations with films made of lithium chloride in several different binders. To avoid confusion, only the readings obtained in the first series of tests with each detector, corresponding to the black circles of figures 17 and 18 , are represented.

In these tests, which were made before those of figures 17 and 18, the balancing resistance of the detector before coating was not measured, only that of open circuit. It is believed, however, that had the conductance of the uncoated detector been taken into account, it would have been found that none of the films with the exception of the glycerol had any significant conductance at less than 5-percent relative humidity. The glycerol film (which was not the one represented in fig. 17) gave reproducible readings without regard to previous exposure within the range of humidities tried; all the others shifted to new curves every time the films were exposed to very high or very low humidities. 


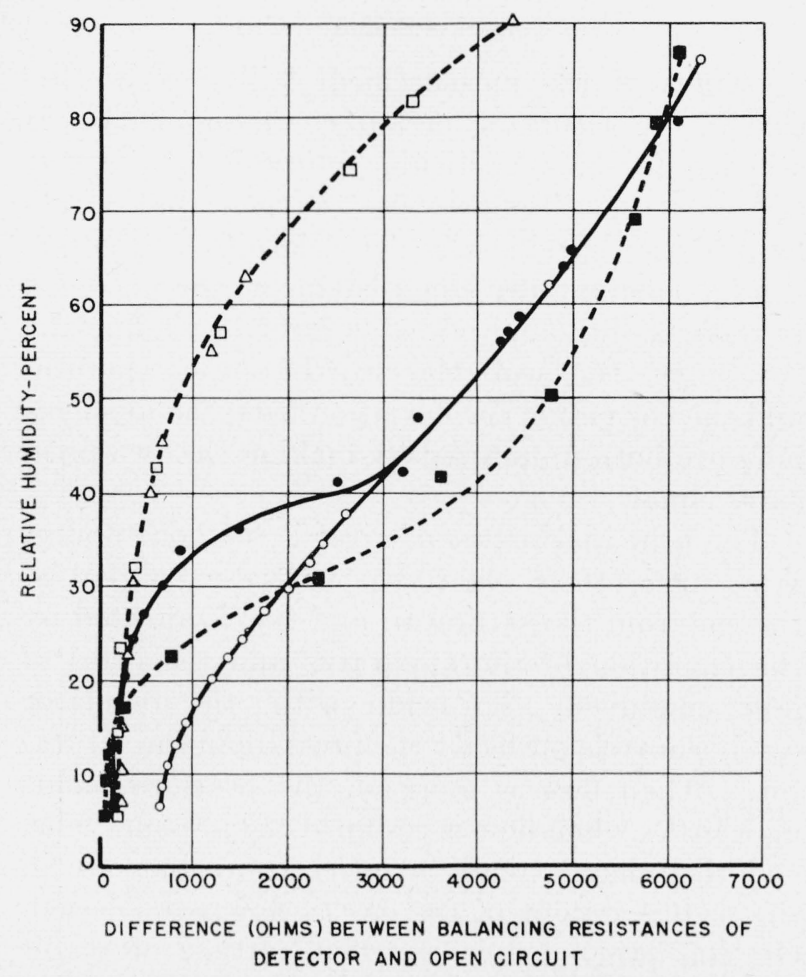

FIgURE 19. Observations with several films containing lithium chloride.

, Lithium chloride in glycerol; $\bullet$, lithium chloride in polyvinyl acetate; , lithium chloride in gelatin hardened with formaldehyde; $\square$, lithium chloride in soft gelatin; $\triangle$, lithium chloride in gelatin and glycerol.

In addition to the films represented in figures 17 to 19 , several other salts were tried with some of the plastics, and cellulose acetate was tried as a binder. Lithium chlorate, whose saturated solution should have the lowest vapor pressure of any known salt, appeared to be quite as good as lithium chloride, but not noticeably better; and none of the other salts seemed to be as good for general use. Less soluble salts may be useful in simple alarms. ${ }^{4}$ Cellulose acetate films aged slowly and were particularly slow in reaching equilibrium after a change of humidity.

Several points of interest may be noted in connection with figures 17 to 19 . The resistance at a given humidity of a salt solution in glycerol is independent of the past history of the film provided it has not lost material and not been diluted enough to flow by exposure to very high

\footnotetext{
4 Such an alarm, consisting of a relay energized through a circuit that includes a salt film, will be actuated only when the vapor pressure of water in the atmosphere reaches the vapor pressure of a saturated solution of the salt. The choice of the salt will determine the relative humidity that will cause a signal.
}

humidities. When subjected to a very dry atmosphere, the conductance of the film does not approach zero, and it responds to changes of humidity as low as 1 percent, far below the vapo pressure of a saturated solution of the salt. These observations seem to indicate that the salt is in true solution in the glycerol and that the latter acts to some slight extent as an ionizing solvent. As a true solution, the properties depend only on composition.

Films in which colloidal binders are used behave differently. Their conductances approach zero, not at zero humidity but at relative humidities as high as 20 percent. With the exception of solutions containing soft gelatin, the calibration curves have pronounced knees in the neighborhood of the vapor pressure of the saturated solution of the unmixed salt, but the position and magnitude of the knee-like bend depends on the colloid used. If the gelatin in a film is made tougher and less soluble in water (or less of a solvent for water) by the use of formaldehyde, a knee develops. But if the gelatin is made into a rubberlike jelly (printers' roll) by adding glycerin, its properties as a supporting material for an electrolyte are changed very little. The resistances of all the plastic films appear to depend on their past exposures to different humidities, particularly to strong drying, and when first formed they change more or less rapidly for a considerable time. Calibration curves retain their general form, including the knee but not their position on the resistance scale. Of the plastics tried by the authors, methyl methacrylate seems to reach a condition of stability most rapidly.

None of the plastic films respond to changes of humidity with the speed of phosphoric acid or of a salt in glycerol, but the methyl methacrylate films are fast enough for the purpose for which they are likely to be used. The readings of the film represented in figure 17 required about 3 minutes each, with the exception of those at the two or three highest humidities, which became substantially steady only after a much longer time. Unfortunately the methyl methacrylate films do not adhere well to the detector. Three days after the tests represented by figure 18, for example, the resistance of the film was infinite, probably because it had detached itself from one or both electrodes. We have had other experiences of the same sort. 


\section{Procedures, Corrections, and Sources of Error}

\section{Operation of the Instrument}

(a) Procedure in Testing Compressed Gas

The method of operating the instrument when testing oxygen has already been given but is so simple that it will be repeated here for convenience in the more detailed discussion of points of interest. Referring to figure 1, gas from the nitrogen cylinder is maintained in the saturator at a pressure of about 500 psi by means of the regulator. The cylinder of gas to be tested is connected to valve $C$. Valve $B$ is opened widely and valve $A$ is opened a little to permit a slight flow of gas from the saturator through the cell. The indicating circuit is adjusted, usually by changing resistance $R$ (but sometimes $V$ ) of figure 7 to produce any convenient scale reading of the galvanometer, and as soon as this reading is sufficiently constant, it is noted. This reading will be referred to as the balance-point. Valves $A$ and $B$ are closed in that order and valve $D$ opened widely. Valve $C$ is then opened to permit a moderately brisk flow of the gas to be tested through the cell. As soon as this gas reaches the cell, the galvanometer needle goes off-scale on the dry side, corresponding to a high resistance of the detector. Valve $D$ is now closed gradually, and the pressure built up in the cell until the galvanometer needle swings back to or past the balance-point. If, as usually happens, the first adjustment carries the needle past the balancepoint, valve $D$ is opened a little, carefully; if the new adjustment overshoots the balance-point in the opposite direction, the valve is closed a little, still more carefully. This series of approximations is continued until a satisfactory adjustment to the balance-point is obtained. It is something of a game of skill, the object of which is to make the galvanometer reading come to the balance-point as quickly as possible and stop there. When this is substantially accomplished, the pressure in the cell, $P_{x}$, is read. If there is any doubt that the pressure reading is sufficiently accurate, valve $C$ or $D$ is changed and another adjustment of the galvanometer to balance is made. When the observer is satisfied as to the balancing pressure, the thermometer is read and the concentration of water vapor is computed. (b) Control of Standard Gas

Details of the measurement will now be discussed. A saturator pressure, $P_{s}$, of $500 \mathrm{psi}$ is selected for this particular purpose, because at ordinary room temperature, oxygen that meets Army-Navy specification for aviator's oxygen will have a substantially equal balancing pressure, $P_{x}$. If there is the same probable error in reading the two gages, the probable error of the comparison and the correction for deviation from the ideal gas laws are both minimized by making the two pressures equal.

The principal source of error is, without doubt, some uncertainty regarding the water content of the gas from the saturator, and this is affected by the condition of the apparatus and the rates of flow employed. To begin with, the regulator rarely controls perfectly the pressure in the saturator. When flow is stopped, the pressure builds up a little; when flow is resumed the pressure falls, and this change tends to produce an increase in the water content of the gas as flow is increased. On the other hand, the evaporation of water within the cylinder tends to cool the gas and cause the water content to decrease during the test. If the rate of flow is too high, there may not be time for complete saturation. Expansion at the valve causes a sharp drop in temperature of the gas with a tendency to precipitate the water as liquid. Fortunately most of the cooling takes place after the gas passes the narrowest passage in the valve, and any mist that is formed reevaporates. The massive block is intended to supply heat rapidly to the valve seat and prevent, as far as practicable without auxiliary heating, the chilling of the inlet to the valve and the condensation of water from the gas before expansion. This is never completely accomplished unless the valve-block as a whole is warmer than the saturator, and from time to time a little condensed water comes through the valve and produces a momentary movement of the galvanometer needle toward the wet side. In practice these brief deflections of the galvanometer are disregarded. They are comparatively rare, and the amount of water indicated would not affect the reading of the instrument much if it were distributed throughout the gas stream. The slower the flow, the less effect there is from this source of difficulty.

In practice it is assumed that the gas flowing through the cell is at atmospheric pressure. Of 
course it is not, or it would not flow. Consequently, the detector is exposed to a little higher concentration of water than would otherwise be the case. The gas cooled by expansion may not reach room temperature by the time it arrives at the detector. This affects the reading in two ways; the lower temperature tends to condense more water in the film and thus cause a decrease of resistance, but a film containing a given quantity of water has a high temperature coefficient in the opposite direction. Available data seem to indicate that under some conditions of temperature and pressure the net effect is in one direction, under other conditions in the opposite direction. This is still somewhat uncertain, but the needed study of temperature effects has been deferred until a more elaborate set of controls is made available.

The discussion thus far would indicate that accuracy is promoted by making the flow of gas from the saturator very slow. We should add that at a very high rate of flow there is danger that liquid water will be carried over from the saturator mechanically and that there is even the possibility that a sudden blast of gas over the detector will displace the film (this not infrequently happens with the gas to be tested if valves are manipulated carelessly).

Another factor of importance enters, however. The dry side of the instrument is rarely completely dry. Even though the parts of the apparatus are made, dried, and assembled with care, they seem to have the property of sorbing water from moist gas in sufficient quantity to be readily detected and giving it up later to a drier atmosphere. Gages are the worst parts of the apparatus in this respect; valve packings probably next. This exchange of moisture with surfaces and pockets within the apparatus generally affects the resistance of the detector when there is no flow of gas. A very small flow is affected to some extent, a large flow is not affected appreciably. For this reason we do not want gas from the saturator to flow too slowly; there is also a saving of time in reaching equilibrium if the rate is increased. A rate of $250 \mathrm{ml} / \mathrm{min}$ from the saturator is probably usually about right. It is not necessary to measure it, however; the observer soon learns to control it satisfactorily by other means. In a quiet room the gas escaping from the saturator at 500 psig should be barely audible to a normal ear, or silent but on the verge of audibility. The stream issuing from the small outlet of valve $B$ should not be perceptible to the hand unless the outlet is blocked momentarily with a finger or thumb. The little spurt of gas when the pressure is relieved should be noticeable. Momentarily blocking the flow should also cause the galvanometer to respond decisively and at once. If the apparatus is thoroughly dry, the galvanometer reading should be the same for any rate of flow of gas sufficient to prevent diffusion upstream from the outlet valve and not great enough to build up appreciable pressure in the cell. To save time, it is better to adjust near the latter limit than the former one. The American Instrument Co. puts an adjustable stop on valve $A$, which permits it to be opened the right amount without uncertainty or delay, and this is a distinct convenience.

\section{(c) Troubleshooting}

The condition of the apparatus can usually be judged by the quick and simple tests that follow . Set the rate of flow (with valve $A$ ) at what is considered a little more than is desirable, to produce a slight pressure in the cell, then close the valve half way. A prompt but slight deflection toward the dry side (higher resistance) is the normal reaction if the system is dry, because the pressure in the cell diminishes. An immediate and permanent deflection toward the wet side indicates that water is entering the gas stream steadily as it evaporates from a packing, screw thread, or other source near the main channel of gas flow. A strong momentary deflection followed by the return to a steady reading, which is equal to or on the dry side of the reading obtained before the change of flow, indicates a nearly isolated pocket in which wet gas can accumulate and from which it is released only by a change of pressure. This pocket is usually the gage. If no deflection occurs when the rate of flow is changed it may be because the rate was initially too low to produce appreciable pressure in the cell, because the detector or indicator is insensitive, or because there is so much water in the cell or its connections that the gas is nearly saturated regardless of rate of flow.

The conditions may be further explored by checking and releasing the flow with a thumb at the outlet of valve $B$. Usually the galvanometer deflects sharply to the wet side when flow is 
stopped, and returns to the original reading when it is released. Sometimes a sequence of deflections will follow the release in such a way as to disclose a source of water, but this is less likely than with the less violent changes of flow produced by valve $A$.

If stopping and starting the flow at the outlet does not produce normal deflections of the galvanometer, the detector should be taken out of the cell and its response to the ever-changing humidity of room air noted, particularly the effect of bringing the detecting film near the operator's hand. If the indicator responds normally to this by promptly indicating a much lowered resistance. and particularly if the resistance of the detector in the cell was low, the apparatus is probably flooded. If exposing the detector to the atmosphere near the skin does not cause a sharp decrease of resistance, the system is inherently insensitive. If touching the electrodes with the finger does not produce a quick off-scale deflection, the trouble is in the electrical indicator and may be caused by a run-down battery, a broken connection, shunting by a low resistance, or the like. If the response to touching the electrodes is normal the trouble is in the film, which must be renewed.

The troubleshooting procedure is not as cumbersome as its description suggests. It should not require more than 2 or 3 minutes including the renewal of the sensitive film, if that is needed. Correcting faults in the electrical system and drying out the apparatus, when this is necessary, take longer.

If liquid water in quantity has gotten into the dry side of the apparatus, it is all but impossible to dry it out completely except by disassembling the apparatus and baking the individual parts. If the moisture has come only from exposure to gases of fairly high humidity, it can usually be removed sufficiently by attaching a cylinder of dry gas and alternately building up and discharging a pressure of several atmospheres in the system. The cycle can be repeated every 2 or 3 seconds. If 500 or 1,000 cycles are not effective, more thorough means of drying should be resorted to. This treatment is usually needed and usually successful after the apparatus has been out of use for a considerable period of time. (d) Selecting and Matching a Balance Point

It has been remarked by one of the users of the instrument that the galvanometer reading is always drifting, and this is substantially true. There are numerous possible causes for drifting, especially when gas is coming from the saturator. To those causes that will be evident from the preceding discussion must be added changing battery voltage and the effect of changing temperature and humidity on the measuring circuit, including the resistance of the insulation of leads and detector. That these are real effects is clearly shown by the different balancing resistances required from time to time with an open circuit. Probably, however, the major cause of drifting is the slow approach to equilibrium within the glass insulator. The glass is, after all, an extremely viscous liquid that never possesses infinite resistance. In time, the electrolyte with which it is in contact probably diffuses into the glass to a considerable depth, making it more conducting. The subsurface electrolyte reaches equilibrium with water only very slowly, probably only at a rate comparable to that at which the electrolyte penetrated originally. When not in use, the detector is usually exposed to the relatively high concentration of water in normal air and tends to reach equilibrium with it. Then when the detector is used with gases of far lower water content, the freshly applied surface film follows closely the momentary changes of water vapor in the atmosphere, but the resistance of the underlying glass drifts slowly and without much reference to the surface changes, usually toward a higher value. Usually we cannot afford to wait for the reading in the standard gas to become constant, and we have to wait only for it to become so slow that we are not concerned with the change that takes place in a minute or two, for it will take no longer than that to complete the comparison with the unknown gas. Neither are we concerned with the temperature coefficient of the film, the condition of the batteries, or the electrical connections, provided these do not change appreciably during the measurement and that the measuring instrument is still sensitive enough. All these effects are cancelled out by the fact that they influence the reading with the standard gas to the same extent that they influence the unknown. 
Usually it is a waste of time to set the electrical resistance with the first gas involved in the comparison so that no current passes through the galvanometer or that any other predetermined reading is indicated. It is more convenient merely to bring the reading well onto the scale so that later the approach to it can be observed, and to make a mental note of it. The observer may forget the balance-point occasionally, but it will take less time to recompare the gases in the few cases of doubt than to adjust to preselected points or to jot down the balance-point in all cases. When following conditions that cannot be reproduced at will, it is safest to record each balance-point, of course.

As the galvanometer is expected to drift, there is virtue in completing the test as quickly as possible. Just as anything dries more quickly in a wind than in still air, the completion of the test is hastened by a rapid flow of the unknown gas. Too strong a gust, however, wastes gas, tends to displace the film, and fails to warm up enough between the valve and the detector and introduces an uncompensated thermal effect. In testing compressed oxygen, the initial rate of flow through valve $C$ with $D$ wide open is probably best made at about 1 to 1.5 liters per minute. This will be considerably reduced as $D$ is closed down.

When tests are being made only to determine whether gas does or does not meet a specification, one takes account of the temperature and the setting of the regulator and computes the pressure at which gas that just meets the specification would balance. Thereafter until test conditions are changed, it is necessary only to run the pressure of the gas to be tested up to the predetermined value and note whether the galvanometer reading is to the right or left of that made with the standard gas. A setting with the standard gas is made with each cylinder, but this is easily done by an observer while someone else changes the test cylinder. It has been found practicable for one observer, with a sufficient crew of laborers to shift cylinders, to make tests by this method at the rate of 100 cylinders an hour. If it is to be determined how much water is present, not merely whether it is above or below a certain limit, more time is required. A test does not often require more than 2 minutes exclusive of the time required to move and connect the cylinder. (e) Use of Compressed Gas as Standard

Actually it is not practicable to measure the water content of most of the aviators' oxygen now made by direct comparison with gas from a saturator, even if the saturation pressure is $1,000 \mathrm{psi}$ instead of the recommended 500 psi. If, for example, gas saturated at 1,000 psi and $25^{\circ} \mathrm{C}$ $\left(77^{\circ} \mathrm{F}\right)$ and expanded to 1 atmosphere matches gas at the usual charging pressure for storage cylinders, 2,000 psi, the water content of the stored gas is 4 micrograms per liter (after expansion to 1 atmosphere). If the saturation pressure is $500 \mathrm{psi}$, the minimum measurable water content of the stored gas is 7 micrograms per liter. Most of the aviator's oxygen tested at the Bureau of Standards, after the oxygen manufacturers began trying to comply with the specified maximum of 20 micrograms, has contained less than 4 micrograms per liter. To determine the water content actually present in such dry compressed gas, or to measure conveniently the water content below 0.2 or $0.3 \mathrm{mg}$ per liter of gas not initially under pressure, it is best to use a cylinder of fairly dry compressed gas as a secondary standard. Even for gases within range of direct comparison with the saturator, the cylinder is a convenience because less care is required than in the control of the saturator, and the composition of the standard gas is less dependent on temperature.

The gas to be used as the secondary standard must be compared frequently with gas from the saturator, for the water content of gas discharged from a cylinder invariably increases as the pressure falls, because the gas in the cylinder is always in near equilibrium with water adsorbed on the walls. This equilibrium is somewhat affected by temperature, but changes in the gas are slow.

A cylinder of gas to be used as a secondary standard in testing other cylinders can usually be selected from the lot. Otherwise it can be conveniently prepared in a laboratory in which compressed air and a vacuum pump are available by thoroughly drying an evacuated cylinder, admitting as much air from the room as is desired, and filling with compressed air, dried with a good desiccant after compression. An an example, assume that a water content of about 25 micrograms per liter is desired in the secondary standard, that compressed air is available at 1,800 psi, 
and that the laboratory air is 50 percent saturated at $25^{\circ} \mathrm{C}$. The room air contains about 11,500 micrograms of water per liter. At 1,800 psi, the cylinder will contain about 125 volumes (at 1 atmosphere) of air. Hence we want about $(25 \times 125) / 11,500=0.27 \mathrm{~atm}=210 \mathrm{~mm} \mathrm{Hg}$ of room air in the cylinder. As a secondary standard this gas can be used, while still at the initial pressure, to measure gas at 1 atmosphere containing from about 25 to about 3,000 micrograms per liter, or gas compressed at 1,800 psi at about 0.2 microgram per liter after expansion. It will measure the quantity corresponding to saturation with liquid water in the cylinder of any gas above about 4 atmospheres. As the gas in the standard cylinder is used up, the usable range becomes narrower. The upper limit decreases because only lower comparison pressures ( $P_{c}$ of eq 2) are available; the lower limit increases because some water evaporates from the cylinder walls.

The actual use of standard gas from cylinders differs from the use of a saturator in only one important respect. It is more often advantageous to use the secondary standard at other than a pressure of 1 atmosphere; unless advantage is taken of the fact that the barometric pressure is known more accurately than any small pressure can be measured on the gage attached to the instrument, accuracy is favored by making the pressures of standard and unknown gas as high as practicable. There is less reason than with the saturator to avoid excessive flows, and the observer may wish to gain speed by increasing somewhat the flow used. On the other hand, he may wish to conserve the supply because of the trouble of renewing it.

\section{(f) Operations Other Than Testing Compressed Gases}

In most of the numerous possible applications of the method other than testing compressed gases, the gas to be tested is at atmospheric pressure. Instead of varying the pressure of the unknown gas to obtain a balance corresponding to an observation already made of the standard gas, the first galvanometer setting is made with the unknown gas, and the pressure of the standard, whether from saturator or calibrated cylinder, is varied to obtain a balance. The details of the procedure are so like those already given that they probably require no further description. Because we lack the ability to change the pressure of the unknown sample the range of concentrations that can be measured with a single standard is narrower than in testing compressed gas, and we may need two secondary standards in addition to the saturator, whereas we rarely need more than one in work with compressed gases.

One source of error should be emphasized in connection with miscellaneous uses of the instrument. No rubber whatever can be used in any connection through which a gas to be tested flows. Exposing the gas to contact with any rubber surface is almost equivalent to exposing it to contact with an equal free surface of water.

\section{Deviation from the Ideal Gas Laws and Com- putation of Results}

(a) Oxygen, Nitrogen, and Air

The equations given in the introduction would serve to compute correctly the results of experiments provided all the gases involved, including water vapor, behaved as ideal gases. This statement is meant to include as a part of the behavior of ideal gases the commonly assumed rule that the mass of water vapor per unit volume in equilibrium with liquid water is independent of the presence of other gases. The rule is not strictly true, and the deviation from it is to be attributed to forces between the molecules of water vapor and other gases, which are the same forces that cause the deviations from Boyle's and Dalton's laws. Hence it is correct as well as convenient to include the rule of constant vapor pressure among those defining relations for ideal gases.

In the initial use of the pressure-balancing method for water in oxygen, the amount of water found was always lower than that found by gravimetric determinations. C. E. Earle, of the U.S. Navy Department, suggested deviation from ideality as the explanation. The results of past determinations were studied statistirally by the junior author, and simplified eq 2

$$
W=\frac{S P_{c} P_{w}}{P_{s} P_{x}}
$$

was replaced by the empirical equation,

$$
W=\frac{S P_{c}\left(1-K P_{c}\right) P_{w}\left(1-K P_{w}\right)}{P_{s}\left(1-K P_{s}\right) P_{x}\left(1-K P_{x}\right)},
$$


and a tentative value of 0.00015 was assigned to the constant $K$ when pressures are expressed in pounds per square inch. If pressures are expressed in atmospheres, this amounts to $K=$ 0.0022 .

Entirely independently an attempt was made to evaluate $K$ from data in the literature on the concentration of water vapor in compressed gas in equilibrium with the liquid and the deviation of oxygen from Boyle's law. The available data were not entirely adequate; they involved some uncertain extrapolations, but they led to the value $K=0.002$. An additional decimal place was not justified by the accuracy of the data. This may be considered a satisfactory agreement with the observed results.

Figure 20 represents the results of one set of experiments intended to determine the value of $K$. The equation in the figure is eq 5 with pressures expressed in pounds per square inch and $P_{c}$ and $P_{w}$ each equal to 1 atmosphere. In the tests the pressure of saturation was varied as much as practicable, and the determination completed by the usual method of comparison. When plotted with respect to the pressure of saturation the water formed from the uncorrected eq 2 passed through a maximum (this plot is not shown), producing a substantially symmetrical curve. Since the product of $P_{s}$ and $P_{x}$ decreases when $P_{s}$ increases, the parts of the curve on opposite sides of the maximum, which occurred at a value of about 350 psi for both $P_{s}$ and $P_{x}$, could be combined in a more condensed figure by plotting the amount of water found with respect to the lower of $P_{s}$ and $P_{x}$. This has been done in figure 20 , in which four different plots have been made of results calculated with four different values of $K$ from 0 to 0.00018 . It is at once apparent that all results are low and in poor agreement with each other if $K$ is given a value of 0 or 0.00010 . If the value assigned to $K$ is 0.00015 , the average of the results by the electrical method is in agreement with the average of the gravimetric tests, but the plotted results still show a definite slope. If we assign the slightly higher value $K=0.00018$, there is no longer a distinct slope to the plot, but it shows a higher average than the gravimetric tests. However, of the three gravimetric tests two were close together and the third about 10 percent low. In a case of this kind, there is probably as much reason to accept the two closely agreeing results as the average of the three. If this is done, all observations agree with the gravimetric result within 2 micrograms per liter.

It is to be noted that the factor $K$ can apparently be determined almost as well from the agreement of results at different pressures of saturation as from agreement with gravimetric tests. There was some question as to whether the same value should be used for the $K s$ affecting $P_{s}$ and $P_{x}$, i. e. whether a high pressure in the saturator and a low matching pressure was exactly equivalent to a reversal of the two. Both from the results shown in figure 20 and from much more numerous tests with other cylinders, it was decided that any error introduced by using the same value of $K$ in connection with all observed pressures was outside the limit of error of the current observations.

There was also a question whether the same value of $K$ should be used for nitrogen and oxygen. This was tested directly several times by substituting air and oxygen for nitrogen in the saturator for testing the same cylinders of gases. Although we should expect a slightly lower factor for nitrogen than for oxygen, the difference again seemed to be outside the limit of error. Hence the same constant, 0.00015 , has been used for air, oxygen, and nitrogen. The value 0.00017 may be better.

Without doubt the exact value of the constant changes with temperature; but again the effect is not noticeable in comparison with other variations within the usual range of laboratory temperatures, hence the same constant is used at all ordinary temperatures. The true value may be expected to decrease with increasing temperature.

(b) Computer and Its Use for Compressed Gas

The solution of eq 5 involves ascertaining the value of $S$, the saturation pressure of water at the temperature of test, and reducing four pressures from gage to the absolute scale in addition to the subtractions and multiplications indicated by the formula. The time involved in doing this by longhand is greatly in excess of that involved in making the tests themselves. Accordingly, a simple computer was designed by the authors to do most of the work. It is in principle a circular slide rule with three pressure scales on two rotating disks above a base-plate. The base has two scales. The computer is made of either metal or plastic. Computers of both types are shown in 


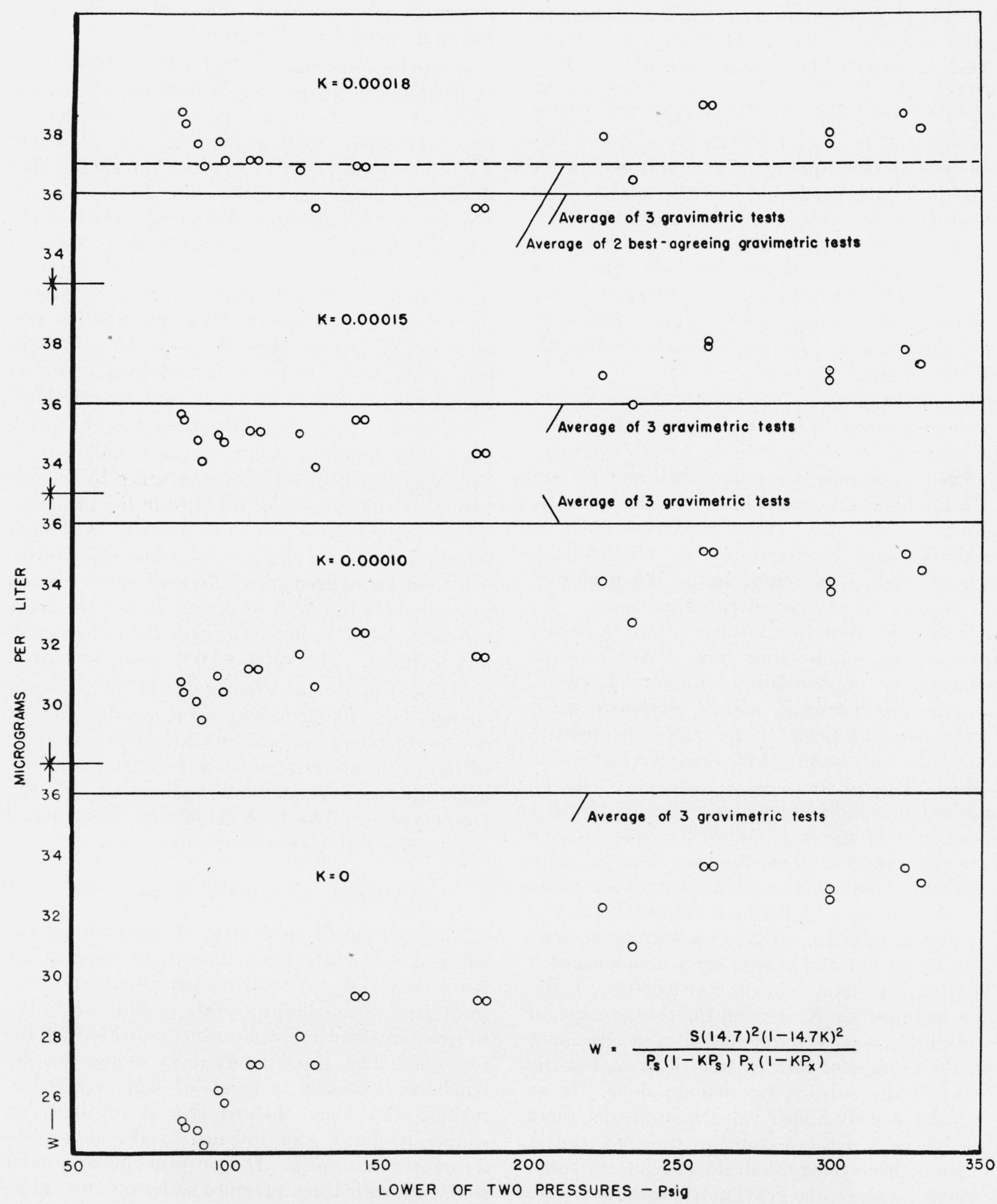

FIGURE 20.-Correction for deviation of water vapor in oxygen from ideal vapor. 
figures 21 and 22 . The computer is designed to give numerical results from eq 5 when pressures are expressed in pounds per square inch gage, barometric pressure is $14.7 \mathrm{psi}$, and $K=0.00015$. The scale for the vapor pressure $S$ is engraved on the base plate by laying off angles proportional to the logarithms of the vapor pressures at definite temperatures and marking the temperature in degrees Fahrenheit to which each angle corresponds. On the scales for saturation pressure, $P_{s}$, for test gas pressure, $P_{x}$, and for comparison pressure, $P_{c}$, angles are proportional to the logarithms of absolute pressures, but marked with the corresponding gage pressures when the barometric pressure is 14.7 psi. Values of $W$ are on an ordinary (slide rule) logarithmic scale and are marked in fractions of a milligram per liter from 0.001 to 1.0. The computer is designed for a constant value of $P_{w}$ of $14.7 \mathrm{psi}$, which is represented by the angular spacing on the base plate of the scales for $S$ and $W$.

Further understanding of the operation of the rule will be best conveyed by a description of some actual computations. In figure 21 the computer is set to show the concentration of water in gas discharged from a cylinder at atmospheric pressure if the standard gas, saturated at 500 psig and $70^{\circ} \mathrm{F}$ and expanded to 0 psig (14.7 psi), is matched by gas from the cylinder at a pressure of 400 psig. The number 500 on the saturation pressure is set opposite $70^{\circ} \mathrm{F}$ on the temperature scale. The zero of the comparison pressure scale is set opposite 400 of the test gas pressure scale, and the desired answer, $0.0215 \mathrm{mg} /$ liter, is read opposite the zero of the comparison pressure scale. Since both $P_{c}$ and $P_{w}$ are equal to 1 atmosphere in the example given, the value of $W$ is just opposite that of $P_{x}$, and any line drawn from the center across the scales would serve as well as the zero of the comparison pressure scale to connect the two points. The Air-Force designer of the plastic computer thought it more convenient to use a line on the handle of one of the disks for this purpose than to use the end of the comparison pressure

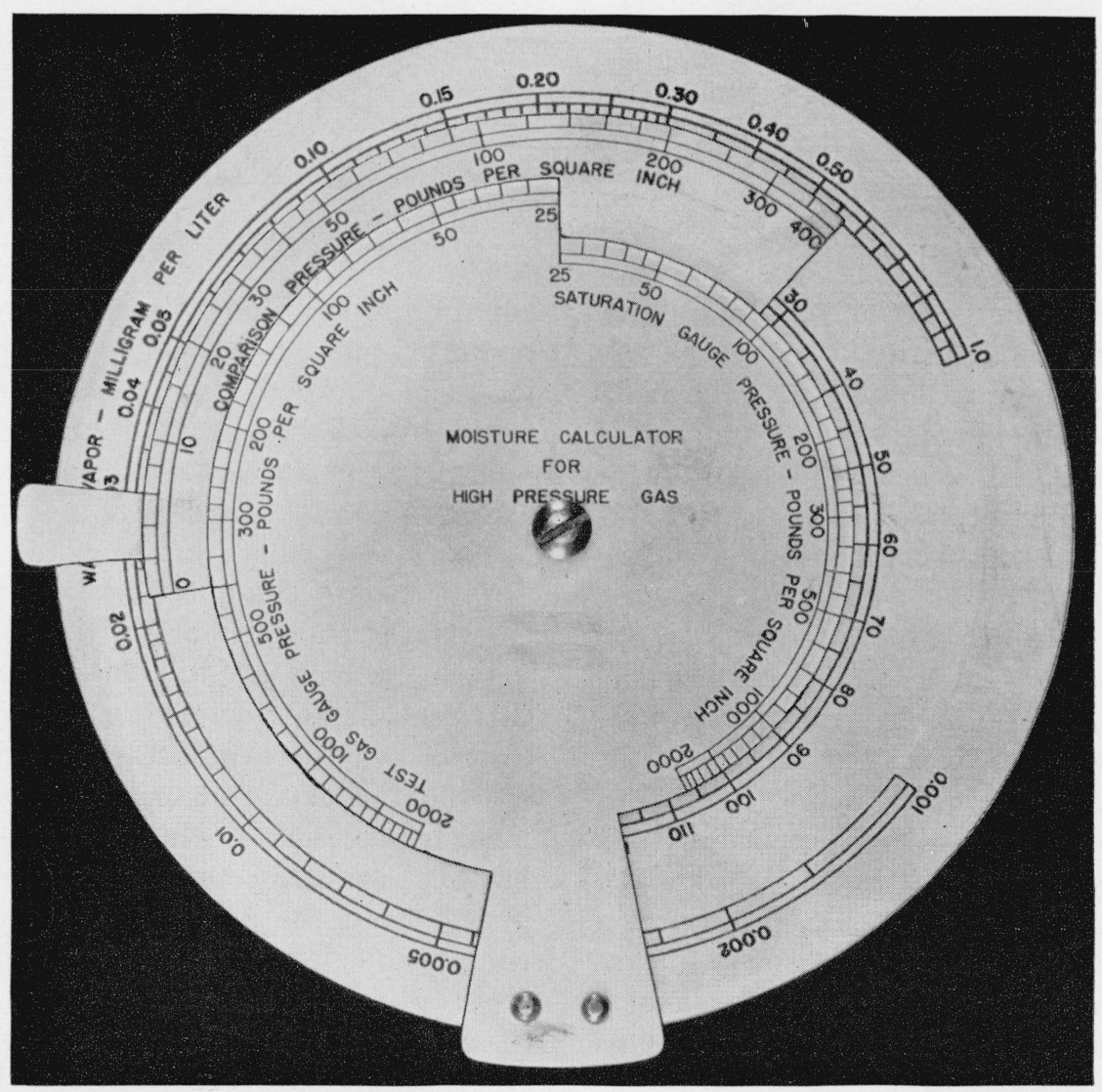

Figure 21.-Metal computer. 


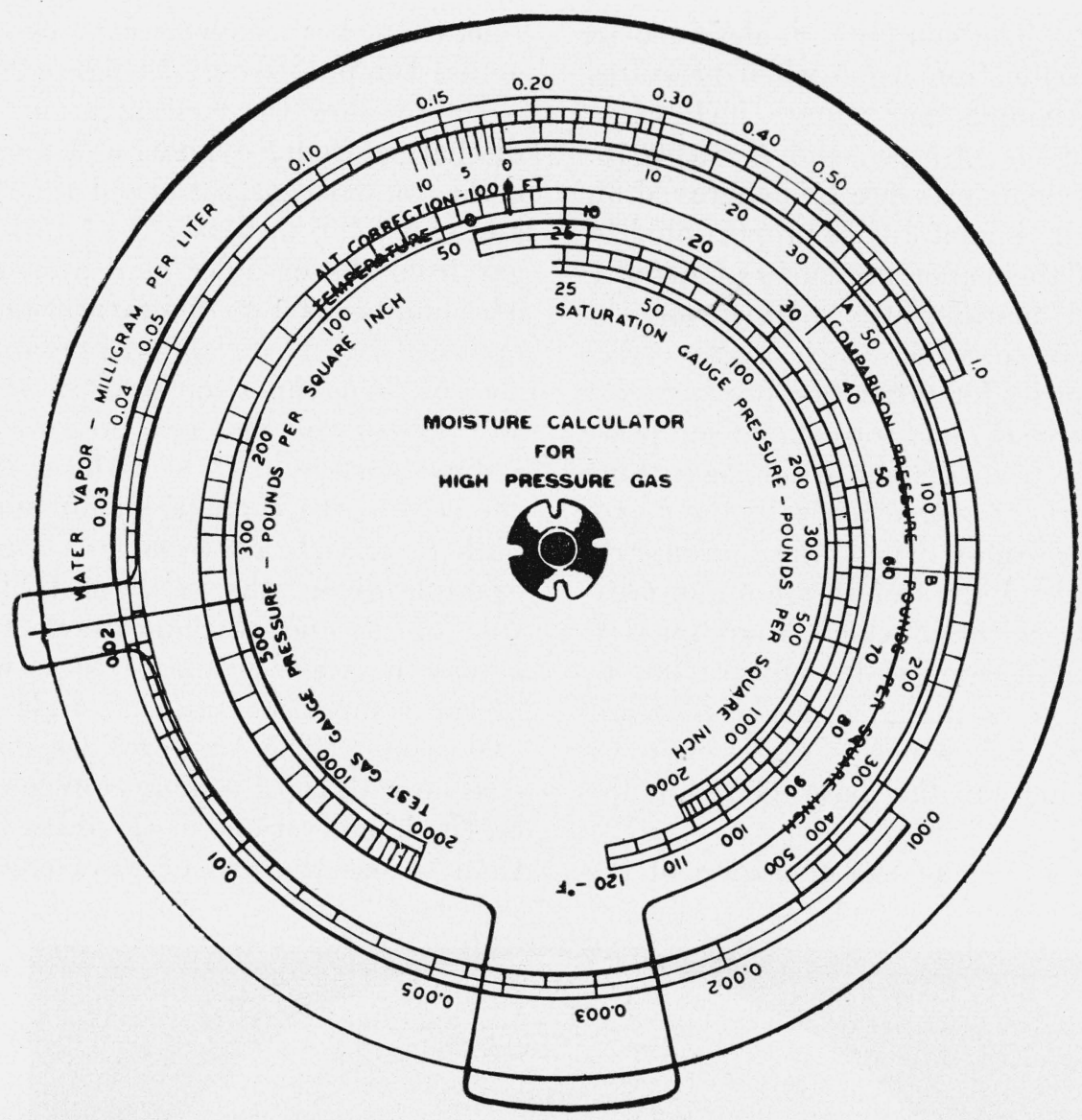

Figure 22.-Plastic computer.

scale. Accordingly the solution of the above problem is usually found with the setting of the plastic computer shown in figure 22 . The position of the line on the handle, as the computer is made, has no significant relation to the zero of the comparison pressure scale. This is unfortunate, for a small change in the position of the handle would make the angle between the two equal to an exact decade on the water-vapor scale, and this would be convenient for many purposes.

If we wish to make use of the comparison pressure scale, its zero must be set opposite $P_{x}$ of the test gas pressure scale, as shown in figure 21 . For example, had the gas from the saturator been expanded only to $20 \mathrm{psig}$ instead of 0 psig, and had the matching pressure of the unknown gas been 400 psig on the test gas pressure scale as represented by the setting, the gas after expansion from the cylinder would be shown to contain 0.05 mg per liter.

A glance at eq 5 shows that $P_{c}$ nad $P_{w}$ enter the equation in the same way, so that the comparison pressure scale can be used equally well to compute values of $W$, when $P_{c}$ is 0 psig and $P_{w}$ is something else. If both $P_{c}$ and $P_{w}$ are more than 0 psig, we must add the corresponding angles in succession as we would make successive multiplications on an ordinary slide rule.

The plastic computer has a scale of altitude corrections attached below the zero of the comparison pressure scale. The primary purpose of this scale is to prevent an incorrect determination of whether compressed oxygen meets the specification of $0.02 \mathrm{mg}$ per liter when the measurement is made in a testing station at high altitude. In this case, the comparison pressure $P_{c}$ of eq 5 is less than the 0 psig (14.7 psi) for which the comparison pressure scale was constructed. The absolute pressures represented by given readings of the gages that show saturation pressure and test gas pressure are also less than correspond exactly to the scale, but the corrections are 
rather small fractions of the probable values of these pressures. Since the humidity with which we are most concerned is $0.02 \mathrm{mg}$ per liter, and this is usually obtained with scale readings of about $500 \mathrm{psig}$ on both the saturation and test gas pressure scales, the altitude correction was computed for the values 0,500 , and 500 psig of the three significant pressures and marked on the computer. When making a test of oxygen by the usual routine at the altitude of Denver, the saturation gage pressure is set opposite the temperature of saturation and the zero of the comparison pressure scale is set opposite the test gas gage pressure, as usual, but the water content of the gas discharged from the cylinder is read opposite 5.3 thousand feet, the altitude of the city. A setting that would result for a gas that just meets the specification is shown by figure 23 . If the correction for altitude were not applied, the determination would be in error by about $0.0035 \mathrm{mg}$ per liter. (c) Computing Relative Humidities

As the scale marked water vapor is an ordinary logarithmic scale, its use is no more confined to that one quantity than is the scale of an ordinary slide rule. In computing relative humidities, it is convenient to use it to represent ratios. In combination with the comparison pressure scale it is possible to work a large variety of problems involving ratios and gage pressures just as a slide rule would be used. One edge of the handle of the upper disk can be used as a marker in place of the glass slide of the conventional rule.

Three examples will be given:

1. Room air at atmospheric pressure is matched with air from the saturator, which is at room temperature, by adjusting the comparison pressure at which it flows over the detector in the cell. If the pressure in the saturator is $300 \mathrm{psig}$ and the comparison pressure at which matching occurs is 100 psig, what is the relative humidity in the room?

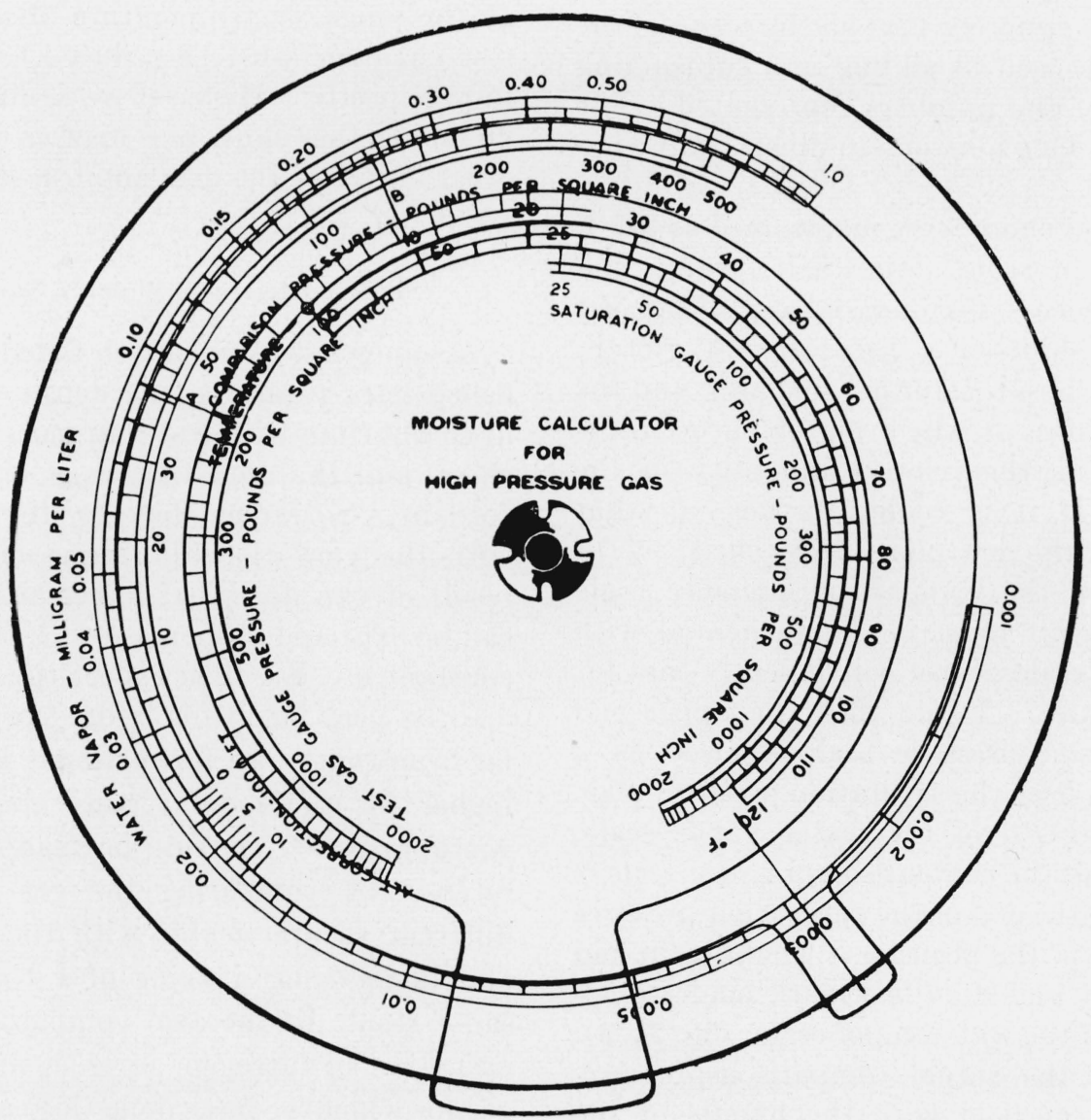

Figure 23.-Plastic computer set for altitude of Denver. 
Solution: Set 300 of the comparison pressure scale under 1.0 of the water vapor scale. Opposite 100 of the comparison pressure scale, read 37.5 percent, the relative humidity measured.

2. A cylinder containing 300 psig of oxygen is compared with gas delivered at a comparison pressure of 35 psig from a saturator in which the pressure is 400 psig. Matching occurs at a test gas pressure of $25 \mathrm{psig}$; cylinder and saturator are at the same temperatures. It there liquid water in the oxygen cylinder?

Solution: Set 400 of the comparison pressure scale opposite 1.0 of the water vapor scale. Mark the position of 35 on the comparison pressure scale. (It indicates a relative humidity of about 12.5 percent in the cell when the comparison was made.) Bring 25 under the mark. Then 300 on the comparison pressure scale is found opposite $0.9 \%$. This is too close to 1.0 (which would definitely indicate the presence of liquid) to be considered safe, and the cylinder should be baked out before it is refilled.

3. It should be apparent that all the scales of the computer can be used in adding and subtracting the logarithms of the numbers represented. The last problem will be a long one to illustrate the use of several scales.

Problem: A test chamber is maintained at $32^{\circ} \mathrm{F}$ and atmospheric pressure. Air drawn from it (and warmed in the process) is compared at atmospheric pressure with gas from a saturator at $75^{\circ} \mathrm{F}$. The pressure in the saturator is $1,000 \mathrm{psig}$, and the comparison pressure at which matching occurs is 70 psig. What is the relative humidity in the test-chamber? If it is cooled further, at what temperature will the dew point be reached?

Solution: Since the comparison pressure scale ends at $400 \mathrm{psig}$, it must be supplemented with one of the other scales, most conveniently that for saturation pressure. To do this, the upper end of the comparison pressure scale is used as a marker, and 1,000 of the saturation pressure scale is brought under 1.0 of the water vapor scale. The end (400) of the comparison pressure scale is now set opposite the 400 of the saturation pressure scale and is now in the position it would be in had it been extended and its 1.000 mark made to coincide with 1.0 of the water vapor scale (fig. 24, a). The position of the actual comparison-pressure, $70 \mathrm{psig}$, is now marked with the handle of the upper disk. It is found to be at about 0.097 .
As gas from the test chamber matches that from the saturator at the test pressure, it would have a relative humidity of 9.7 percent if heated to $75^{\circ}$ F (fig. 24, b). The end of the comparison pressure scale is now placed on this point as a marker, and the upper disk is rotated to bring the edge of its handle over $32^{\circ} \mathrm{F}$ of the temperature scale (fig. 24, c). The two disks are now rotated together until the handle-marker reaches $75^{\circ} \mathrm{F}$. We have thereby rotated the other marker through the angle between the marks corresponding to these two temperatures and have thereby multiplied a relative humidity of 9.7 percent by the ratio between the vapor pressure of water at $75^{\circ}$ $\mathrm{F}$ and that at $32^{\circ} \mathrm{F}$. The result, read at the end of the comparison pressure scale, is 44 percent, the relative humidity in the test chamber (fig. $24, \mathrm{~d})$. We now rotate the upper disk to bring its handle to 1.0 of the percentage scale (fig. 24 , e). The angle between this marker and the other (the end of the comparison pressure scale) now represents the ratio of saturation pressures at the ends of the range of temperature through which the test chamber must be reduced to cause moisture to precipitate. Hence if we again rotate the two disks together until one marker is at $32^{\circ} \mathrm{F}$, the other indicates the dew-point in the test chamber, $13^{\circ} \mathrm{F}$ (fig. 24, f).

\section{(d) Measurement of Water in Carbon Dioxide}

A somewhat hasty search failed to disclose published data regarding the density of water vapor in equilibrium with water in more than a very few gases, and the data that exist are not very concordant. So far as they go, they are consistent with the view that the increased density is the result of van der Waal forces and that the effect can be expected to increase with the van der Waal constant $a$. We then expect the value of $k$ in eq 5 to be very small for hydrogen and helium, not far from that of air for methane, and considerably higher for the more readily condensable gases. An approximation can be made in any case of interest by comparing the gas at pressures as different as practicable with the same standard, and introducing a value of $k$ that will give the same result in the two comparisons. With the exception of nitrogen, oxygen, and air, the only gas for which we have done this carefully is carbon dioxide. 

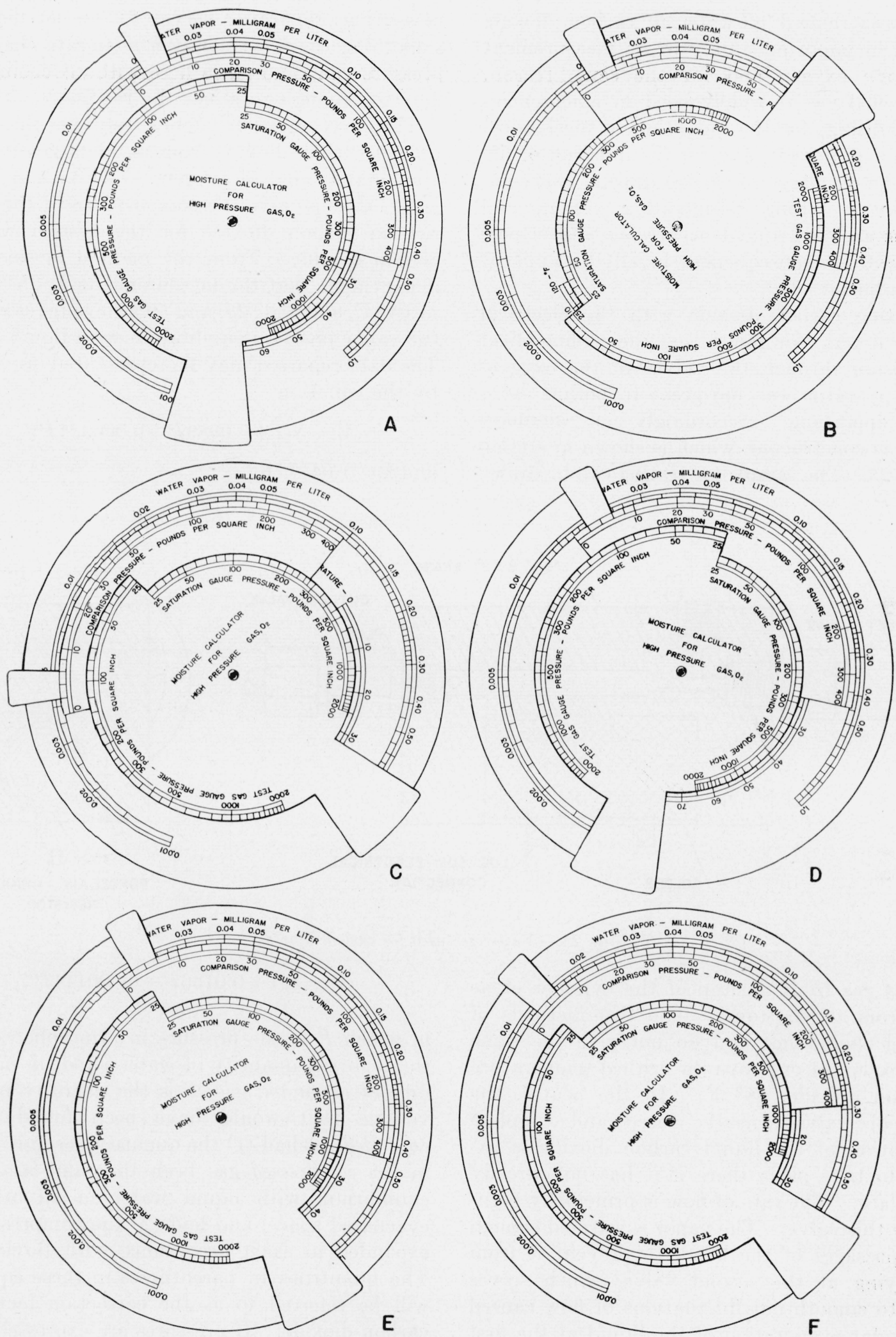

FIGURE 24.-Settings of computer for problem 3.

\section{Water in Gases}


The measurement of water in carbon dioxide is second in importance only to its measurement in aviator's oxygen and for the same reason. The liquefied gas is widely used in emergencies for fire fighting, for the operation of mechanical equipment in aircraft, and for the inflation of life rafts. The discharge of carbon dioxide is accompanied by a strong refrigerating action, and freeze-ups are of frequent occurrence and of possibly disastrous consequences in all the applications mentioned.

In testing carbon dioxide with the electrical indicator it was soon found that the cooling effect of expansion through the valves of the oxygentesting apparatus was too great to permit satisfactory operation. Accordingly an auxiliary heater was constructed, which is shown in section in figure 25. The sample for testing can be drawn measuring apparatus serves as an auxiliary in smoothing the flow. Only a moderate change of pressure can take place here without cooling the detector enough to affect the reading.

The effect on water-vapor pressure of the de viation of carbon dioxide from an ideal gas is much greater than that of oxygen. The data of Wiebe and Gaddy [4] give the compositions of the phase rich in carbon dioxide for the system watercarbon dioxide. From the method of sampling, it is evident that the measurements at $25^{\circ} \mathrm{C}$ and $31.04^{\circ} \mathrm{C}$, and at 1,25 , and 50 atmospheres were of the vapor phase in equilibrium with liquid water. The data reported may be represented for $25^{\circ} \mathrm{C}$ by the equation

$$
W=S\left(1+0.0089 P+0.000324 P^{2}\right),
$$

and for $31.04^{\circ} \mathrm{C}$ by

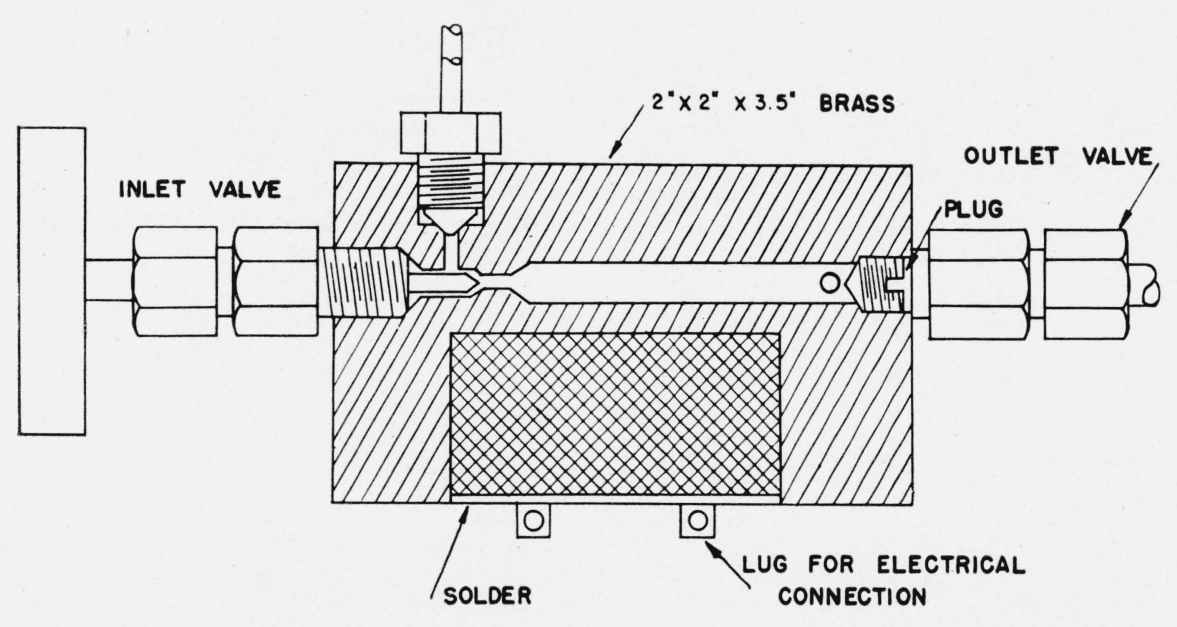

FIGURE 25.-Vaporizer used for carbon dioxide.

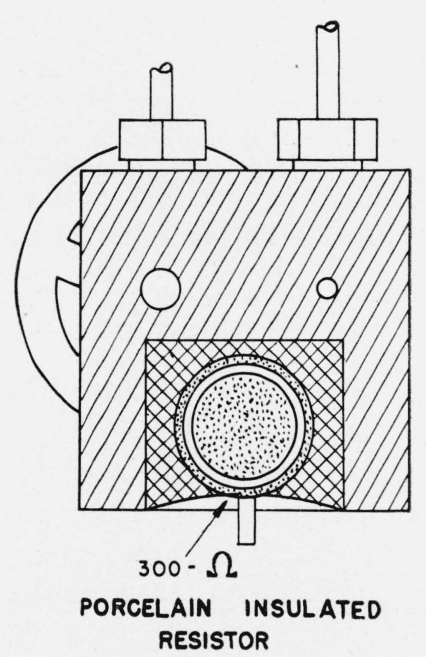

either as gas from the top of the cylinder or as liquid from the bottom. (The two methods of sampling should not and do not give the same results except at or above the critical temperature of carbon dioxide, $88^{\circ} \mathrm{F}$ ). In the heater, the first needle valve is nearly closed, and complete vaporization of the liquid carbon dioxide is expected to take place there if it has not already taken place. The rate of flow is principally regulated by this valve. The vapor is warmed enough in the passages of the block to prevent it from reliquefying at the second valve, which serves chiefly to smooth out fluctuations of flow caused by irregular evaporation of the liquid at the first valve. The first valve $(C)$ of the regular water-

$$
W=S\left(1+0.0136 P+0.000144 P^{2}\right),
$$

in which $P$ is the pressure in atmospheres; $W$ is the reported quantity of water vapor in unit volume of expanded gas; $S$ is the quantity per unit volume that would have been found in the expanded gas had (1) the quantity per unit volume in the compressed gas been the same as that in equilibrium with liquid water in an otherwise evacuated space, and had (2) the compressed gas expanded in exact accordance with Boyle's law. The quantities in parentheses in these equations will be referred to as the correction factors for carbon dioxide. If pressures are expressed in the usual gage readings, the factors are 
For $25^{\circ} \mathrm{C}\left(77^{\circ} \mathrm{F}\right)$

For $31.04^{\circ} \mathrm{C}\left(87.9^{\circ} \mathrm{F}\right)$
$1+0.000605 P+0.00000150 P^{2}$.

$1+0.000925 P+0.00000067 P^{2}$.
It is probable that the correction factor to be applied to carbon dioxide containing the fairly small percentage of water vapor represented by saturation at $25^{\circ}$ or $30^{\circ} \mathrm{C}$ will apply satisfactorily to still smaller percentages.

When we compare carbon dioxide with air containing a known quantity of water and make the calculations with the computer for use with oxygen, we automatically apply a correction for the pressure of carbon dioxide as though it were air. It we divide the total corrections to be made according to eq 6 and 7 by the correction introduced by the computer, we find the corrections to be applied to the results obtained with the aid of the computer. These corrections, for the two temperatures are as follows:

For $25^{\circ} \mathrm{C}$ :

$$
W=W_{1}\left(1+0.0067 P+0.000305 P^{2}\right) .
$$

For $31.04^{\circ} \mathrm{C}$ :

$$
W=W_{1}\left(1+0.0114 P+0.000114 P^{2}\right) .
$$

$W_{1}$ is the concentration of water found by using the computer only.

The accuracy of the data from which these equations were derived and the accuracy of the tests themselves probably do not justify the somewhat laborious application of these equations in routine work nor even the use of different correction factors for different temperatures within the ordinary range of temperature in the laboratory. Hence, the simpler correction factor

$$
\frac{1}{1-0.0007 P_{x}}
$$

was selected empirically to be applied to results computed with the oxygen calculator. If this factor is used, the entire correction, including that inherent in the calculator is

$$
\frac{1}{\left(1-0.0007 P_{x}\right)\left(1-0.00015 P_{x}\right)} \text {. }
$$

In figure 26 are plotted this correction factor, curve $C$, and the correction factors from eq 6 and 7 , curves $A$ and $B$. It is evident that if eq 6 and 7 are correct and if measurements are made at any

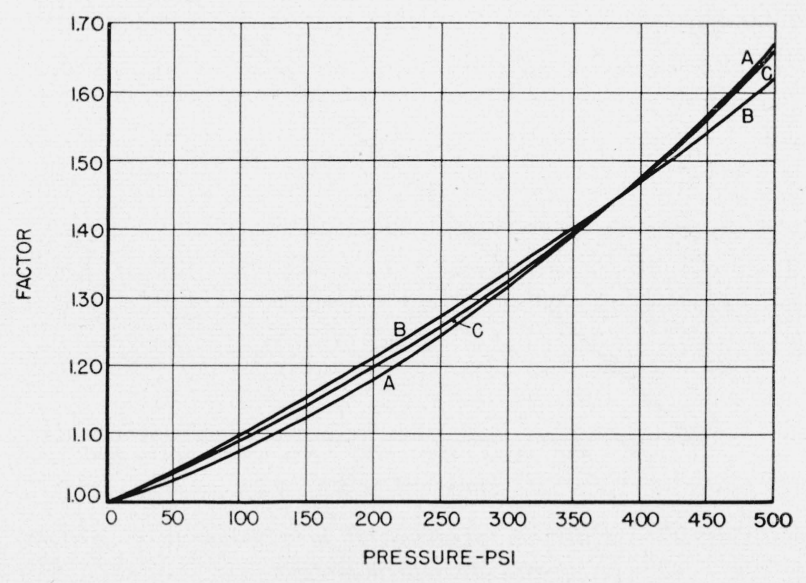

Figure 26.-Correction factors for water vapor in carbon dioxide.

\begin{tabular}{|c|c|}
\hline \multicolumn{1}{|c|}{ Curve } & Correction factor \\
\hline A & $1+0.000605 P+0.0000015 P^{2}$ \\
\hline B & $\begin{array}{c}1+0.000925 P+0.000000067 P^{2} \\
(1-0.00015 P)(1-0.00070 P)\end{array}$ \\
\hline
\end{tabular}

temperature between $25^{\circ}$ and $31^{\circ} \mathrm{C}$ and at pressures of carbon dioxide less than $450 \mathrm{psi}$, no error greater than about 1 to 5 percent of the water present can result from using the computer and multiplying the results by

$$
\frac{1}{1-0.0007 P_{x}}
$$

Measurements were made of the water vapor in gas from a commercial cylinder of carbon dioxide, for the purpose of determining the applicability of this correction formula, by comparing it with a cylinder of compressed air in which the water vapor had been measured ( $0.183 \mathrm{mg}$ per liter). First the water vapor was determined by a comparison made with the carbon dioxide at atmospheric pressure. The average of two determinations was $0.840 \mathrm{mg}$ per liter. A curve was then plotted (fig. 27) showing the relation between pressures of air and carbon dioxide that would give this value if the results to be obtained in theory from the oxygen computer were multiplied by the factor

$$
\frac{1}{1-0.0007 P_{x}} .
$$




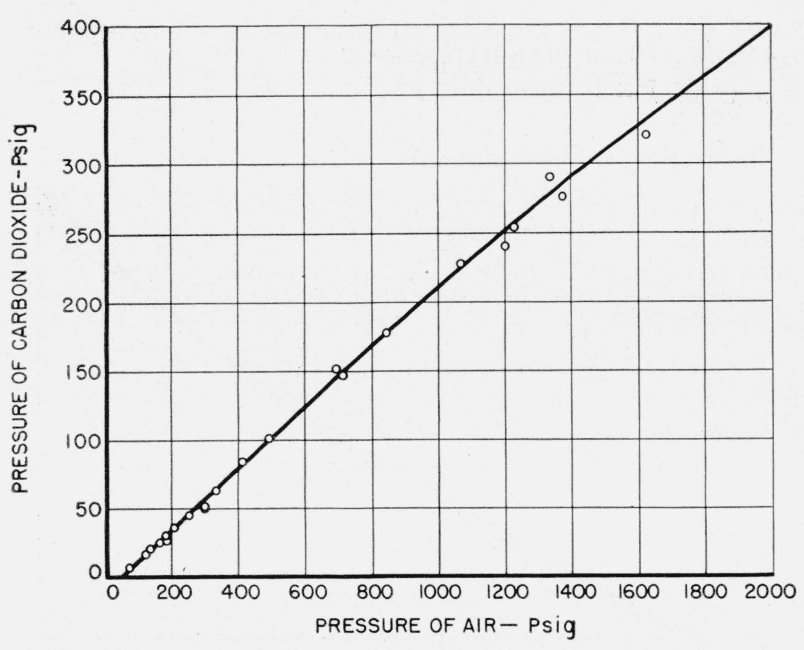

Figure 27.-Effect of pressure of measurement on carbondioxide determination.

Then a series of comparisons of air and carbon dioxide from the two cylinders was made at a temperature of $76^{\circ} \mathrm{C}$ and at different pressures. The points marked by circles on figure 27 show the results. The curve in this figure was plotted in advance, not drawn to represent the observations. The results of the series of observations are shown in detail in table 5. The last two columns were computed by the use of the correction factor $C$.

The trend of the results indicates an overcorrection for the carbon dioxide if anything, but they are too scattered to make this certain. The results would not be appreciably improved by using the theoretical correction factor $A$ (represented by curve $A$ of fig. 26) instead of $C$, which must be considered as satisfactory as anything available until a more accurate study is made.

\section{Applications and Results}

\section{Compressed Gases}

The application of the method to the measurement of compressed gases has been sufficiently described. Here will be reported briefly some results obtained. In effect, others have been given already in figures 20 and 27 . Figure 28 shows the results of seven electrical and three gravimetric tests of the same cylinder of oxygen. The change of water content of the discharged gas as the pressure in the cylinder decreases is typical of many cylinders that have been tested and is attributed to water adsorbed on the cylinder
TABLE 5.-Comparison of carbon dioxide and air at different pressures

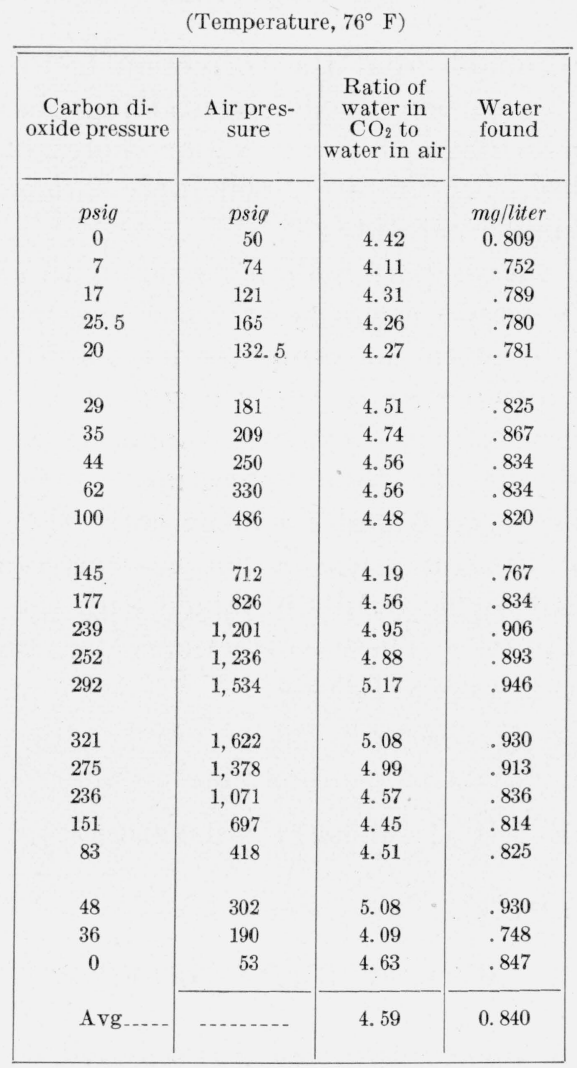

walls, mainly in the scale or rust that is always present to some extent. When the water vapor changes with pressure in this way, the large samples needed for a gravimetric test gives the average of a changing composition. A spot sample taken before a gravimetric sample nearly always shows less water, one taken afterward shows more water than the gravimetric test.

During 3 or 4 years, approximately 100 cylinders were tested by both gravimetric and electrical methods. In general the agreement was good, taking into account the changes of pressure during the gravimetric tests. Sometimes they were not good, and a part of the disagreements unquestionably resulted from errors in the electrical method. Sometimes the fault may have been in the gravimetric method, as shown by occasional irregular results of gravimetric tests of the same cylinder. Approximately half a dozen cylinders persistently showed differences between repeated gravimetric and electrical determinations that must have represented some real effect. In each of these 


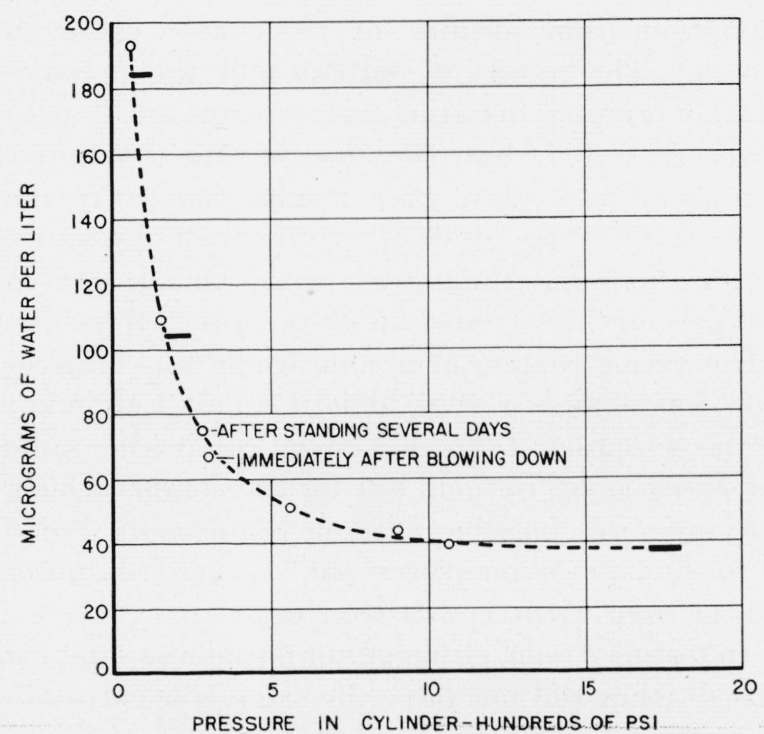

Figure 28.-Water vapor in gas from a cylinder of compressed oxygen determined gravimetrically and electrically.

, Gravimetric test; $\bigcirc$, electrical test.

cases the electrical test was low. The best explanation seems to be that something was taken out by the phosphorus pentoxide used in the gravimetric method that affects the conductivity of phosphoric acid little or not at all. The source was probably the lute used to seal the threads of the cylinder valve. Sometimes this is shellac dissolved in alcohol, sometimes it is litharge and glycerin. Both glycerin and alcohol are held by phosphorus pentoxide, at least in part. The discrepancy between the results of different methods of test was never too great to be accounted for by saturation with the vapor of glycerin to say nothing of alcohol.

That the thread-sealing compound could be a troublesome source of vapor was disclosed by experience with the cylinders sent from one company by the Navy Department for checking, which repeatedly showed more than the amount of water permitted by specification, while those from other companies were generally under 20 percent of the limit specified. This seemed the more remarkable because the company having trouble apparently had the best practice in drying cylinders and filled them directly with oxygen from the liquid phase. After inquiry disclosed that cylinder valves were being sealed with a suspension of graphite in water, no cylinder from that company failed to pass the specification readily.
In table 6 are shown the results of measurements of water in four cylinders of oxygen with an electrical apparatus and four frost-point instruments, which it was the purpose of the observations to test. The table shows the agreement obtained between successive electrical tests of the same sample as well as the agreement with frost-point instruments.

TABLE 6.-Comparative tests of compressed oxygen made with electrical and frost-point instruments

(Tests made on different days are separated by a space)

\begin{tabular}{|c|c|c|c|c|}
\hline \multicolumn{5}{|c|}{ Water found with- } \\
\hline \multirow{2}{*}{$\begin{array}{l}\text { Electrical } \\
\text { instru- } \\
\text { ment }\end{array}$} & \multicolumn{4}{|c|}{ Frost-point instruments a number- } \\
\hline & 1 & 2 & 3 & 4 \\
\hline \multicolumn{5}{|c|}{ CYLINDER A } \\
\hline mg/liter & mg/liter & $m g /$ liter & mg/liter & mg/liter \\
\hline - n & 0.024 & - & -..... & (n.... \\
\hline 0.022 & .022 & -...... & -....... & - n.... \\
\hline .022 & .020 & - n & - n & ....... \\
\hline .020 & .021 & -..... & - n.... & -...... \\
\hline .022 & .022 & - & ........ & - n. \\
\hline .022 & .017 & - n. & ....... & - n. \\
\hline .023 & .024 & - n. & - n & -...... \\
\hline .020 & .020 & ....... & - n..... & (n) \\
\hline - n.... & .018 & - n & - n & - n \\
\hline (n) & .018 & - n & (n) & (n) \\
\hline .021 & .024 & & & \\
\hline .021 & .022 & -....... & - n & (n...... \\
\hline -........ & .021 & .. & -- & $\ldots$ \\
\hline .022 & .021 & 0.028 & ........ & -...... \\
\hline .022 & .024 & .028 & ........ & - n. \\
\hline - n & .016 & .028 & $\ldots$ & $\ldots$ \\
\hline - . n.... & .016 & .028 & -...... & - n \\
\hline - n & .016 & .027 & -...... & - n. \\
\hline - n. & .017 & .025 & -...... & - n \\
\hline - & .016 & .025 & - & - \\
\hline - n & .018 & .025 & - . & - \\
\hline - n & .024 & .025 & - & . \\
\hline ......... & .016 & .025 & (n....... & -....... \\
\hline$\ldots$ & .018 & .028 & - & - \\
\hline - & .016 & .028 & - & . \\
\hline - n. & .018 & .027 & ....... & . \\
\hline ....... & .019 & .026 & - & . \\
\hline ...... & .017 & .026 & - & - n \\
\hline . . & .018 & .027 & - . & . \\
\hline - & .018 & .027 & - . & - \\
\hline - n. & .019 & .025 & - & ..... \\
\hline$-\cdots$ & 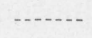 & .025 & - n & - n \\
\hline .020 & .023 & .019 & 0.022 & \\
\hline .021 & .019 & .018 & .022 & - \\
\hline .022 & .019 & .018 & .020 & - \\
\hline - & .019 & - & .021 & - \\
\hline - n & .019 & . & ....... & ....... \\
\hline -...... & .019 & - n & - n & (n) \\
\hline .022 & ........ & - n & - n- & 0.028 \\
\hline - & -...... & - . . & - & .023 \\
\hline - & - & - & - & .019 \\
\hline$\ldots \ldots$ & ......... & ...... & ........ & .025 \\
\hline
\end{tabular}


TABLE 6.-Comparative tests of compressed oxypen made with electrical and frost-point instruments - Continued

\begin{tabular}{|c|c|c|c|c|}
\hline \multicolumn{5}{|c|}{ Water found with- } \\
\hline \multirow{2}{*}{$\begin{array}{c}\text { Electrical } \\
\text { instru- } \\
\text { ment }\end{array}$} & \multicolumn{4}{|c|}{ Frost-point instruments a number- } \\
\hline & 1 & 2 & 3 & 4 \\
\hline \multicolumn{5}{|c|}{ CYLINDER B } \\
\hline 0.045 & 0.046 & 0.065 & 0.051 & \\
\hline .048 & .045 & .063 & .050 & \\
\hline .048 & .045 & .060 & .048 & - \\
\hline .049 & .045 & .061 & .047 & - \\
\hline - . & .047 & .061 & .046 & - \\
\hline - & - & .061 & .046 & - \\
\hline - . & ....... & .061 & .046 & - . \\
\hline ...... & - & .055 & ...... & - . \\
\hline ........ & - & .054 & - & -...... \\
\hline -...... & ......... & .054 & - & -....... \\
\hline \multicolumn{5}{|c|}{ CYLINDER C } \\
\hline 0.060 & 0.060 & 0.077 & & \\
\hline - & .060 & .078 & - n & - \\
\hline (n- & .060 & .078 & (n...... & (....... \\
\hline .060 & .070 & .085 & - & - \\
\hline - . & .065 & .080 & - & ........ \\
\hline - . & .064 & .082 & - & $\ldots$ \\
\hline (n) & (n) & .082 & (n..... & (n) \\
\hline (n-...- & (n)..... & .080 & - & (-...... \\
\hline \multicolumn{5}{|c|}{ CYLINDER D } \\
\hline 0.097 & 0.094 & 0.095 & - . & .... \\
\hline .100 & .092 & .094 & ....... & - \\
\hline .100 & .090 & .090 & - . & - \\
\hline - . & .091 & .089 & - n. & -...... \\
\hline - & .091 & .092 & -...... & ........ \\
\hline - n & .091 & .092 & 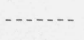 & (n) \\
\hline (n...... & (n) & .092 & - & (n) \\
\hline
\end{tabular}

a In a frost-point apparatus, observations are always made with falling temperatures. If thermal distribution and measurement were always perfect, the results should be a little low because of the lag between the formation of the first frost and its observation.

\section{Freon}

The electrical method was used in a study of the distribution of water in a refrigerating system using Freon 12 (dichlorodifluoromethane) and of the action of driers within the system. The Freon used showed, in the original cylinder, a water content of about $0.008 \mathrm{mg}$ per liter, much too low for direct comparison with gas from a saturator. Two cylinders of gas containing about $0.05 \mathrm{mg}$ and $0.003 \mathrm{mg}$ per liter were used as secondary standards.

The first question that arose was naturally the deviation from ideality of the water vapor in Freon. The moisture content and the pressure of the original material were much too low to determine this; but the use of the computer for water in oxygen gave results that were the same within the limit of error at all pressures. Later the same thing was found to be true in samples of high water content drawn from the refrigerating system at a time when the composition was changing very little if at all. It is not to be supposed that the deviation is the same for Freon as for oxygen, but for the comparatively low pressures possible without condensing Freon at ordinary temperatures the oxygen computer can be used with very little error.

In testing Freon, either gas or liquid was sampled at will (they did not have the same concentration of water, of course). In both cases it was necessary to make the expansion through a heated valve. The apparatus shown in figure 25 was used as for carbon dioxide.

The only difficulty encountered in the measurements was from the compressor oil, which is in solution in the Freon and came over as a fog that deposited on the detector, screening it from the gas and eventually washing off the phosphoric acid. Even this oil interfered with the tests much less than might have been expected. Apparently the first oil does not affect greatly the action of the detector.

No determination of water in the Freon was made by an independent method, hence there is nothing with which to compare the electrical measurements. However, the amount of water dissolved in the Freon when the expansion valve froze was always in rough agreement with the published solubility of ice in Freon at the temperature of the experiment.

Figure 29 shows two sets of measurements of water in the liquid freon in the pipe between the liquid receiver and the silica-gel dryer following the introduction of small quantities of water into the receiver. The regularity of the curves indicates that changes of one part by weight of water per million of Freon are readily followed at intervals of 1 minute or less. The step-like breaks in the descending portions of the curve were sufficiently reproducible in numerous tests to establish their reality, and they were satisfactorily explained by considering the mechanical system involved. 


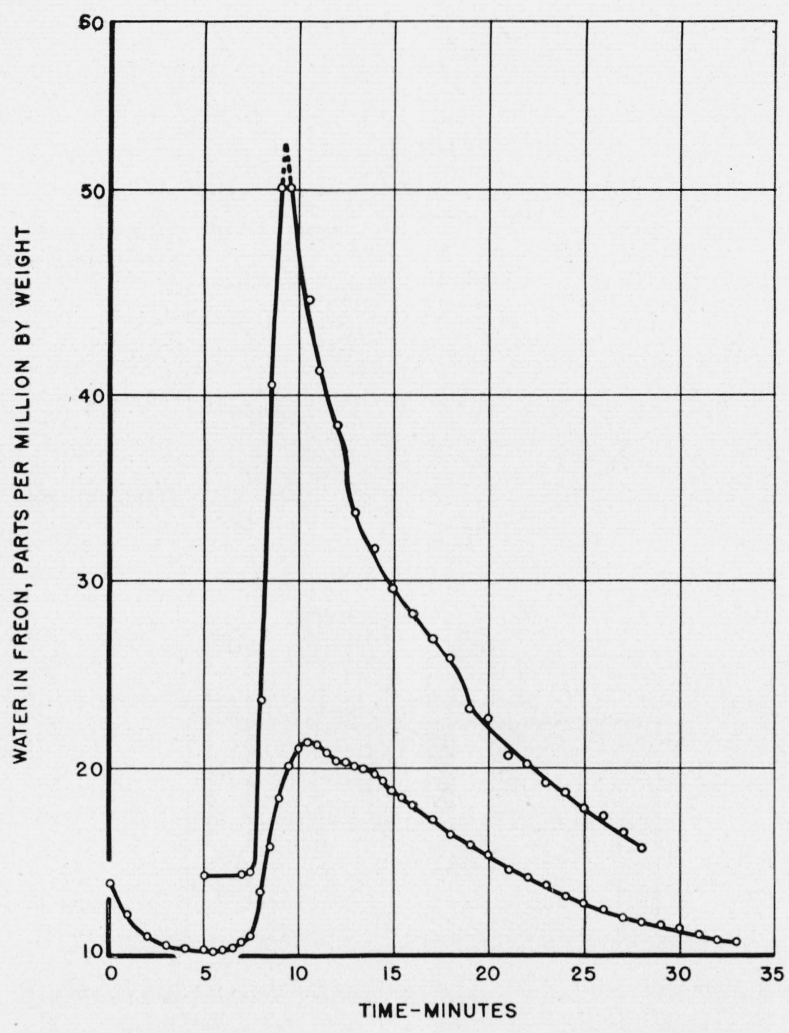

FIGURE 29.-Typical series of measurements of water in Freon.

\section{Measurement of Relative Humidity}

A detector in the air follows monetary changes of relative humidity with great rapidity. Ordinarily there are large and constantly changing local differences in the air of a laboratory. For one thing, we respire roughly once a second and deliver 100 to $200 \mathrm{ml}$ of air saturated with moisture at $98^{\circ} \mathrm{F}$, which becomes distributed at the rate and in the manner easily seen by watching a puff of tobacco smoke. Perspiration is an equally important source of moisture, distributed irregularly by our movements. The galvanometer needle indicates these changes by shifting like a flag in a breeze. Because of this irregular movement, it is usually a little hard to determine what galvanometer reading represents the average humidity of the room. Once this is decided, the detector is screwed into the cell, and gas from the saturator used to reproduce the previous galvanometer reading. Relative humidity is then computed as already described.

The sources of error in relative humidity determinations are almost exclusively those involved in uncertainty regarding the moisture content of gas from the saturator, which have already been discussed. An uncertainty of $1^{\circ} \mathrm{C}$ in the temperature of saturation amounts to an uncertainty of about 5 percent in relative humidity in the upper ranges.

Relative humidities taken approximately daily in the laboratory during 1 month gave the following average results in comparison with wetand-dry bulb thermometers in the stream from an electric fan:

\begin{tabular}{|c|c|c|c|}
\hline \multirow{2}{*}{$\begin{array}{c}\text { Number of } \\
\text { tests }\end{array}$} & $\begin{array}{c}\text { Saturator pres- } \\
\text { sure }\end{array}$ & \multicolumn{2}{|c|}{ Relative humidity } \\
\cline { 3 - 4 } & Electrical & $\begin{array}{c}\text { Wet-and-dry } \\
\text { bulb }\end{array}$ \\
\hline & psig & & \\
\hline 5 & 460 & 31.8 & 32.1 \\
21 & 230 & 31.6 & 31.4 \\
\hline
\end{tabular}

Individual results were somewhat scattered but not more so than could be reasonably explained by uncertainties in the uncontrolled temperature of the saturator.

There is little doubt that with careful control of the conditions of measurement the method will give excellent results for relative humidity. However, the instrument is more elaborate than the psychrometers commonly employed, and would not give better results with the same attention.

The electrical method is not recommended for ordinary psychrometry for these reasons, but it does have advantages of speed of response, of range of humidity measurable, and from the fact that it can be located in and will measure the humidity of small spaces with relatively little effect on that humidity and without the necessity of blowing the air over it. It is much easier to arrange for its use in places that are accessible with difficulty than either dew-point or wet-anddry bulb instruments. It has already found some applications in which these characteristics are important and should find others.

Figure 30 shows an arrangement that has been used at this Bureau for measuring water in small closed containers without disturbing their atmospheres. The detector is screwed into a flat disk, which forms one-half of a rotating slide valve. The other half is another disk through which a hole leads to the container. By rotating the upper disk, the detector is brought to the opening 


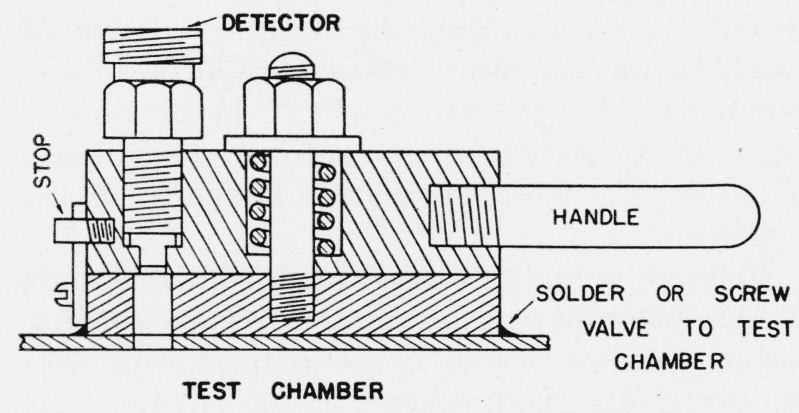

Figure 30.- "Valve" used to connect detector to a testchamber.

of the container, where it can reach equilibrium with the confined atmosphere; or it can be turned away and the container left sealed. The detector is then unscrewed from its plate, inserted into the cell of a regular instrument, and the reading it had when in communication with the test chamber is matched in the usual way. One merit of this arrangement is that with the duplication of only the flat valve, a single detector and measuring apparatus can be used with a number of containers.

A somewhat more elaborate apparatus was designed for another Government Department and was built and used by it with reported satisfaction. It is shown in figure 31 ; it differs from the previously described arrangement only in the presence of channels in the base plate of the slide valve through which a standard gas can be brought to the detector when the valve has been rotated to the position for comparison. In other words, the comparison cell is built into the valve head. If a very wide range of humidities is expected in the test chamber, an auxiliary screw to tighten the detector support over the comparison cell is supplied as shown. A channel around the port for the standard gas leading to the outside prevents the possibility that high pressure under a large area will unseat the valve plate and contaminate the test chamber.

\section{Estimating Moisture in Powdered Solids}

By passing dry air at a steady rate through a powdered solid and thence through the measuring cell and recording at short intervals of time the electrical resistance of the detector, the amount of water removed from the solid can be estimated. Of course, any desired temperatures may be applied so long as the water driven off does not
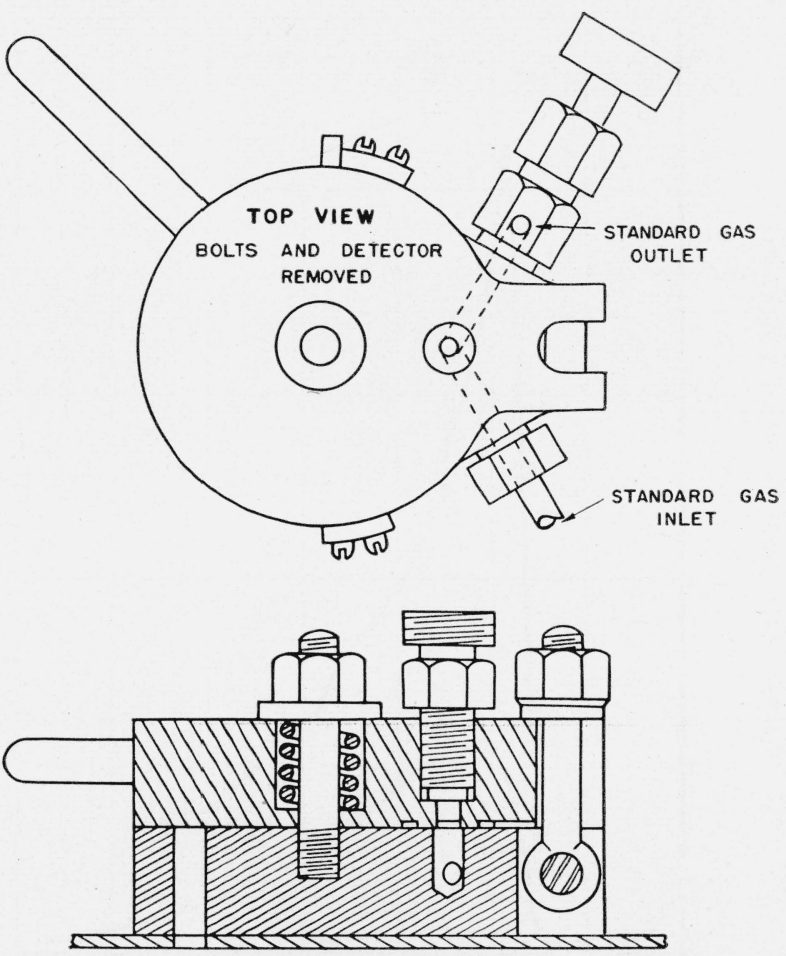

FiguRE 31.- "Valve" used to connect detector alternately to test chamber and to built-in "cell" for calibration.

condense on the way to the cell. The advantages of the procedure are those of the method in general, use of small samples, speed, sensitivity to very small quantities of water, independence of many (not all) other volatile substances that would be involved in a measurement of loss of weight, and ability to follow the course of the drying operation. The principal application made of this procedure has been in determining the relative dryness of samples of silica gel of a particle size corresponding to about a 30 -mesh sieve. The apparatus used in shown in figure 32. The sample to be tested, usually about $1 \mathrm{~g}$, was placed in the thin-walled tube in an atmosphere of steam above vigorously boiling water and several minutes were allowed for the solid to reach steam temperature. Then a brisk flow of dry air was started through the solid, and the resistance of the detector observed. The moist air in the connections always caused a momentary sharp drop of resistance of the detector, but a steady resistance was quickly attained and remained almost constant for several minutes, then quickly broke to nearly the resistance corresponding to the moisture content of the incoming gas. Experi- 


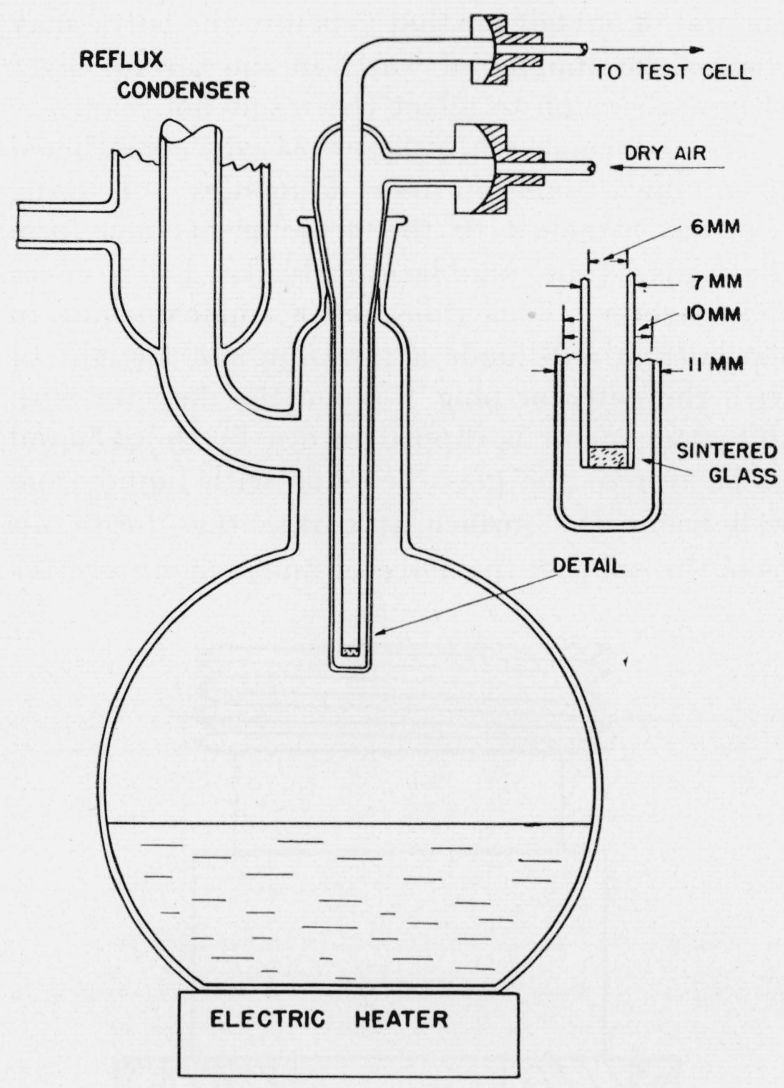

FIGURE 32.-Arrangement used to test moisture content of powdered solids.

ment showed that the moisture content of the gas leaving the gel during the period of constancy was nearly independent of the rate of flow, of the amount of solid, and of the moisture content of the entering gas, which could be either higher or lower than that of outflowing gas. In other words, the greater part of the gel had a characteristic water-vapor pressure, and the air entering came to equilibrium with this so rapidly that the system behaved almost as though a plug of air in equilibrium with the sample were pushed along between the initial and final portions of the flow. Different treatments of the gel resulted in products having vapor pressures at $100^{\circ} \mathrm{C}$ from about 0.1 to $20 \mathrm{~mm}$ of $\mathrm{Hg}$. A few comparisons with gravimetric tests made by drying the gel at much higher temperatures showed fairly good correlation. The need for the test was ended before comparisons could be made between determinations of moisture by weighing and by integrating the product of rate of flow and moisture content of the air passed through the material. The work done on this subject therefore demonstrated merely that observations can be made in a few minutes that will show approximately the condition of such a drying material, once the observer has learned to interpret the results.

An alternative method for determining adsorbed or capillary moisture on solids, which should be a better one in many cases, is to shake up the solid with an organic liquid, and to determine the water in the resulting solution by the method described in the second section, $\mathrm{V}, 6$.

\section{Testing the Capacity of Drying Agents}

On a larger scale, the drying capacity of several reagents at normal atmospheric pressure and at 1,650 psi were measured at various rates of flow by saturating the gas, passing it through about 2 feet of $1 / 2-i n$. iron pipe filled with the dryer, measuring the moisture at the outlet at the pressure of experiment, usually in a small flow through a by-pass, and finally measuring the volume of the whole stream at atmospheric pressure with a gas meter.

Figure 33 shows a typical curve, in this case for silica gel previously dried at $165^{\circ} \mathrm{F}$ when saturated air is passed into it at about $80^{\circ} \mathrm{F}\left(27^{\circ} \mathrm{C}\right)$ at the rate of 20 times the volume of the desiccant per minute. Under these conditions the desiccant dries the air to about $0.1 \mathrm{mg}$ per liter (a relative humidity of about 0.03 percent) for approximately 1 hour. At the end of this time the weight of the

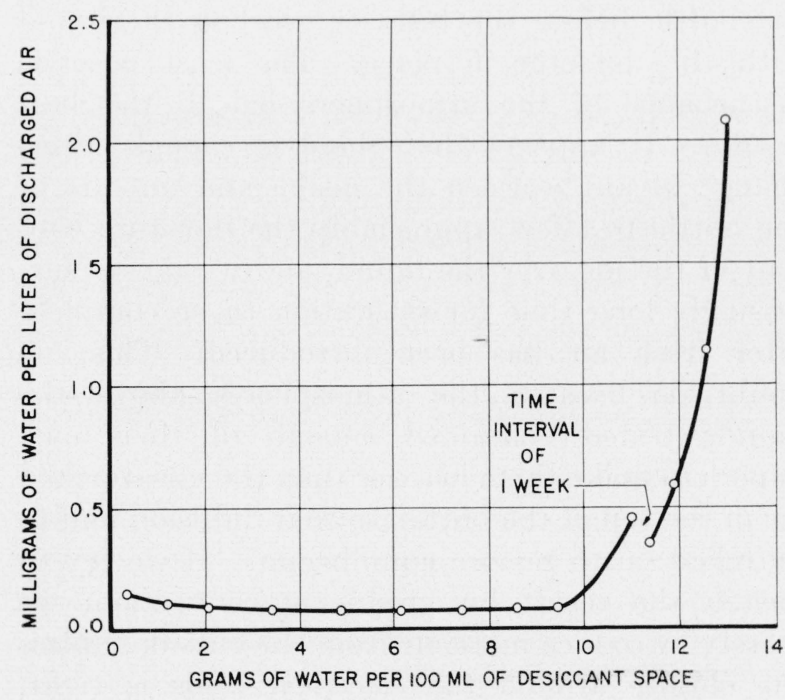

Figure 33.-Adsorption of water by silica-gel. 
adsorbed water is about 10 percent of the weight of liquid water that would fill the space occupied by the desiccant. A point of interest is the interruption of the test after the break-point of the curve had been reached, and its continuance 1 week later. The purpose of this interruption was to see whether the drying power of the nearly exhausted desiccant would be significantly increased by permitting the water adsorbed by the surface layers of the pieces of solid (screen-size, 6 to 16 meshes per inch) to diffuse to the interior of the lumps.

\section{Water Content of Organic Liquids}

It is certain that at a definite temperature the water content of a liquid of otherwise constant composition will bear a definite relation to the water content of the air with which it will come to equilibrium. If we know from past experience what this relation is and have a means for quickly measuring the moisture content of the air, this can also be used to determine the amount of water in the liquid. With this certainty in view, some experiments were made to find whether it is practicable to determine water in organic liquids by exposing the electrical detector to the atmosphere above them.

The first tests were made by the simple procedure of removing the stopper from a reagent bottle, such as ether, and thrusting the detector on the end of its electrical connections nearly to the surface of the liquid. Irregular results were obtained that were made worse by shaking the bottle before the tests or swirling the liquid with the detector in place. The least possible disturbance of the atmosphere led to the best results. It appears that there is enough interchange of air between the inside and outside of the bottle to affect appreciably the moisture content of the air over the liquid, and it takes a surprisingly long time for saturation to be complete after fresh air has been introduced. This, no doubt, is because the atmospheres above the liquids tested contained enough of their own vapors to make them heavier than the unsaturated air in the top of the bottle, so that diffusion had to be relied on to restore equilibrium. If we try to hasten the result by producing convection, we merely introduce more air from the outside, unless the closure around the electrical leads is tight. It seems quite possible that in some cases the amount of outside air that gets into the bottle may change the amount of water in the surface layer of liquid enough to affect the result noticeably.

The device shown in figure 34 was constructed to minimize some of these difficulties. A spring clip was attached to the detector of such form that a glass tube could be quickly attached to cover the detector. This tube had a small opening in the bottom and made a snug but not airtight fit with the detector plug. When the detector with this attachment is dipped into a bottle of liquid to be tested, the glass cell fills with liquid from well below the surface at a rate that forces air from the cell past the detector under slight positive

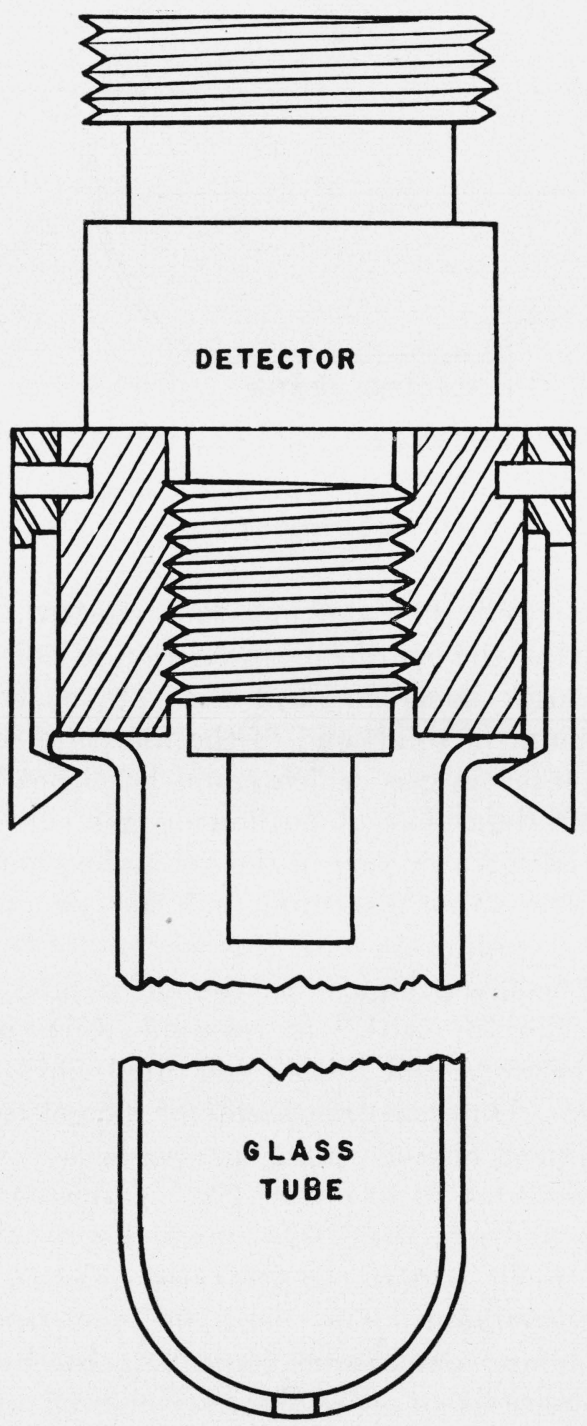

FiguRE 34.-Arrangement used in testing water vapor in equilibrium with a liquid. 
pressure. The detector is lowered until the detecting surface is only a few millimeters above the liquid surface and left there; or it may be raised once to let the nearly saturated air in the bottle outside the cell sweep it out, then again lowered into place. The resistance of the detector is followed. It changes rapidly at first, but soon reaches practical constancy when the small volume of residual air becomes saturated. Since this volume is almost isolated from the surrounding atmosphere, which is itself fairly near to equilibrium with the liquid, there is very little disturbance by diffusion from the outside. Two or three minutes usually suffices to obtain a steady reading, and successive tests are reproducible.

As many clean, dry glass tubes as will be needed for all the tests to be made in rapid succession should be provided so that one liquid will not be contaminated with another and there will be no interchange of water between the liquid to be tested and any film on the wall of the tube. The method has been tried in a preliminary way with several liquids, including ether, petroleum hydrocarbons, carbon disulfide, carbon tetrachloride, and benzene, the vapors of which are believed not to affect the reading appreciably, and with alochol, the vapor of which does affect the apparent water content markedly. Only ether and alcohol will be discussed.

Figure 35 shows results obtained with ethyl ether, the water content of which had been determined by Stanley Clabaugh by an independent method. To this ether measured quantities of water were added. The data obtained are plotted both on a linear scale to show adequately the upper part of the humidity curve and on a logarithmic scale to show the lower part. The method should be capable of measuring with speed and precision very small amounts of water in such a liquid as ether. It can probably be used to determine the water in things that dissolve in ether, such as fats or cellulose derivatives, by testing their solutions.

Alcohol presents complications. In an atmosphere saturated with the vapor of alcohol, believed from other tests to be practical water-free, the detector had a conductivity equal to that in air of about 11-percent relative humidity. According to recorded data, alcohol in equilibrium with an atmosphere of 11-percent relative humidity should contain about 2 percent of water. Small additions

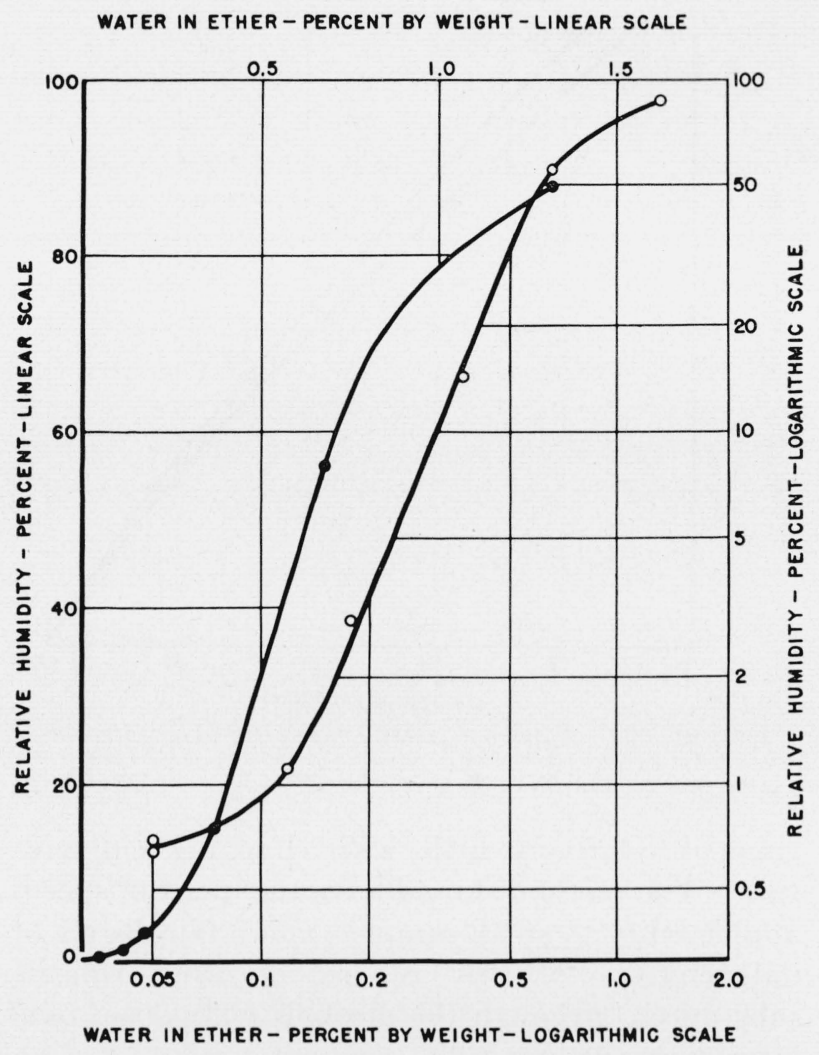

Figure 35.-Relative humiaity above ether.

of water increase the conductivity of the gas above absolute alcohol by very nearly the amount they would be expected to increase that above 98 percent alcohol, if the alcohol vapor itself had no effect. The experiments made were of the sketchiest kind. Results are shown in figure 36, in which are represented the relative humidities of atmospheres in equilibrium with alcohol containing water at $20^{\circ}$ and $40^{\circ} \mathrm{C}$ [5] and the apparent relative humidity of atmospheres above alcohol at $28^{\circ} \mathrm{C}$. The points representing the observed data have been shifted to the left by 2 percent, where they are shown by the solid dots. This entire subject merits further investigation when better facilities, particularly a better saturator, are available. The electrical method will probably be of little use in determining the dryness of otherwise pure alcohol, because other methods that are quick and easy are available, but it gives promise of usefulness in the case of solutions of other things in alcohol that would interfere with the simple determination of water by other methods. It is desirable to express moisture content in terms of relative humidity in this case, because this ratio 


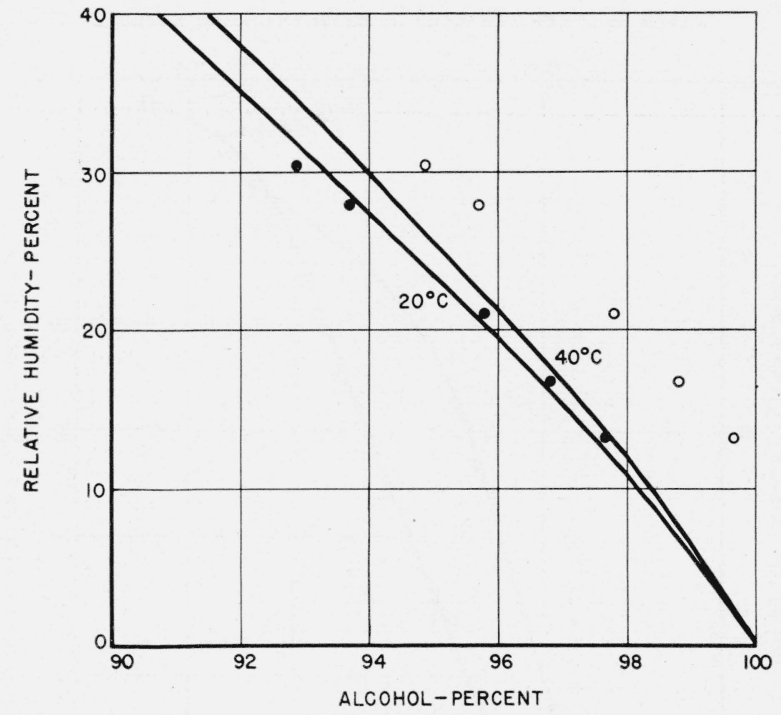

Figure 36.-Apparent relative humidity above alcohol.

$\mathrm{O}$, Observed results at $28^{\circ} \mathrm{C} ; \boldsymbol{\bullet}$, observed results minus 2 percent of alcoho?.

changes relatively little with changing temperature. The method should have the merit of speed, applicability to small samples, and a fair degree of independence of the presence of other volatile substances, although the alcohols will cause some interference.

\section{Permeability of Membranes to Water}

The permeability to water vapor of protective films or membranes used in packaging materials for shipment and storage is a matter of considerable importance. For a closely related problem, the permeability of ballon fabrics to hydrogen and helium, the Shakespear Permeameter [6] has been extensively used. In the Permeameter, the fabric or membrane to be tested is clamped between the two halves of a permeability cell, onehalf of which is suddenly swept out with the gas, e. g., hydrogen, for which permeability is to be determined. The rate at which hydrogen builds up in the other side of the cell is then measured by a physical method, in the Permeameter by thermal conductivity. A comparison of the time required for the concentration to change between two preselected values is taken as a measure of the permeability. Because of its speed and convenience, the use of the Permeameter has almost superseded in practical use methods that give more direct but more delayed results.

It seemed probable that a similar method of comparing intervals of relative humidity by tim- ing would be applicable to measuring permeabilities to water vapor with the aid of the electrical detector. The arrangement used is shown in figure 37. The vapor barrier is clamped over the top of what is, in effect, a dish of water. Above the barrier is a space, arbitrarily chosen as 1 inch, at the top of which is the detector. This space is connected through valves to a supply of dry air and to the outer atmosphere. Before inserting the detector, its resistance is determined in the usual way at a relative humidity of 25 percent. It is then inserted in the space above the vapor barrier, and the space is swept out with a brisk stream of dried air for 1 minute. Then the valves are closed and the time is recorded until the resistance of the detector indicates a relative humidity in the space of just 25 percent. The definite duration of sweeping out with dry gas is for the purpose of producing reproducible though arbitrary conditions of the moisture gradient in the membrane itself.

Table 7 shows the results of testing 15 different membranes by this method. The observations were made by Jean Doyle. Tests in any horizontal row are duplicates on the same piece of membrane and show the agreement between tests that should have given the same result. The tests were only preliminary and were hastily made without temperature control. Probably a more important factor in the variability of results is the failure to establish a regular gradient of dissolved moisture through the barrier before beginning the timing. Probably because of this failure, thick films show excessively greater resistance to the passage of moisture than do thin films of the same material. Considering the probability that the method can be greatly improved with a little attention to details, it is apparent that a quick method for getting at least approximate results is available.

One characteristic of the method that may be of value in some cases is the possibility of applying

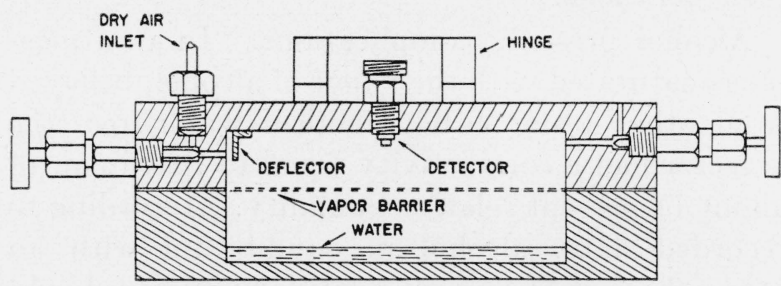

FIGURE 37.-Cell for testing permeability of vapor-barriers. 
TABLE 7.-Time required for 1 inch of gas space above water barrier to reach a relative humidity of 25 percent

\begin{tabular}{|c|c|c|c|c|c|c|c|c|c|c|c|c|}
\hline \multirow{3}{*}{ Material } & \multirow{2}{*}{$\begin{array}{l}\text { Thick- } \\
\text { ness }\end{array}$} & \multicolumn{10}{|c|}{ Test } & \multirow{2}{*}{$\begin{array}{c}\text { Time } \\
\text { divided } \\
\text { by thick- } \\
\text { ness }\end{array}$} \\
\hline & & \multicolumn{2}{|c|}{1} & \multicolumn{2}{|c|}{2} & \multicolumn{2}{|l|}{3} & \multicolumn{2}{|c|}{4} & \multicolumn{2}{|c|}{5} & \\
\hline & $m m$ & $\min$ & $\sec$ & $\min$ & $s e c$ & $\min$ & $s e c$ & $\min$ & $\sec$ & $\min$ & sec & $\underset{\mathrm{mm}}{\min / 0.01}$ \\
\hline Cellulose acetate_. & 0.03 & 0 & 46 & 0 & 50 & 0 & 34 & 0 & 32 & 0 & 43 & 0.23 \\
\hline Do & .13 & 3 & 55 & 5 & 02 & 4 & 47 & 4 & 28 & 5 & 21 & .36 \\
\hline Cellophane......... & .03 & 0 & 47 & 0 & 50 & 0 & 49 & 0 & 51 & 0 & 34 & .26 \\
\hline Polyvinyl alcohol & .05 & 1 & 39 & 1 & 33 & 1 & 45 & 1 & 50 & 1 & 05 & .31 \\
\hline Nylon............... & .03 & 1 & 45 & 1 & 24 & 1 & 15 & 1 & 15 & 1 & 39 & .49 \\
\hline$\ldots$ Do ...... & .04 & 3 & 40 & 3 & 36 & 3 & 32 & 3 & 38 & 3 & 19 & .89 \\
\hline Vinylite plasticizer, a...... & .07 & 6 & 47 & 7 & 15 & 7 & 15 & 7 & 40 & 5 & a 06 & .97 \\
\hline Do & .13 & 22 & 40 & 22 & 28 & 30 & 16 & 29 & 30 & 31 & 09 & 2. 09 \\
\hline Do . . D ......... & .23 & 225 & 34 & $\cdots$ & - & & $\cdots-$ & & & & & 9.67 \\
\hline Plasticizer b...- & .11 & 16 & 08 & 16 & 14 & 15 & 47 & 16 & 14 & 17 & 12 & 1. 48 \\
\hline Plasticizer c & .08 & 18 & 54 & 23 & 47 & 20 & 15 & 23 & 38 & 22. & 30 & 2. 73 \\
\hline Plasticizer d..... & .13 & 30 & 04 & 35 & 43 & 39 & 25 & 42 & 40 & 42 & 20 & 2. 93 \\
\hline Plasticizer e & .10 & 12 & a 44 & 17 & 01 & 15 & 57 & 17 & 51 & 17 & 51 & 1. 63 \\
\hline Do $\ldots \ldots \ldots$ & .15 & 81 & 00 & & & & & & & & & 5. 40 \\
\hline Saran $b \ldots . . .$. & .05 & & .... & & & & & & & & & \\
\hline
\end{tabular}

a Test made after membrane had been exposed to saturated atmosphere orernight.

b Did not reach 25-percent saturation in 4 hours.

it to very small samples. Although account would have to be taken of the water combined with the phosphoric acid on the detector, it seems entirely possible that a satisfactory test could be made on an area of membrane equal only to that of the end of the detector, a few square millimeters, and that it could be done with nearly the same speed and accuracy as the testing of a large sample.

The sample of Saran was so slow in responding to the previously used test that it was decided to vary the method by observing the relative humidity reached in a given time after sweeping out with dry air. The time chosen was 1 hour, and three tests were made. They showed close agreement at about 10-percent relative humidity.

For membranes of high permeability another method is available, which is to sweep dry air over the surface of the water barrier at a measured rate and to determine the amount of water in the stream in the usual way. This method is slower than the one experimented with, but the results should be easier to interpret in comparison with those obtained by the usual procedure of collecting and weighing the water in solid desiccants.

\section{Gas Detection}

One purpose for which the method has been used from time to time since its first description [1] is the detection of oxygen in a combustible gas or of a combustible gas in oxygen or air. The method is obvious: the gas is thoroughly dried then passed over a heated filament or catalyst and thence over a detector. Since almost all fuel gases, including the explosive gases of mines, contain either free or ${ }^{*}$ combined hydrogen, water is formed wherever combustion takes place, and it can be detected and measured if desired when the amount present is only a minute fraction of that which could cause explosion. The promptness of the reaction suggests its possible use as a leak detector. The sensitivity would be high; if combustion were complete methane, for example, would provide two volumes of water vapor per volume of gas and should be detectable without difficulty in a concentration of 0.001 percent even at atmospheric pressure. Oxygen in hydrogen also gives two volumes for one. In a hydrocarbon it will give less, because some of it will go to carbon monoxide, and for this reason the amount of oxygen present may be hard to determine 
accurately. However, under any conditions of combustion enough water should be formed to make the method a sensitive one for detection.

The use of combustion in connection with that of a permeability cell offers so obvious a method for measuring permeability to oxygen, to hydrogen, or to a variety of hydrogen compounds, that it need be no more than mentioned.

\section{References}

[1] E. R. Weaver and P. G. Ledig, Tech. Pap. BS 17, 637 (1923) T242; Ind. Eng. Chem. 15, 931 (1923).
[2] Francis W. Dunmore, J. Research NBS 20, 723 (1938) RP1102.

[3] Francis W. Dunmore, J. Research NBS 23, 701 (1939) RP1265.

[4] R. Wiebe and V. L. Gaddy, J. Am. Chem. Soc. 62, 815 (1940).

[5] International Critical Tables 3, 290 (1928).

[6] G. A. Shakespear, Tech. Repts. Adv. Comm. Aero. (British) 2, 579 (1916-17).

[7] H. A. Daynes, Gas analysis by measurement of thermal conductivity, p. 266-77. (Cambridge Univ. Press, Cambridge, Mass., 1933).

Washington, June 19, 1947. 